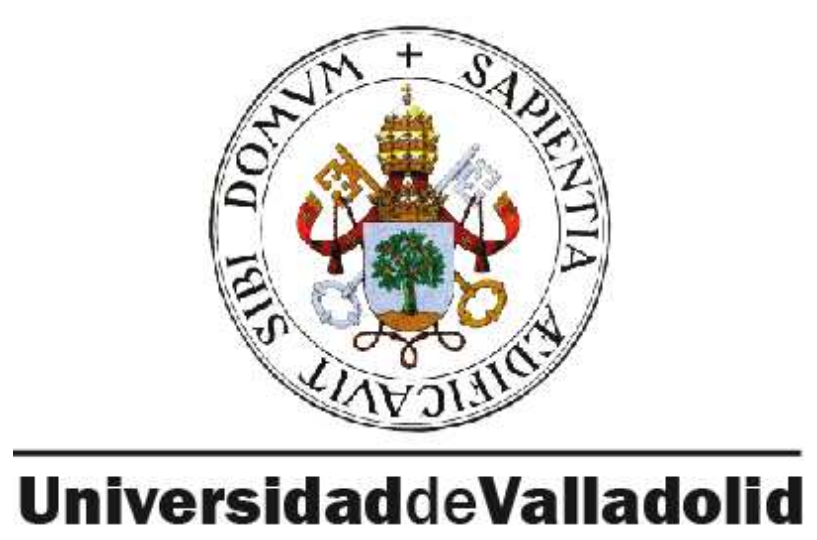

FACULTAD DE MEDICINA

Dpto. BIOQUÍMICA Y BIOLOGÍA MOLECULAR Y FISIOLOGÍA

INSTITUTO DE BIOLOGÍA Y GENÉTICA MOLECULAR (I.B.G.M.)

\title{
LYP, UNA FOSFATASA DE TIROSINA IMPLICADA EN ENFERMEDADES AUTOINMUNES. ESTUDIO DE SU MECANISMO DE ACCIÓN MOLECULAR
}

Memoria para optar al grado de Doctor por la Universidad de Valladolid presentada por María Luisa de la Puerta Turrillas

Dirigida por:

Dra. Yolanda Bayón Prieto

Dr. Andrés Alonso García

Valladolid, 2010 

Dña. Yolanda Bayón Prieto, Doctora en Medicina y Profesor Contratado por la Universidad de Valladolid; y D. Andrés Alonso, Doctor en Medicina y Científico Titular del Consejo Superior de Investigaciones Científicas (CSIC).

\section{CERTIFICAN}

Que Dña. María Luisa de la Puerta Turrillas, Licenciada en Ciencias Biológicas por el Instituto de Empresa (IE) de Segovia, ha realizado bajo su dirección los estudios y experimentos necesarios para la elaboración de la memoria titulada "Lyp, una fosfatasa de tirosina implicada en enfermedades autoinmunes. Estudio de su mecanismo de acción molecular", presentada para optar al grado de Doctor por la Universidad de Valladolid.

Y para que así conste, a los efectos legales, firman la presente en Valladolid, a 30 de Abril de 2010. 
La memoria con título "Lyp, una fosfatasa de tirosina implicada en enfermedades autoinmunes. Estudio de su mecanismo de acción molecular" ha sido realizada siendo María Luisa de la Puerta Turrillas beneficiaria de una beca asociada a proyecto de la Mutua Madrileña. 
A mi familia y Nacho

Si haces lo que siempre has hecho nunca llegarás más allá de donde siempre has llegado. 

No quisiera dejarme a nadie en el tintero al agradecer los casi seis años que he estado aquí, tanto a los que ya han emigrado, como a los que aún permanecen aquí. Ahora que veo terminar esta dura etapa de mi vida, me vienen a la cabeza momentos muy buenos vividos con todos vosotros.

En primer lugar me gustaría agradecer al Dr Andrés Alonso y a la Dra Yolanda Bayón por la acogida en su laboratorio y por la confianza depositada en mí durante estos años, gracias.

Quiero agradecer a mis compañeros de laboratorio, Antonio y $\mathrm{M}^{\mathrm{a}}$ Carmen, vuestro apoyo y sonrisas en muchos momentos, queda un poco mal que yo lo diga, pero éramos tres jimaquinonas!! muchas gracias por todo chicos!!!. En especial quiero agradecerte a tí, Antonio, mi "novio" de la ciencia, (iporque yo diría que he pasado más horas contigo que con Nacho! jeje) todo lo bueno que vivimos, espero y deseo que te vaya genial en Glasgow.

No me quiero olvidar del labo por donde me he paseado mis últimos meses, bien para distraerme, bien para distraeros o para comprobar, cual jubilado, cómo iban las obras del Clínico, gracias a Martín, Espe, Clara, Lucía y Luis por vuestros consejos y los ricos cafés para poder continuar la mañana, porque como tú bien dices Martín, la vida no es sólo esto.

Voy a ir por laboratorios ipara no dejarme a nadie! Gracias a Carmen García por tus consejos buenos y sabios que, en muchas ocasiones, me han llevado a reflexionar antes de actuar, cosa que me ha venido muy bien para atemperar mi pronto. A Maribel, Patri y Cris, gracias por todos los ratos buenos, jmuchos de ellos en cultivos!

A Yoli y Sara por vuestra cercanía y por vuestras muestras de felicidad, con una sonrisa en la cara durante todos los días del año, no he visto personas más positivas que vosotras, da gusto veros porque alegráis la mañana a cualquiera, no quiero olvidarme de Cris y Etzel que aunque hemos coincidido en menos ocasiones también habéis puesto un granito de vosotras en mi carrera.

A mis niñas de abajo, Isa, Sonia y Arancha, agradeceros los buenos ratos de comidas (con mendrugo incluido), cafés, risas, llantos y confesiones, me habéis ayudado muchísimo en esta última etapa, en especial quiero agradecerte a ti, Isa, por estar siempre ahí pendiente de todo, para lo bueno y para lo malo, este año hemos pasado un montón de ratos juntas y no los cambiaría por nada, eres una tía muy especial para mí y te quiero un montón, iiconseguirás todo lo que te propongas en la vida!!

Ahora a los que se han ido, primero a Edurne por ponerme lo dientes largos con sus fotografías y hacer así que no pierda el interés en seguir con este hobby que tanto me gusta, pero 
iiideja de mandarme fotos buenas!!! Jajajaja además no puedo olvidarme de tus achuchones, creo que fuiste la fundadora y ahora todas somos esclavas de un buen ijachuchón!! ¡Te Quiero!

A Jose e Isela, a Jose por la frase "no te calientes la cabeza" iino sabes que bien me ha venido!!! también quiero darte las gracias por esos ratos buenos de charla y por jiapuntarte conmigo a todos los cursos!!! Jeje. A Isela, por tenerte y sentirte muy cerca aunque estés a kilómetros y kilómetros de distancia (algo más accesibles gracias al free de iberia! jeje), iigracias por tu apoyo y amor!!! Os deseo lo mejor chicos, iiiique seáis muy muy felices!!!!

A Nus, ahora un poco más alejadas, pero siempre ahí, prometo hacer más visitas y ver a la pequeña Sofía crecer, ique luego me cuesta un triunfo ganarme su confianza! Te quiero un montón!

A la que ya se ha ido y ha pasado a una vida mejor jsin tener que morir! Elena, jte sienta genial! también se te echa mucho de menos por aquí, tu espontaneidad y tu risa siguen por aquí y me da la sensación de que vayas a salir de tu labo en ¡cualquier momento! me alegro de que te vaya tan bien y iiespero que el año que viene siga siendo así!!

A Javi, por tus risas y gracias, espero también que todo te vaya muy bien por San Diego.

A Laura Vay, mi compi de carrera, trabajo, piso, fatigas y de iiitó!!! Espero que en Cambridge salga el sol y dé una nueva luz a tu proyecto, de todas formas recuerda que la vida no es sólo eso y disfrútala que jsolo tenemos una! iiTe quiero!!

Como la vida no son sólo cascadas de señalización también quiero compartir el esfuerzo de esta tesis con mis chicos y chicas del CLUB ESPELEOLÓGICO JASPE porque sin "pelotear mucho" son la gente más maravillosa que he conocido nunca (no ofenderse los demás, cada uno es maravilloso en lo que es), quizás por las experiencias vividas que me han hecho ver la vida de otra manera y saber que siempre hay alguien dispuesto a darlo todo por ti. Pisé en el grupo por primera vez con 18 añitos y empezando la carrera, ahora con $30 \mathrm{y}$, a punto de hacerme doctora, no me saca de aquí ni el tato, aunque haya faltado casi un año entero y ¡me tengáis que dar otro curso para ponerme al día! jeje. Estad preparados porque ¡habrá que tomarse unos espirituosos en algún "bujero" para celebrar mi reincorporación! iiOs quiero!!

A todas mis niñas del pueblo porque, aún en la distancia, nuestro foro Paradinero sigue funcionando y nos une cada día más, todas somos un gran apoyo para todas, me encantan las novedades de este año y iime hacen todas muy feliz!! ¡Os quiero a todas! 
A Fuen, la primera hermana postiza adoptada en la familia y una de mis mejores amigas, hace ya tiempo que nos conocimos y los momentos vividos contigo durante la carrera no tienen precio (para todo lo demás....), estos momentos se han hecho extensibles a otros 6 años más de amistad, aunque ahora un poco más alejadas, pero siempre ahí para lo verdaderamente importante ¡o para una fiesta! Jeje Te quiero un montón pero "iiimuere cerdo!!!" (ya sabes que tono lleva) jajajajajaja.

Por último y no menos importante quiero dar las gracias a los dos grandes pilares de mi vida, a mi familia y a Nacho. A mis padres porque sin vuestros consejos y apoyo continuo no lo habría conseguido, también quiero agradecer la cercanía y el apoyo recibido por todos mis hermanos: a ti Cris y los sobrinos que traes en camino, espero que todo te vaya muy bien y que la vida te sonría, si no es así jitu ya sabes como hacer que sonría!!, a Esther, me alegro un montón del cambio que estás experimentando, con ganas y fuerza todo se consigue!, a Miguel por ser tan cielote, tan agradable y por tus achuchones, también espero que la vida te depare lo mejor, pero ¡hay que luchar por lo que se quiere!, y por último María, también un amor de niña, bueno ya de mujer aunque siempre serás la enana, jeje, espero que sigas siempre con la misma ilusión con la que haces todo, jeso te llevará donde tu quieras! Os quiero a todos!!!!

No voy a dar las gracias detalladamente al resto del familión por su apoyo porque no acabaría, pero, en especial, quiero dedicar unas palabras a mi abuela Fina, muchas gracias por tus consejos y por tus oraciones, han calado muy dentro de mí y me han hecho ser mejor persona, te quiero muchísimo.

Por último quiero darte las gracias Nacho, por ser como eres jy quererme como soy! por aguantarme en mis peores momentos, unos cuantos en este último año de tesis, por poner calma, serenidad y orden en mi vida, además de por hacerme feliz, por todo esto y ¡mucho más muchas gracias amor! iiTE QUIERO!!

\section{iiiii En resumen, mil gracias a todos!!!!!}



Abreviaturas, acrónimos y

aminoácidos 

aa: aminoácido

ADN: ácido desoxiribonucleico

Ag: antígeno

AP1: activator protein 1

ARN: ácido ribonucleico

ARNm: ARN mensajero

BCA: ácido bicinconínico

BSA: bovine serum albumin

Cbl: del acrónimo inglés Casitas $B$ lineage lymphoma

CD: cluster de diferenciación

$\mathrm{CO}_{2}$ : dióxido de carbono

Csk: c-src tyrosine kinase

DSPs: fosfatasas de especifidad dual

DTT: dinitrotreitol

ECL: del acrónimo inglés Enhanced Chemiluminescence

EDTA: etilendiamonotetraacetato de sodio

EGTA: ácido N,N,N'-tetraacético

ERK: extracellular-signal regulated kinase

Fyn: proteina tyrosina kinasa p59fyn

GFP del acrónimo inglés Green Fluorescent Protein

Grb2: growth factor receptor bound protein 2

GST: glutatión S Transferasa

HA: hemaglutinina

HBSS: solución salina balanceada de Hanks

HRP: horseradish peroxidase

Ig: Inmunoglobulina

IL-2: interlecukina 2

LAT: del acrónimo inglés Linker for Activation of $T$ cells

Lck: del acrónimo inglés lymphocyte-specific protein tyrosine kinase

Lyp: del acrónimo ingles Lymphoid tyrosine phosphatase

MAPK: del acrónimo inglés Mitogen-activated protein kinase

NFAT: Nuclear factor of activated T-cells

NFкB: Nuclear factor immunoglobulin kappa chain enhancer B cells transcription

P85: phosphoinositide-3-kinase, regulatory subunit

PAG/Cbp: phosphoprotein associated with GEMs/Csk-binding protein

p-NPP: para-nitrophenylphosphate 
PTP: protein tyrosine phosphatase

PTPN22: protein tyrosine phosphatase, non-receptor type 22

PV: pervanadato sódico

AR: artritis reumatoide

SLE: acrónimo ingles Systemic Lupus Erythematosus

SLP-76: SH2 domain containing leukocyte protein of $76 \mathrm{kDa}$

SNP: single nucleotide polymorphism

TCR: $T$ cell receptor

VCP: valosin containing protein

Zap70: Zeta-chain-associated protein kinase 70

\section{Aminoácidos}

\begin{tabular}{|c|c|c|}
\hline A & Ala & Alanina \\
\hline C & Cys & Cisteína \\
\hline D & Asp & Ácido aspártico \\
\hline E & Glu & Ácido glutámico \\
\hline F & Phe & Fenilalanina \\
\hline G & Gly & Glicina \\
\hline H & His & Histidina \\
\hline I & Ile & Isoleucina \\
\hline K & Lys & Lisina \\
\hline L & Leu & Leucina \\
\hline M & Met & Metionina \\
\hline N & Asn & Asparragina \\
\hline P & Pro & Prolina \\
\hline Q & Gln & Glutamina \\
\hline R & Arg & Arginina \\
\hline S & Ser & Serina \\
\hline T & Thr & Treonina \\
\hline V & Val & Valina \\
\hline W & Trp & Triptófano \\
\hline Y & Tyr & Tirosina \\
\hline
\end{tabular}


Îndice 



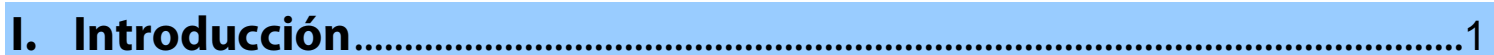

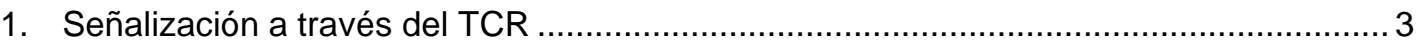

1.1. Regulación de las kinasas de la familia src ................................................ 4

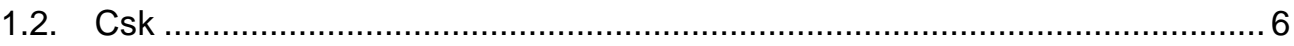

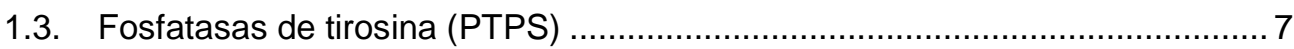

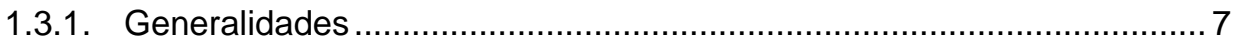

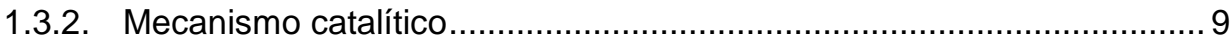

1.3.3. Regulación por oxidación................................................................. 12

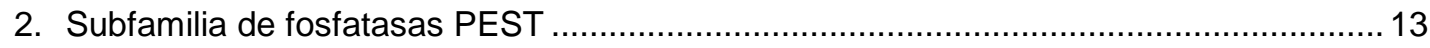

2.1. Características.................................................................................. 13

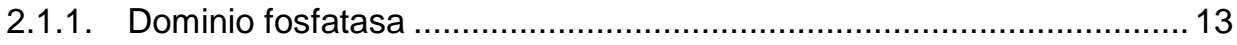

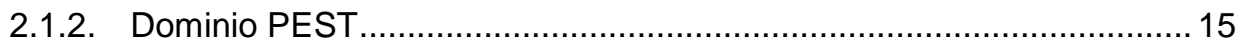

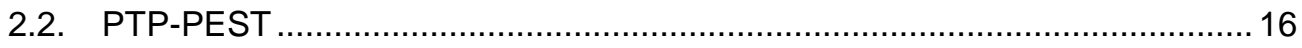

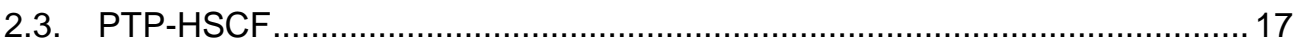

2.4. Lyp

2.4.1. Estructura: dominio PTP y domnio PEST ......................................... 19

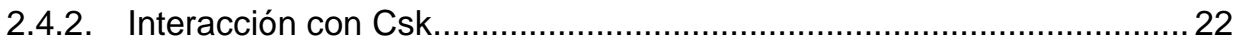

2.4.3. Interacción con proteínas y posiblessubstratos ..................................... 24

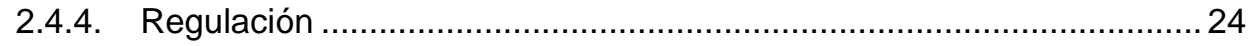

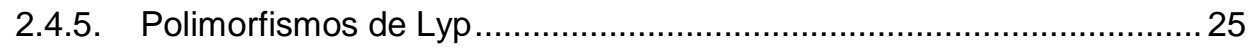

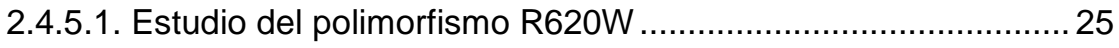

2.4.5.2. Estudio del polimorfismo R263Q.......................................... 29

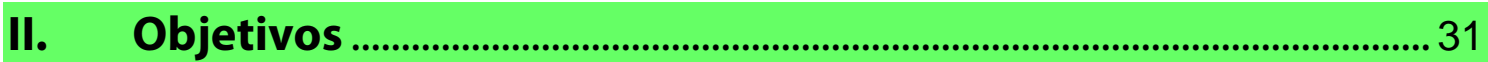

III. Material y Métodos............................................................................................. 35

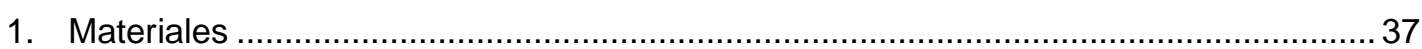

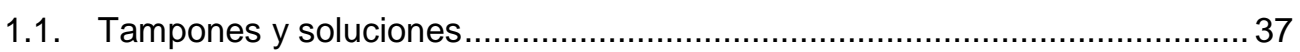

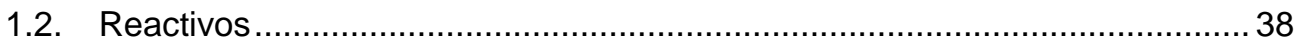

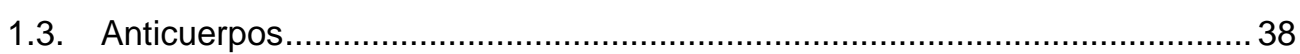

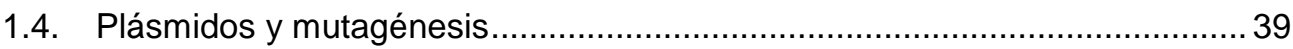


2. Métodos experimentales 40

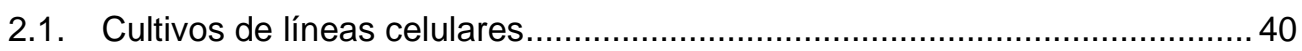

2.2. Métodos de transfección transitoria ..................................................... 41

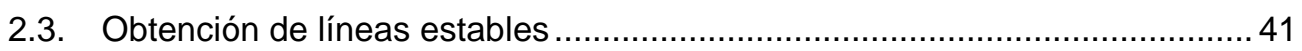

2.4. Análisis de proteínas mediante inmunodetección (western blotting) ..............42

2.5. Valoración de la concentración de proteína ............................................. 43

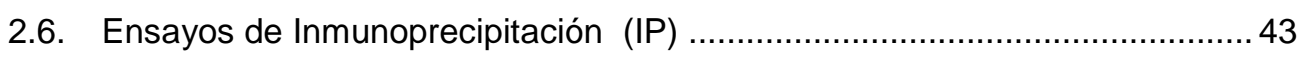

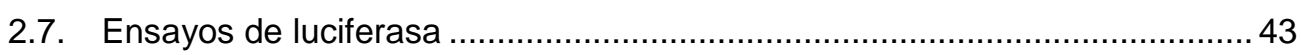

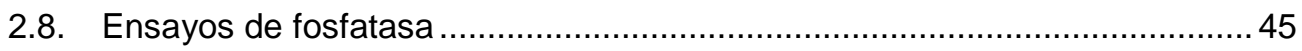

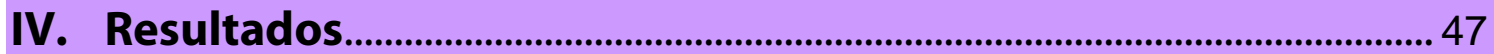

1. Interacción de lyp con otras proteínas.......................................................... 49

2. Estudio de la interacción entre Lyp y Csk .....................................................50

2.1. Dominios de lyp implicados en la interacción con Csk ..............................5 53

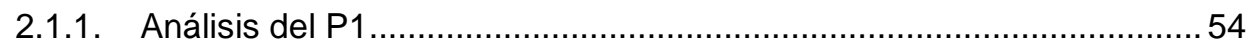

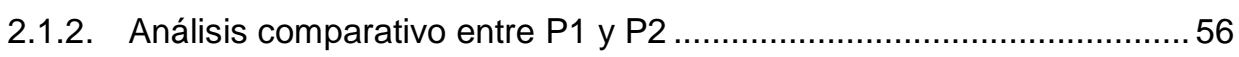

2.1.3. Implicación de las argininas de los motivos P1 y P2 en la interacción con Csk ......................................................... 57

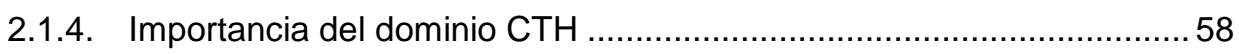

2.2. Dominios de CSK implicados en la interacción.....................................59

2.2.1. Efecto de las mutaciones de Csk sobre la señalización celular ..........60

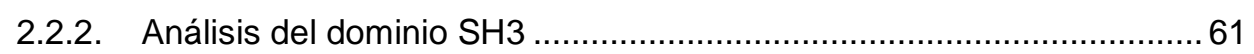

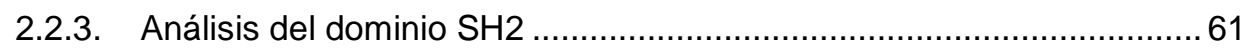

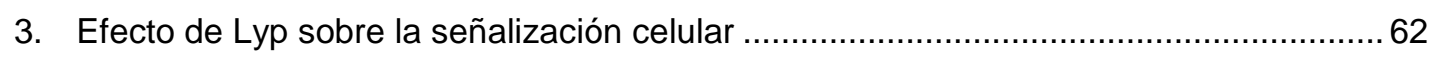

3.1. Efecto de Lyp sobre la activación de los factores de transcripcción

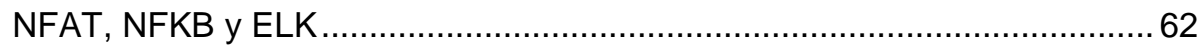

3.2. Efecto de Lyp en la desfosforilación de Lck........................................ 64

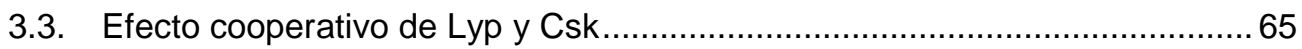

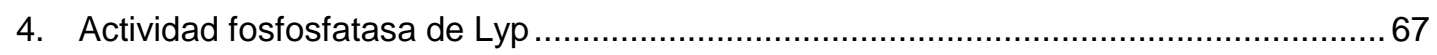




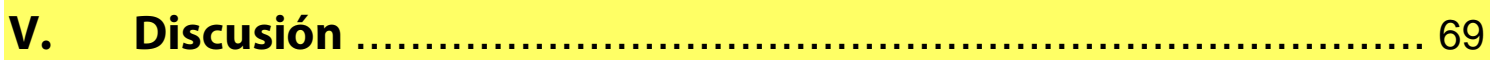

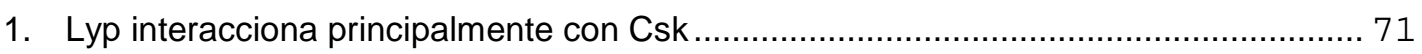

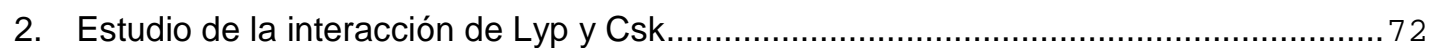

3. Lyp R y Lyp W reducen la activación transcripcional de una manera similar

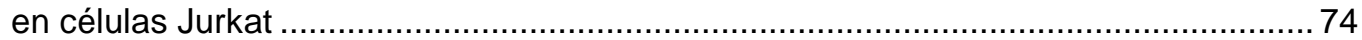

4. La cooperación de Lyp y Csk en la señalización no depende de su asociación ............75

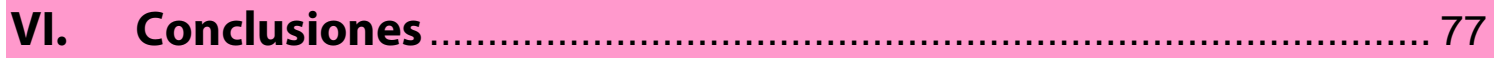

VII. Referencias Bibliográficas ......................................... 81

VIII. Publicaciones y Proyectos ........................................... 89 

I. Introducción 

Podemos definir señalización celular como una compleja red de interacciones o mecanismos de transducción de señales, que comienza cuando un estímulo alcanza la superficie celular y que produce respuestas tales como la alteración de la actividad enzimática, cambios en el citoesqueleto, cambios en la permeabilidad de membrana, síntesis de ADN y activación o represión de genes, procesos que son cruciales para el correcto funcionamiento celular. Cualquier distorsión en esta red de interacciones puede traducirse en el desarrollo de numerosas enfermedades humanas. Por este motivo, una profunda y detallada comprensión de estas interacciones nos permitirá predecir y modular la respuesta fisiológica de la célula a un estímulo específico, y facilitará el desarrollo de nuevas estrategias de diseño molecular que puedan ser utilizadas en el tratamiento de algunas de estas enfermedades.

\section{Señalización a través del TCR.}

Los linfocitos $T$ son los principales agentes en los procesos de inmunidad adaptativa y alteraciones en los mecanismos de transducción de estas células pueden provocar enfermedades en el sistema inmune. En los últimos años han sido numerosos y muy relevantes los avances realizados en el conocimiento de la señalización iniciada por el receptor de linfocitos T (TCR). Gracias a la identificación y caracterización de un gran número proteínas implicadas en las vías de señalización iniciadas por este receptor, ahora somos capaces de comprender mejor cómo el linfocito $T$ decodifica señales en la membrana para producir distintas respuestas, como proliferación, apoptosis, producción de citokinas o tolerancia a antígenos.

En la señalización iniciada por el TCR, la fosforilación de proteínas en tirosina ejerce una función esencial. El estado de fosforilación de las proteínas está controlado por kinasas y fosfatasas, enzimas que catalizan la fosforilación y la desfosforilación de proteínas respectivamente. La unión de un grupo fosfato puede provocar importantes cambios en la proteína aceptora, ya que puede alterar su estructura y, con ello, su función. En general, la fosforilación en tirosina de una proteína modifica su actividad y/o su interacción con otras proteínas a través de dominios de unión a tirosinas fosforiladas, por ejemplo dominios SH2 (src homology 2) y PTB (phosphotyrosine binding) (Yaffe y Elia 2001; Yaffe 2002).

La activación de los linfocitos $\mathrm{T}$ por antígenos requiere que los péptidos antigénicos presentados por el complejo MHC (Major Histocompatibility Complex) de las células presentadoras de antígenos interaccionen con el TCR, y que lo hagan en presencia de una segunda señal proporcionada por la unión del receptor CD28 del linfocito $T$ con la molécula B7 de la célula presentadora de antígeno. La ausencia de esta segunda señal conduce a la célula a un estado de anergia, estado en el que las células no responden a determinados antígenos y que el sistema inmune usa para evitar respuestas inadecuadas frente a antígenos propios. Sin embargo, 
la activación de los linfocitos T a través de los receptores TCR y CD28 en la respuesta antigénica conduce a la proliferación de estas células iniciando su expansión clonal y con ello la respuesta inmune adaptativa.

Esta unión entre los receptores TCR y CD28 y sus ligandos inicia una compleja cascada de señalización intracelular en la que la fosforilación de proteínas en tirosinas es crucial. Así, en primer lugar, se produce la activación de la kinasa de tirosinas de la familia Src, Lck (lymphocytespecific protein tyrosine kinase) que fosforila los ITAM (immunoreceptor tyrosine-based activation motif) de las subunidades $\gamma, \delta$ y $\varepsilon$ del complejo CD3 y de la cadena $\zeta$ asociada a este complejo. Lck se encuentra asociada con los receptores CD4 y CD8 en los linfocitos T, receptores que interaccionan con el complejo MHC de la célula presentadora de antígenos. De esta forma, la interacción del péptido presentado por el complejo MHC con el TCR aumenta la concentración de esta kinasa junto a sus substratos, los motivos ITAM. La fosforilación de estos motivos permite reclutar la kinasa Zap70 (70 kDa zeta associated protein) a la membrana a través sus dominios SH2 (Samelson 2002). Zap70, una vez en la membrana, es fosforilada y activada por Lck (Palacios y Weiss 2004) y es capaz de amplificar la señal fosforilando proteínas adaptadoras, principalmente LAT (linker for activation of T cells) (Zhang et al. 1998) y SLP76 (SH2 domain containing leukocyte protein of $76 \mathrm{kDa}$ ) (Bubeck Wardenburg et al. 1996). Estas proteínas adaptadoras, reclutan otras proteínas de forma que la señal iniciada en la membrana celular se transmite al interior de la célula modulando diversos procesos celulares, tales como la migración celular o la expresión de genes, que en definitiva conducen a la activación de los linfocitos T dentro de la respuesta inmune.

\subsection{Regulación de las kinasas de la familia src.}

Las kinasas de la familia Src, Src, Fyn, Yes, Lyn, Lck, Hck, Fgr, Blk y Yrk, son todas ellas importantes enzimas de señalización (Thomas y Brugge 1997). Su actividad está regulada de forma muy estricta, ya que su alteración podría provocar su activación constitutiva y, con ello, modificar el comportamiento celular. La actividad de las SFKs (Src Family Kinases) se regula principalmente por el estado de fosforilación de dos tirosinas conservadas en esta familia. Una tirosina, situada en el lazo de activación del dominio kinasa, cuya fosforilación aumenta la actividad de estas kinasas y otra tirosina, situada en el extremo carboxilo, que al ser fosforilada inactiva estas kinasas.

La estructura de Lck (56 kDa), la SFK que inicia la activación de los linfocitos T por el TCR, presenta una estructura similar a las otras kinasas de esta familia. En ella destacan, como elementos estructurales más importantes, un dominio SH3 (Src homology domain 3), un dominio $\mathrm{SH} 2$ y el dominio catalítico, que es el que posee la actividad kinasa. Además de estos dominios, posee motivos consenso de miristoilación en el extremo amino, que intervienen en el anclaje de 
esta proteína a la membrana, y tirosinas cuya fosforilación permite regular su actividad, que en el caso concreto de Lck son la Y394 del lazo de activación del dominio catalítico y la Y505 del extremo carboxilo terminal (Xu et al. 1997) (Figura 1).

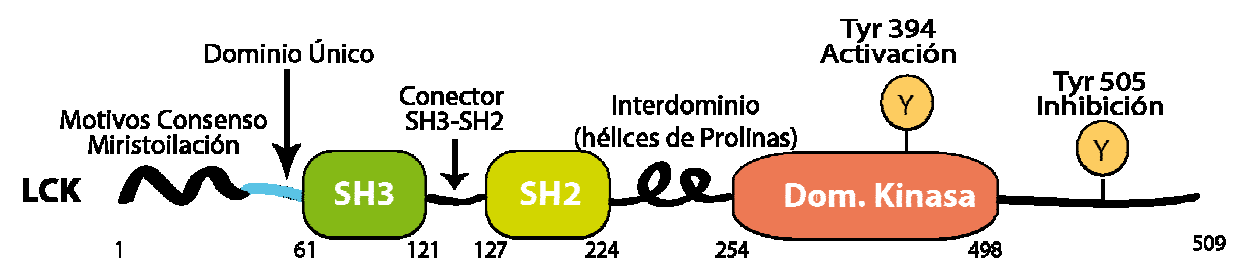

Figura 1: Representación de la estructura lineal de Lck. Siguiendo la estructura desde el extremo amino, encontramos una región de miristoilación seguida de un dominio único característico de cada SFK que se continúa con los dominios SH3, SH2 y el dominio kinasa. También se representan las tirosinas 394 y 505 implicadas en su regulación.

La fosforilación de la Y394 provoca un cambio conformacional que activa la kinasa (Yamaguchi y Hendrickson 1996). Esta fosforilación se puede producir por autofosforilación en trans o por otras kinasas de tirosina (Hardwick y Sefton 1995). Además, Lck se regula negativamente por la fosforilación de su Y505 o tirosina inhibitoria, de forma que, cuando la Y505 está fosforilada, el grupo fosfato interacciona con el dominio SH2 de la misma molécula, forzando así una conformación inactiva (Liu et al. 1993). Esta conformación inactiva se ve favorecida por la interacción del dominio $\mathrm{SH} 3$ con la región comprendida entre el dominio SH2 y el dominio kinasa (Xu et al. 1997). Por lo tanto, Lck se encuentra completamente activa cuando la tirosina Y394 está fosforilada y la tirosina Y505 está desfosforilada (Figura 2).
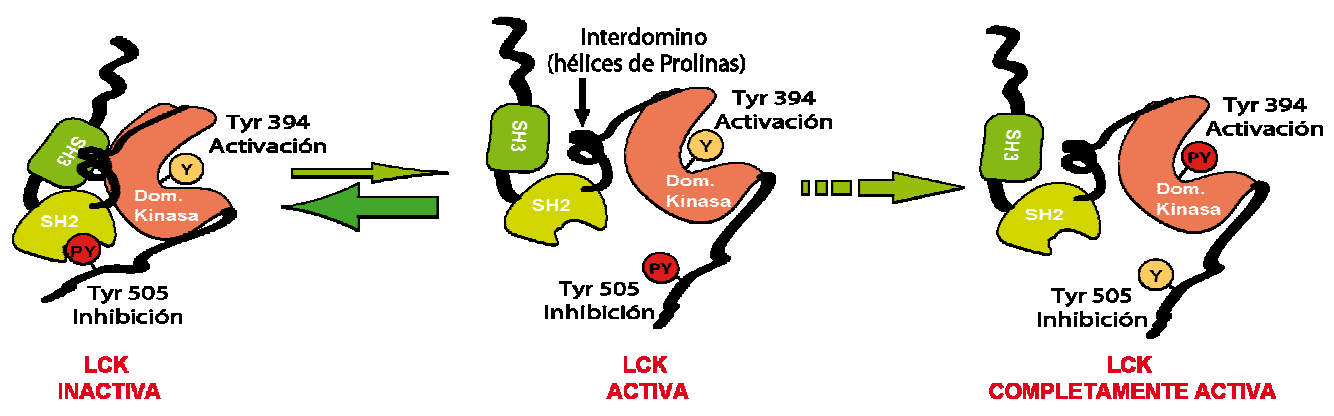

Figura 2: Cambios conformacionales de Lck en su ciclo de activación-inactivación. La fosforilación de la Y505 da lugar a una conformación cerrada que mantiene la proteína en estado inactivo. El equilibrio entre la conformación inactiva (cerrada) y la conformación activa (abierta) resulta de una disociación 
transitoria y reversible del dominio $\mathrm{SH} 2$ con el fosfato de la Y505 y del dominio SH3 con el segmento intermedio que se une a él. El grosor de las flechas indica hacia donde está desplazado el equilibrio. La activación completa se da cuando la Y505 está desfosforilada y la Y394 es autofosforilada. Figura adaptada de Chong et al. (Chong et al. 2005).

Por el momento, la única kinasa descrita que fosforila la tirosina inhibitoria de Lck es Csk (Nada et al. 1991) y la fosfatasa mejor caracterizada que la desfosforila es CD45 (Mustelin et al. 1989). Por otro lado, se han descrito varias fosfatasas de tirosina que pueden desfosforilar la Y394 de Lck, entre ellas están CD45 y las fosfatasas de tirosina pertenecientes a la familia PEST, PEP (Matthews et al. 1992) y su homólogo humano Lyp (Cohen et al. 1999), y PTP-PEST (Yang et al. 1993).

\subsection{Csk.}

Csk es una proteína citoplasmática de $50 \mathrm{kDa}$ con actividad tirosina kinasa que tiene una expresión ubicua (Nada et al. 1991), aunque es más abundante en células hematopoyéticas. Presenta una estructura primaria muy semejante a la de las Src kinasas que, aunque carente de las tirosinas reguladoras del lazo de activación y del dominio carboxilo terminal y de las secuencias de miristoilación necesarias para anclarse a la membrana, comparte con ellas la presencia en su estructura de sus tres dominios fundamentales, que son el dominio $\mathrm{SH} 3$, el dominio SH2 y el dominio kinasa (Sondhi y Cole 1999). Csk y las Src kinasas tampoco comparten la misma estructura tridimensional, ya que, en el caso de Csk, los dominio $\mathrm{SH} 2$ y $\mathrm{SH} 3$ se encuentran uno a cada lado del dominio kinasa sin interaccionar entre si mientras que en el caso de las Src kinasas ambos dominios se encuentran al mismo lado del dominio kinasa e intraccionan entre si (ref). (Figura 3).

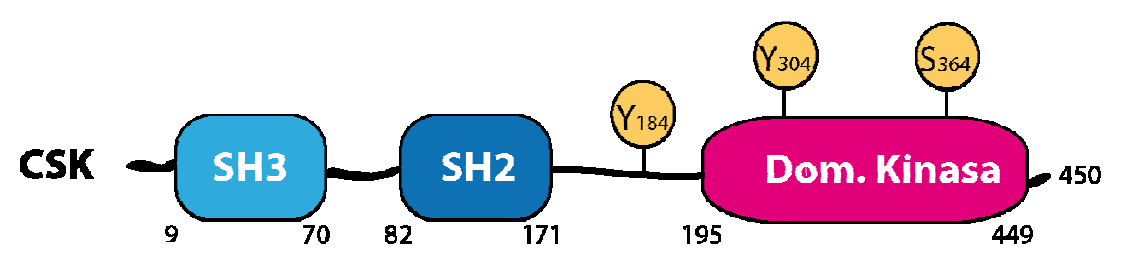

Figura 3: Estructura lineal de Csk. Se muestran los dominios principales de Csk,,SH3, SH2 y el dominio kinasa, así como los aminoácidos tirosina 184, tirosina 304 y serina 364, posiblemente implicados en su regulación.

La fosforilación de la Ser 364 de Csk por la PKA (proteína kinasa A) aumenta su actividad enzimática (Vang et al. 2001), ya que afecta a la interacción intracatenaria entre el dominio SH3 y 
el dominio kinasa de Csk (Sondhi y Cole 1999). También se ha detectado la fosforilación de Csk en las tirosinas 184 y 304, pero se desconoce su función. Se ha propuesto que la fosforilación de la tirosina 184 podría actuar como sitio de unión para dominios SH2. En la actualidad se desconoce la kinasa encargada de fosforilar esta tirosina (Joukov et al. 1997). La fosforilación en la Y304 solo se ha detectado in vitro utilizando concentraciones elevadas de Csk (Joukov et al. 1997) y se cree que es necesaria para el mantenimiento de la estructura del domino kinasa.

La función de Csk es fundamental en el desarrollo embrionario, en particular en la formación del tubo neural (Imamoto y Soriano 1993), la regulación negativa de los linfocitos T (Chow et al. 1993) y la organización del citoesqueleto (Thomas et al. 1995). En los ratones knock out para Csk, se ha comprobado que la ausencia de Csk en las células germinales provoca una hiperactivación de las SFKs, produciendo severos defectos en la notocorda y en el tubo neural que conllevan la muerte de los embriones a los 9-10 días del desarrollo (Imamoto y Soriano 1993; Nada et al. 1993). Por otro lado, la sobreexpresión de Csk inhibe la transducción de señales iniciada por las SFKs en varios tipos de células (Mustelin y Tasken 2003).

Se ha descrito que la subunidad $\beta_{\gamma}$ de las proteínas $G$ heterotriméricas interacciona directamente con el dominio kinasa de Csk (Lowry et al. 2002). Esta interacción conduce a un aumento de la concentración de Csk en la membrana plasmática y a un aumento de su actividad kinasa, lo cual es necesario para la formación de las fibras de estrés inducidas por las proteínas $G$ y para la consecuente reorganización del citoesqueleto. Csk también interacciona con proteínas a través de sus dominios SH3 y SH2 (Cloutier et al. 1995), por ejemplo con las fosfatasas de tirosina PTP-HSCF (Wang et al. 2001), PEP (Cloutier y Veillette 1996), Lyp (Cohen et al. 1999) y PTP-PEST (Davidson et al. 1997).

\subsection{Fosfatasas de tirosina (PTPs).}

\subsubsection{Generalidades.}

Las fosfatasas de tirosina o PTPs (protein tyrosine phoshatases) realizan la acción opuesta a las kinasas de tirosina y, al igual que estas, desempeñan un importante papel en numerosos procesos celulares, entre ellos la diferenciación y división celular (Fischer et al. 1991; Charbonneau y Tonks 1992; Walton y Dixon 1993). En el genoma humano, 107 genes codifican para fosfatasas de tirosina y 90 para kinasas de tirosina (Manning et al. 2002). De los genes que codifican para fosfatasas de tirosina, 11 son inactivos, 2 desfosforilan el ARN mensajero y 13 actúan sobre fosfolípidos de inositol, con lo cual, solo son capaces de desfosforilar proteínas 81 fosfatasas. Por otro lado, de las 90 kinasas de tirosina sólo son catalíticamente activas 85 , de manera que el genoma humano contiene un número similar de fosfatasas y kinasas de tirosina activas. 
Las fosfatasas de tirosina se agrupan en cuatro clases según su secuencia de aminoácidos y sus dominios catalíticos, y cada clase posee un conjunto de substratos específicos (Figura 4) (Alonso et al. 2004). En las fosfatasas de la Clase I, Il y III, el aminoácido esencial para la catálisis es una cisteína del centro activo mientras que en las fosfatasas de la Clase IV, el aminoácido esencial es un ácido aspártico (Li et al. 2003; Rayapureddi et al. 2003; Tootle et al. 2003).

\begin{tabular}{|c|c|c|c|c|}
\hline \multicolumn{4}{|c|}{$\begin{array}{c}\text { Catálisis basada } \\
\text { en Cys }\end{array}$} & \multirow{2}{*}{$\begin{array}{c}\begin{array}{c}\text { Catálisis basada } \\
\text { en Asp }\end{array} \\
\text { CLASE IV }\end{array}$} \\
\hline $\mathrm{CL}$ & ASE I & CLASE II & CLASE III & \\
\hline $\begin{array}{ll}\text { PTPs Clásicas } \\
\text { RPTPs } & \text { (PTy } \\
\text { NRPTPs } & \text { (PTyı }\end{array}$ & & $\begin{array}{l}\text { LMPTPs } \\
\text { (PTyr) }\end{array}$ & $\begin{array}{l}\text { CDC25s } \\
\text { (PTyr, PThr) }\end{array}$ & $\begin{array}{c}\text { EyA } \\
\text { (PTyr, PSer?) }\end{array}$ \\
\hline $\begin{array}{l}\text { DSPs } \\
\text { MKPs } \\
\text { DSPs atipicas } \\
\text { Slingshots } \\
\text { PRLs } \\
\text { CDC14s } \\
\text { PTENs } \\
\text { Microtubulari }\end{array}$ & $\begin{array}{l}\text { (PTyr, PThr) } \\
\text { (PTyr,PThr, mARN) } \\
\text { (PSer) } \\
\text { (PTyr) } \\
\text { (PSer, PThr) } \\
\text { (D3-fosfoinositios) } \\
\text { las (PI(3)P) }\end{array}$ & & & \\
\hline
\end{tabular}

Figura 4. Clasificación de la superfamilia de las fosfatasas de tirosina. Entre paréntesis se muestra la especificidad por el substrato de cada grupo de proteínas. Modificado de Alonso et al 2004 (Alonso et al. 2004).

La Clase I está formada por dos subgrupos que han evolucionado de un ancestro común. El primer subgrupo de 38 proteínas es conocido como fosfatasas de tirosina clásicas (Andersen et al. 2004) cuyos substratos son estrictamente fosfotirosinas y todas ellas tienen ortólogos en ratón. A su vez este subgrupo se puede dividir en receptores de fosfatasas o en inglés receptor protein-tyrosine phosphatases (RPTPs) (21 proteínas) y en fosfatasas citosólicas o en inglés non-receptor protein-tyrosine phosphatases (NRPTPs) (17 proteínas) (Andersen et al. 2004). El segundo subgrupo está formado por 61 proteínas con similitud a VH1 (Vaccinia virus $\mathrm{H} 1$ gene product), estas son fosfatasas de especificidad dual (DSP) y poseen una gran diversidad de substratos.

La Clase II está formada sólo por una proteína de bajo peso molecular, LMPTP (Low Molecular weigh Protein Tyrosine phosphatase), más ancestral que la clase I ya que se encuentran homólogos en todos los phylum, incluyendo plantas, numerosos procariotas y el subreino Archaea. Su estructura está relacionada con las arseniato reductasas de bacterias. 
Las fosfatasas de tirosina de la Clase III, cuyo aminoácido catalítico también es una cisteína, tienen especificidad por proteínas fosforiladas en tirosina y treonina y su dominio catalítico es un dominio rhodanese, nombre de la enzima con actividad sulfotransferasa, donde se describió este dominio. Esta clase está formada por 3 proteínas involucradas en la regulación del ciclo celular, las Cdc (cell division cycle) $25 \mathrm{~A}, \mathrm{~B}$ y C.

Pese a las similitudes en el mecanismo catalítico y en la secuencia del sitio activo, las fosfatasas de las clases I, II y III han evolucionado de forma independiente. Sin embargo, una comparación estructural indica que pueden haber evolucionado a partir de un ancestro común (Alonso et al. 2004).

La Clase IV usa un mecanismo catalítico diferente ya que utiliza un ácido aspártico como nucleófilo para desfosforilar los substratos tanto en tirosinas como en serinas, en una reacción metal-dependiente (Li et al. 2003; Rayapureddi et al. 2003; Tootle et al. 2003), (Rayapureddi et al. 2005). Su secuencia sugiere que pertenecen a la familia de fosfohidrolasas haloácido deshalogenasas (HAD). Los primeros miembros que se identificaron de esta familia recibieron el nombre de proteínas Eya (eyes absent) que además de tener actividad fosfatasa son cofactores transcripcionales que participan en la regulación de la transcripción de genes implicados en la formación de tejidos y órganos.

\subsubsection{Mecanismo catalítico.}

El dominio catalítico de las fosfatasas de tirosina clásicas de la Clase I está formado aproximadamente por 300 aminoácidos. Dentro de este dominio cabe destacar el bucle $\mathbf{P}$ (Figura 5) que contiene la secuencia HCX2GX2R, altamente conservada en esta familia, donde la cisteína (C) y la arginina (R) son esenciales para la actividad catalítica de la enzima y $(X)$ es cualquier aminoácido. El grupo tiol de de la Cys catalítica realiza un ataque nucleofílico sobre el grupo fosfato del substrato, mientras que la arginina estabiliza el intermediario cisteína-fosfato (Zhang et al. 1994). En algunas fosfatasas de tirosinas como PTP1B, se ha identificado también un segundo sitio de unión a fosfotirosinas, próximo al sitio activo, que está implicado en el reconocimiento de los substratos y, por este motivo, se ha utilizado para diseñar inhibidores selectivos que se unen al sitio activo y a este segundo sitio de reconocimiento (Tautz et al. 2006).

Por otra parte, en el dominio fosfatasa también se encuentra el bucle o motivo WPD, una secuencia muy variable en la que los aminoácidos más conservados son el triptófano (W), la prolina $(P)$ y el aspártico $(D)$ que dan nombre a este motivo, donde este último aminoácido es esencial en la catálisis. El bucle WPD cambia de conformación encerrando o atrapando la fosfotirosina del substrato en el bolsillo catalítico donde se encuentra la cisteína que realiza el ataque nucleofílico, a la vez que el ácido aspártico del motivo WPD actúa como donador de 
protones, facilitando la salida del sustrato desfosforilado (protona el oxígeno del grupo tirosilo y rompe la unión del fosfato con la tirosina). Después, el mismo ácido aspártico actúa como aceptor de protones de una molécula de agua, recuperando su estado inicial y permitiendo que dicha molécula de agua ataque al grupo fosforilo unido a la cisteína catalítica. Finalmente, esta cisteína se reduce de nuevo liberando la molécula de fosfato inorgánico. En este último paso, es crucial la participación de una glutamina conservada que se encuentra dentro del bucle $\mathbf{Q}$, que coordina la molécula de agua (Zhang et al. 1994).

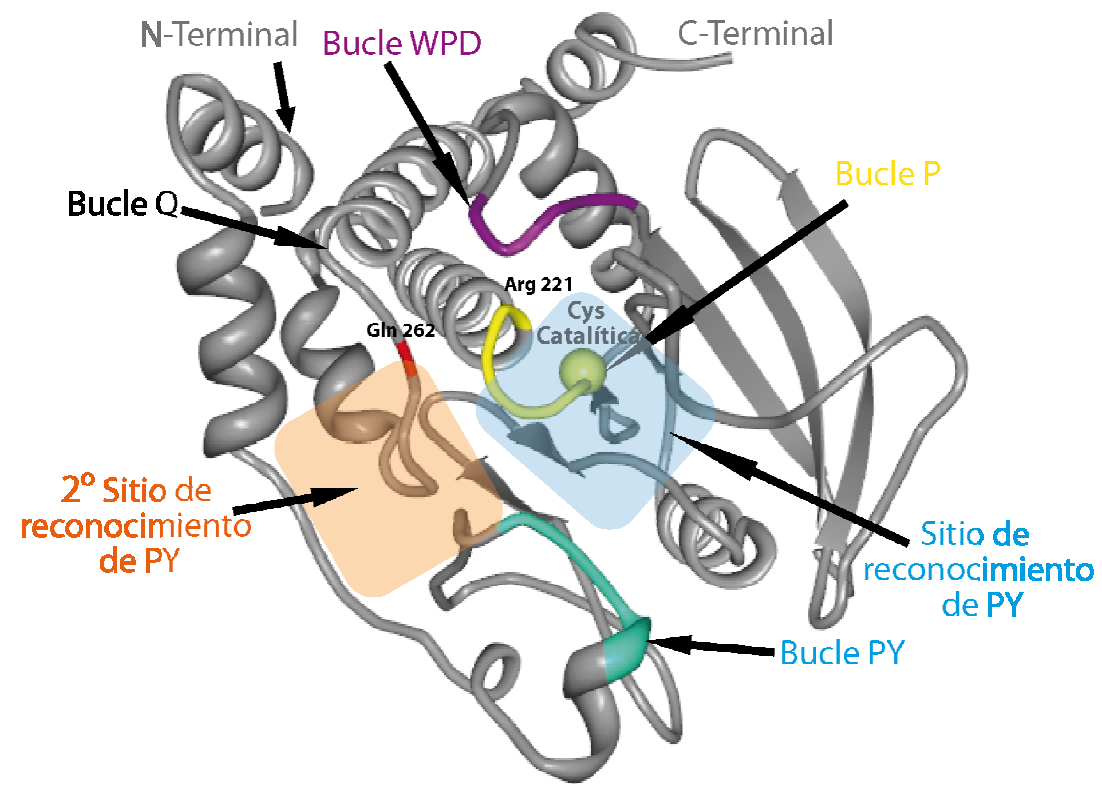

Figura 5: Estructura terciaria del domino fosfatasa de la fosfatasa clásica PTP1B (PDB: 1SUG). En el diagrama de cintas se han destacado en diferentes colores elementos clave de la estructura secundaria. En amarillo, se ha señalado el bucle $P$, rodeándolo se encuentran los aminoácidos que forman parte del bucle de reconocimiento de tirosina (KNRY 60 ) en azul (Bucle PY), el recuadro azul corresponde al bolsillo catalítico donde encajan los substratos. Por otra parte, en morado se muestra el bucle WPD, el recuadro naranja corresponde al segundo sitio de reconocimiento de substratos y por último el bucle $Q$, donde se muestra la Glu 262 necesaria para la catálisis. Figura modificada de Barr et al. (Barr et al. 2009).

El bucle WPD presenta cuatro conformaciones o estados distintos en las fosfatasas de tirosina clásicas: cerrado, abierto, intermedio y, por último, un estado atípicamente abierto. Esta conformación atípicamente abierta se ha observado en tres fosfatasas de diferentes grupos, STEP, Lyp y GLEPP1 (Eswaran et al. 2006), lo que sugiere que esta conformación podría tener relevancia para el conjunto de la familia de fosfatasas de tirosina. La conformación abierta atípica es inactiva ya que el ácido aspártico del motivo WPD está muy alejado del sitio activo (Figura 6). Por ello, se ha propuesto que la ocupación del bolsillo catalítico produciría un movimiento del bucle WPD, el cual adquiriría una conformación "cerrada" que sería activa (Zhang 2002). 
Figura 6: Representación del motivo WPD en los distintos estados conformacionales encontrados en las fosfatasas de tirosinas.En la imagen se representa el motivo WPD de distintas fosfatasa de tirosina como PTP1B, GLEPP1 (fosfatasa de tirosina Receptor 3), STEP (PTPN5) y Lyp. En azul se representa el estado cerrado de PTP1B (PDB: 1SUG), en amarillo el estado abierto de PTP1B (PDB: 2HNP) y en morado los estados atipicamente abiertos de GLEPP1, de STEP y de Lyp (PDB: 2HNP) (Barr et al. 2009).

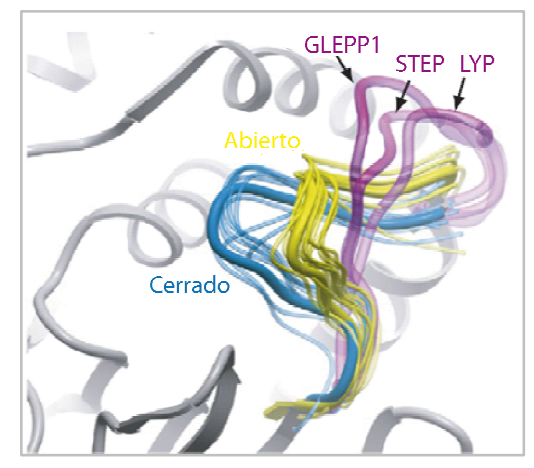

En la cocristalización de STEP junto con una fosfotirosina unida a su sitio activo, el bucle WPD sigue estando en la configuración atípicamente abierta, indicando que la unión de una fosfotirosina no es suficiente para producir el cierre del bucle WPD. Al observar el estado de apertura y cierre del WPD en varias estructuras, se observa que en la conformación cerrada se produce una fuerte unión con una molécula de agua que es coordinada por dos glutaminas conservadas dentro del bucle $Q$. Por el contrario, en estructuras abiertas o atípicamente abiertas esta molécula de agua está desplazada o no se encuentra presente, lo que sugiere que forma parte del mecanismo de cierre del bucle WPD.

Además de la especificidad que confieren estas conformaciones del motivo WPD, la afinidad de las fosfatasas por el tipo de substrato también viene definida por los aminoácidos que, sin formar parte de los motivos antes descritos, generan una topología especial en la superficie de cada fosfatasa. Así, el potencial electrostático de la superficie del dominio catalítico de las PTPs es una propiedad que puede influir en el reconocimiento de substratos, en la asociación con proteínas reguladoras o en su propia regulación, por ejemplo, por dimerización. La diversidad que presentan las fosfatasas en cuanto al potencial electrostático de su superficie (Alonso et al. 2004), (Barr et al. 2009) no se da únicamente entre miembros de diferentes familias sino también en subgrupos individuales. Los cambios de conformación del WPD, antes mencionados, pueden modificar el potencial de superficie, aunque solo afectarían a un área pequeña.

El conocimiento detallado de la estructura del dominio catalítico de las fosfatasas de tirosinas y de los aminoácidos implicados en la catálisis ha permitido diseñar mutaciones que permiten identificar los sustratos de estas enzimas. Así, mutaciones en la cisteína catalítica del bucle $P$ por una serina o alanina $(C / S \circ C / A)$ y en el ácido aspártico del bucle WPD por una alanina (D/A) se han utilizado para identificar sustratos de las fosfatasas. La primera mutación da lugar a una enzima catalíticamente inactiva (Jia et al. 1995; Salmeen et al. 2000; Sarmiento et al. 2000; Yang et al. 2000) y la segunda mutación permite la formación del intermediario cisteínafosfato, paso en el que queda bloqueada la catálisis por la falta del ácido aspártico, por lo que la 
enzima es capaz de retener a los substratos unidos a ella (Flint et al. 1997) y por ello ha recibido el nombre de mutante atrapador de sustratos.

\subsubsection{Regulación por oxidación.}

Numerosos estímulos, por ejemplo factores de crecimiento, citokinas y la luz ultravioleta, inducen la producción de especies reactivas del oxígeno (acrónimo inglés ROS) capaces de cambiar el estado redox hacia la oxidación. La oxidación de la Cys del sitio activo de las fosfatasas, blanco fácil debido a su bajo $\mathrm{pK}_{\mathrm{a}}$, anula sus propiedades nucleofílicas e inactiva estas enzimas. Así pues, la actividad de las fosfatasas de tirosina depende de su estado de oxidación, de manera que para que una fosfatasa sea activa y pueda realizar el ataque nucleofílico, su cisteína catalítica tiene que estar completamente reducida en forma de anión tiolato. Cuando la Cys se oxida, en primer lugar, pasa a un estado de ácido sulfénico. En este punto, la reacción aún es reversible y gracias a un átomo de nitrógeno cedido por un aminoácido contiguo puede pasar rápidamente a un estado de sulfenilamida cíclica, estado en el que la fosfatasa no puede "sufrir" más oxidación, de modo que no alcanza los estados de ácido sulfínico y sulfónico donde la proteína quedaría inactiva de forma irreversible. El azufre de la Cys en el estado de sulfenilamida puede ser reducido de nuevo para volver a formar el anión tiolato y, de este modo, se revierte la inactivación de la enzima. (Figura 7).

Existen evidencias de que al menos parte de las respuestas celulares a distintos estímulos se deben a la inactivación específica y transitoria de las PTPs (den Hertog et al. 2005; Groen et al. 2005), lo que indica que la oxidación de las PTPs es un importante mecanismo regulador de la activación celular y que éstas son sensores importantes del estado redox celular.

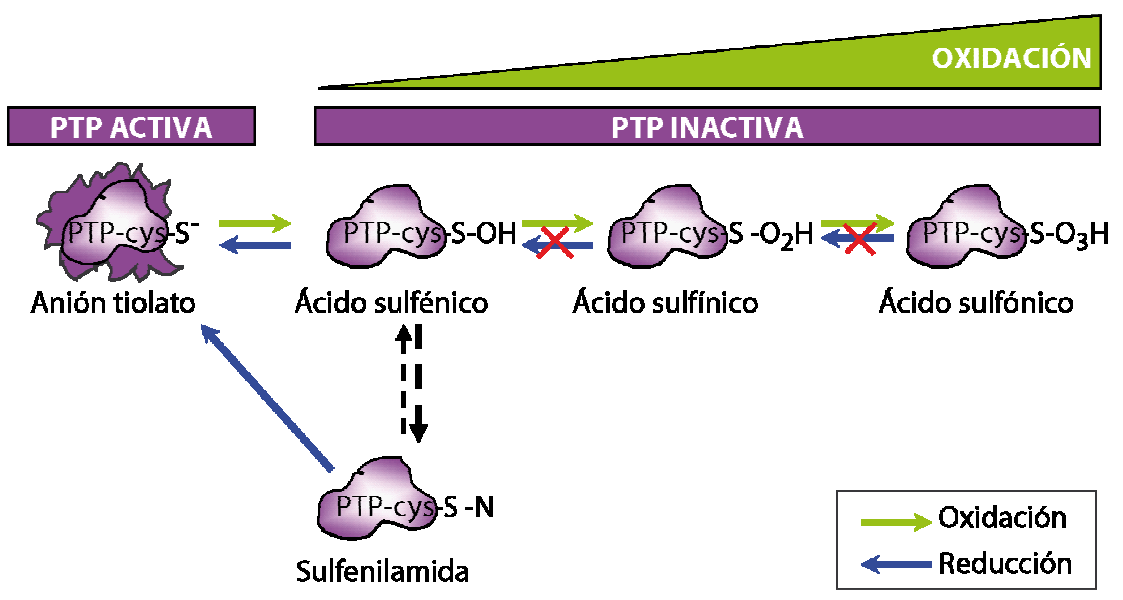

Figura 7: Modificaciones por oxidación de la cisteína catalítica de las fosfatasas de tirosina clásicas. Imagen adaptada de Den Hertog et al. (den Hertog et al. 2005). 


\section{Subfamilia de fosfatasas PEST.}

La subfamilia PEST de fosfatasas de tirosina se encuentra dentro de las fosfatasas de tirosina clásicas de la clase I de tipo no receptor y está formada por tres miembros, Lyp (lymphoid tyrosine phosphatase), PTP-PEST y PTP-HSCF también llamada BDP1, codificadas por los genes PTPN22, PTPN12 y PTPN18, respectivamente. A grandes rasgos, todas contienen en el extremo amino terminal una secuencia de entre 20 y 26 aminoácidos seguida del dominio fosfatasa (domino PTP), con aproximadamente 269 aminoácidos, y una región carboxilo terminal de longitud variable, de 167 a 516 aminoácidos, que es rica en aminoácidos de prolina (P), ácido glutámico $(E)$, serina $(S)$ y treonina $(T)$ y que, por ello, recibe el nombre de dominio PEST, el cual da nombre a esta subfamilia (Figura 8). En general, las proteínas con secuencias PEST se caracterizan por tener una vida media corta ya que son rápidamente degradadas en el interior de las células eucariotas (Rogers et al. 1986). Sin embargo, a pesar de la presencia de las regiones PEST en estas fosfatasas, no se ha encontrado que estas secuencias afecten a la vida media de PEP (Flores et al. 1994), ortólogo murino de Lyp, ni de PTP-PEST (Charest et al. 1995).

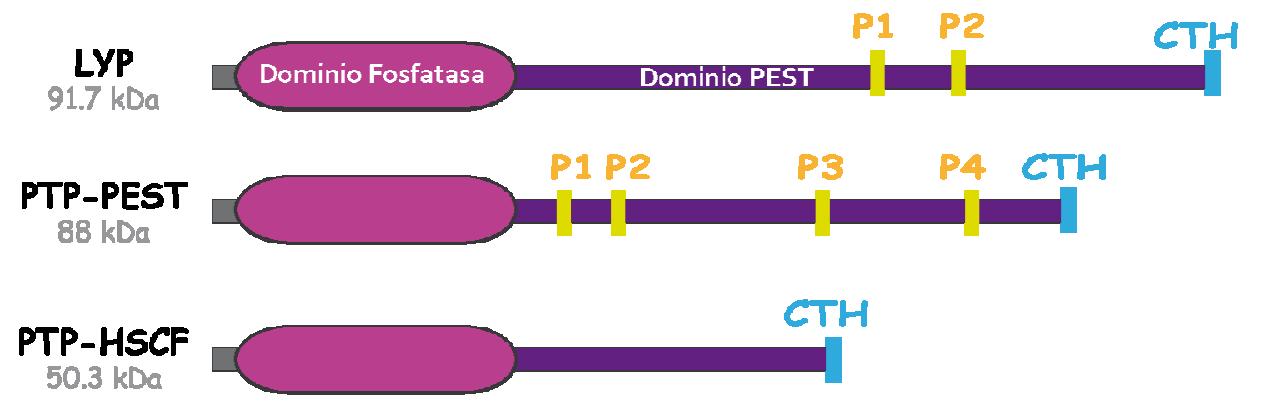

Figura 8: Estructura primaria de la subfamilia PEST. En la imagen se muestran el dominio catalítico, el dominio PEST con los motivos ricos en prolinas (P1 a P4 según la proteína) y el dominio de homología del extremo carboxilo terminal $(\mathrm{CTH})$.

\subsection{Características.}

\subsubsection{Dominio fosfatasa.}

Las fosfatasas de la subfamilia PEST presentan superficies con diferente potencial electrostático (Figura 9). Mientras PTP-PEST y Lyp presentan una conformación del motivo WPD atípicamente abierto con las superficies que rodean al centro catalítico electropositivas (azul), PTP-HSCF presenta una conformación abierta con menos zonas electropositivas. Esta diferencia entre las tres fosfatasas de la familia podría traducirse en el reconocimiento de diferentes substratos o en la interacción con distintas proteínas reguladoras. 


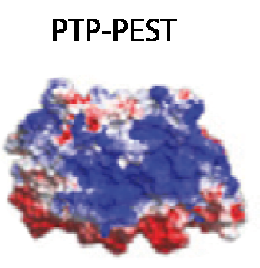

Atipicamente abierto

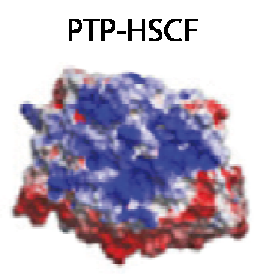

Abierto

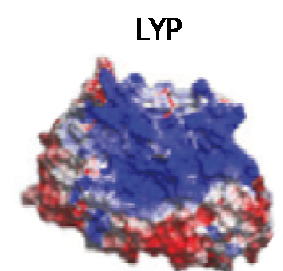

Atipicamente abierto

Figura 9: Distribución del potencial electrostático en el dominio catalítico de las fosfatasas PTPPEST, PTP-HSCF y Lyp. Las estructuras de Lyp y PTP-HSCF se han obtenido por cristalización sin embargo la estructura de PTP-PEST es un modelo obtenido basándose en su homología de secuencia con las fosfatasas anteriores. Las zonas rojas hacen referencia a una superficie electronegativa y las zonas azules a una superficie electropositiva. En la parte inferior de cada imagen se indica la conformación del bucle WPD.

Las fosfatasas PEST presentan en el extremo amino de su dominio PTP una secuencia conservada (STKYKADK) entre la hélice $\alpha 2$ y $\alpha 1$, característica de este grupo, que contiene un aminoácido de serina con una función relevante, en Lyp la S35, en PTP-PEST la S39, y en PTPHSCF la S37 (Figura 10). Se ha descrito que la fosforilación de la S35 de Lyp por la proteína kinasa C (PKC) produce un cambio conformacional que altera el reconocimiento de substratos e impide que la fosfatasa actúe sobre sus dianas, afectando de este modo a su función celular (Yu et al. 2007). Asimismo, la fosforilación de la S39 de PTP-PEST, sea por la PKC o por la PKA, reduce la actividad y la afinidad de dicha proteína por sus substratos (Garton y Tonks 1994). En el caso de PTP-HSCF, la secuencia que rodea la S37 no se ajusta al consenso de los sitios de fosforilación de $\mathrm{PKC}(\mathrm{K} / \mathrm{R}) \mathrm{XX}(\mathrm{S} / \mathrm{T}) \mathrm{X}(\mathrm{K} / \mathrm{R})$, lo cual, junto con la ausencia de datos sobre su fosforilación, sugiere que esta fosfatasa no es buen sustrato para esta kinasa (Pearson y Kemp 1991).

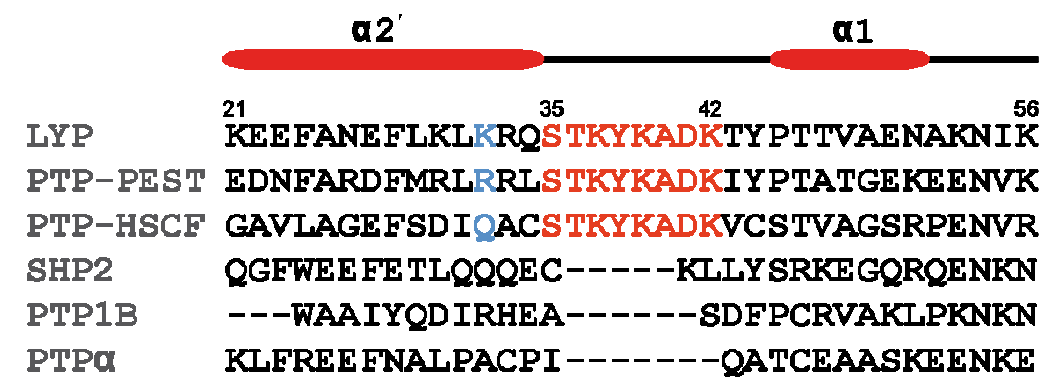

Figura 10: Alineamiento del domino catalítico de distintas fosfatasas de tirosina. En rojo, se destaca el segmento específico presente en las proteínas de la familia de fosfatasas PEST y en azul, el primer aminoácido de la secuencia consenso para la fosforilación por PKC. Modificado de Yu et al. (Barr et al. 2009) 


\subsubsection{Dominio PEST.}

En el dominio no catalítico de estas proteínas se han descrito varias secuencias 0

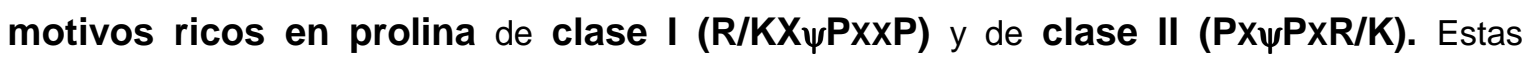
secuencias ricas en prolina, como es sabido, interaccionan con dominios SH3 (Matthews et al. 1992). Además de estos motivos de prolinas, esta subfamilia también comparte en el extremo carboxilo terminal un motivo denominado CTH (C-Terminal Homology) (Figura 8), que se ha demostrado que en PTP-PEST y PTP-HSCF interacciona con PSTPIP (Proline, Serine, Threonine, Phosphatase Interacting Protein), una proteína del citoesqueleto identificada por Spencer et al. en 1997 (Spencer et al. 1997). PSTPIP es una proteína homóloga a CDC15 (cell division control) de Schizosaccharomyces pombe implicada en el ensamblaje de anillos de actina en la citokinesis. En este sentido, Coté et al. describieron la desfosforilación de WASP (WiscottAldrich syndrome protein), una proteína también implicada en la organización del citoesqueleto, por PTP-PEST mediada a través de la interacción mutua con PSTPIP1 (Cote et al. 2002).

Lyp, PTP-PEST y PTP-HSCF se diferencian en su patrón de expresión, en su estructura, en las interacciones con otras proteínas y por tanto, presumiblemente, en su función fisiológica. (Tabla 1) (Veillette et al. 2009).

\begin{tabular}{|c|c|c|c|c|}
\hline NOMBRE & GEN & EXPRESIÓN & PROTEÍNAS ASOCIADAS & SUBSTRATOS POTENCIALES \\
\hline PTP-PEST & PTPN12 & $\begin{array}{l}\text { Ubicua, mayormente } \\
\text { en células } \\
\text { hematopoyéticas }\end{array}$ & $\begin{array}{l}\text { Cas, CasL, Sin, paxilin, } \\
\text { leupaxin, Hic-5, Grb2, Shc, } \\
\text { Csk, PSTPIP }\end{array}$ & $\begin{array}{l}\text { Cas, paxilin, FAK, Pyk2, Shc, } \\
\text { PSTPIP, WASP, c-Abl, } \\
\text { p190RhoGAP, ArgBP2, Lck } \\
\text { (Y394), Fyn (Y417) }\end{array}$ \\
\hline PTP-HSCF & PTPN18 & $\begin{array}{l}\text { células } \\
\text { hematopoyéticas } \\
\text { originales y otras } \\
\text { (cerebro, colon) }\end{array}$ & $\begin{array}{l}\text { Csk, Tec, PSTIPIP } 1 \text { y 2, } \\
\text { Erbb2, Grb2, c-Src, } \\
\text { RhoGAP5, Abl }\end{array}$ & Fyn (Y417), Tec, PSTPIP \\
\hline Lyp/PEP & $\begin{array}{l}\text { PTPN22 } \\
\text { PTPN8 }\end{array}$ & $\begin{array}{l}\text { Células de origen } \\
\text { hematopoyético }\end{array}$ & 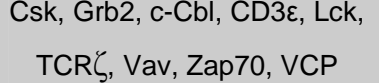 & $\begin{array}{c}\text { Lck (Y394), Fyn (Y417), Zap70 } \\
\text { (Y493) }\end{array}$ \\
\hline
\end{tabular}

Tabla 1: Características de las fosfatasas de la subfamilia PEST. Modificado de Veillete et al. (Veillette et al. 2009) 


\subsection{PTP-PEST.}

La fosfatasa PTP-PEST humana fue clonada por Yang et al. en 1993 y su homólogo murino por Charest et al. en 1995 y se comprobó que se expresaba ampliamente (Yang et al. 1993; Charest et al. 1995) (Davidson et al. 1997; Davidson y Veillette 2001).

PTP-PEST se asocia predominantemente con proteínas implicadas en la regulación del citoesqueleto (Garton et al. 1996) y con proteínas adaptadoras transductoras de señales (Habib et al. 1994) como se muestra en la tabla 1.

Además, PTP-PEST desempeña un papel esencial en el desarrollo embrionario, ya que su ausencia provoca una muerte temprana debida a defectos en la vascularización, en la formación del mesenterio, en la neurogénesis y en el desarrollo temprano del hígado. También se observa una hiperfosforilación de Cas, lo que sugiere que estas alteraciones son debidas a una organización aberrante del citoesqueleto (Sirois et al. 2006). Se ha comprobado en estudios de sobreexpresión y ablación de PTP-PEST en fibroblastos de embriones de ratón, que esta fosfatasa causa una inhibición de la motilidad celular (Angers-Loustau et al. 1999; Garton y Tonks 1999; Sastry et al. 2002; Jamieson et al. 2005; Sastry et al. 2006) reduciendo la migración celular inducida por integrinas, posiblemente por su papel en la desfosforilación de proteínas como Cas y FAK que se localizan en focos de adhesión.

PTP-PEST también está presente en linfocitos y tiene un papel relevante en su función. PTP-PEST controla la señalización a través de los inmunoreceptores de células $T$ y $B$ reduciendo la fosforilación de proteínas como Lck (Arimura et al. 2008), WASP (Badour et al. 2004), Shc, Cas, Pyk2 y FAK (Davidson y Veillette 2001), lo que conlleva su inhibición y, por consiguiente, un bloqueo de procesos tales como la reorganización de la actina, la formación de la sinapsis inmunológica (Badour et al. 2004), la activación de la cascada de señalización Ras-MAPK (Davidson y Veillette 2001), la activación de los factores de transcripción NFAT (Nuclear factor of activated T-cells) y NFKB (Nuclear factor immunoglobulin kappa chain enhancer $B$ cells transcription) (Arimura et al. 2008) y, por tanto, la inducción de IL-2 (Interlecukin 2), que en conjunto participan en la activación linfocitaria. Así PTP-PEST estaría actuando como un regulador negativo de la señalización en los linfocitos $T$ y $B$.

Asimismo, se ha descrito que la expresión de esta fosfatasa está regulada negativamente en respuesta a la activación a través del TCR de los linfocitos T vírgenes $\mathrm{CD} 4^{+}$y $\mathrm{CD} 8^{+}$(Arimura et al. 2008).

En resumen, PTP-PEST controla la adhesión y la migración en células no hematopoyéticas, aunque podría tener una función similar en células inmunes regulando la activación de los linfocitos. 


\subsection{PTP-HSCF.}

En $1996 \mathrm{Kim}$ et al. aislaron el gen PTPN18, que correspondía a otra fosfatasa de este grupo, PTP-HSCF (PTP-hematopoietic stem cell fraction), también llamada BDP1 (Brain-Deribed Phosphatase) porque se describió primero en cerebro y colon, aunque posteriormente se comprobó su expresión en diferentes tipos celulares derivados de tumores (Aoki et al. 1996; Cheng et al. 1996; Dosil et al. 1996; Huang et al. 1996; Kim et al. 1996).

La sobreexpresión de PTP-HSCF en células PC12 de rata aumenta la rapidez en la formación de neuritas inducidas por el factor de crecimiento neuronal (Aoki et al. 1996). Además, en células de la granulosa del ovario, la sobreexpresión provoca la reorganización del citoesqueleto (Shiota et al. 2003) y disminuye la fosforilación en tirosinas de p190 RhoGAP (proteína guanosina trifosfato activadora). Por el contrario, la expresión del dominante negativo de PTPHSCF en la línea celular K562, una línea de eritroleucemia, tratada con éster de forbol PMA, produce la inhibición de la adhesión y propagación de estas células(Dosil et al. 1996). Respecto a las células inmunes, se ha descrito que la sobreexpresión de PTP-HSCF en la línea celular de linfocitos B, Ramos, causa la inhibición de la inducción del promotor c-fos provocada por el BCR (Aoki et al. 2004) y este efecto coincide con la disminución de la fosforilación de las proteínas tirosina kinasas, Tec (Tec tyrosine kinase) y Btk (Bruton's tyrosine kinase).

Al igual que PTP-PEST, los datos disponibles indican que PTP-HSCF regula de forma positiva la reorganización del citoesqueleto, mientras que, en la señalización celular linfocítica, actúa como inhibidor. Sin embargo, la relevancia fisiológica de estas actividades debe ser apoyada en el futuro con estudios en modelos deficientes en esta fosfatasa.

\subsection{Lyp.}

El gen PTPN22 que codifica para Lyp (lymphoid tyrosine phosphatase) se localiza en el cromosoma 1p13.3-13.1. La proteína fue descrita por Cohen et al. (Cohen et al. 1999) y recibió este nombre porque se expresaba en linfocitos, aunque posteriormente también se detectó su expresión en otras células de origen hematopoyético. Inicialmente, se describió la existencia de otra isoforma, Lyp2, que presentaba un procesamiento alternativo del ARNm. La existencia de esta segunda isoforma no ha sido corroborada posteriormente, de hecho Gandhi et al. en el 2005, realizaron un análisis bioinformático de todas las PTPs humanas con el objetivo de comprobar el procesamiento alternativo de las mismas y no encontraron ninguna otra isoforma de Lyp (Gandhi et al. 2005). Según la secuencia de aminoácidos de Lyp (807 aminoácidos), se esperaría un peso molecular de $92 \mathrm{kDa}$, sin embargo, muestra una movilidad electroforética que se corresponde con un peso molecular aproximado de $105 \mathrm{kDa}$ (Cohen et al. 1999). 
Lyp comparte un $70 \%$ de identidad de secuencia de aminoácidos con PEP, su ortólogo murino, codificado por el gen PTPN8, (Matthews et al. 1992) (Figura 11) sin embargo, la identidad de secuencia que existe en los distintos dominios, considerados de forma aislada, es diferente. Así, el dominio catalítico presenta un $89 \%$ de identidad, mientras que en el resto es solo del $61 \%$, porcentaje menor del que suelen presentar otras fosfatasas homólogas de humano y ratón.

En linfocitos, se ha observado que Lyp se localiza fundamentalmente en el citosol, rodeando al núcleo, muy poco en la membrana plasmática y una pequeña cantidad en balsas lipídicas (Bottini et al. 2006). Estudios anteriores en células HEK293 en las que se transfectó Lyp describieron la localización de esta fosfatasa en el núcleo (Flores et al. 1994). De hecho, se ha identificado una secuencia de localización nuclear (PVKRTK) (Dang y Lee 1988; Garcia-Bustos et al. 1991) entre la posición 446 a 451 de PEP (Flores et al. 1994) (Figura 11), pero esta localización nuclear no se ha verificado para la proteína endógena en células hematopoyéticas.

Figura 11. Alineamiento de las secuencias de aminoácido de Lyp y PEP. El alineamiento se obtuvo con el programa de alineamiento de secuencias CLUSTAL W (1.83). El dominio fosfatasa se muestra en azul y la secuencia de localización nuclear de PEP en verde.

\begin{tabular}{|c|c|c|}
\hline $\mathbf{Y P}$ & 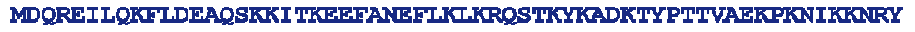 & \\
\hline PEP & 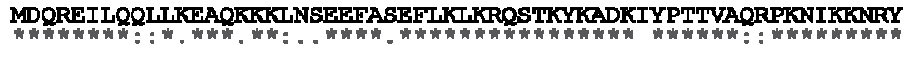 & 60 \\
\hline $\mathbf{P}$ & KDILPYDYSRVELSLITSDEDSSYINANTIKGVYGPKAYIATQGPLSTTLLDFWRMIWUY & 120 \\
\hline PEP & 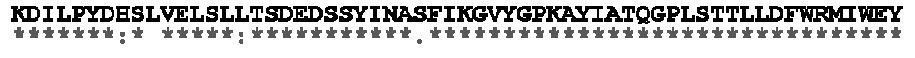 & 120 \\
\hline & SVLI I VMACMEYFMGKKKCFFYVAEPGEMOLEFGPFSVSCFAEKRKSDYIIRTLKVKFNS & 180 \\
\hline PEP & 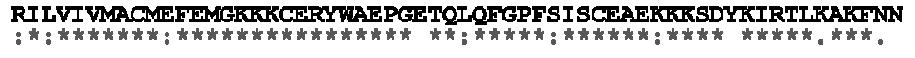 & 180 \\
\hline $1 \mathrm{P}$ & ETRTIYQFEYKNWEDEDVPSSIDPILELIWDVRCYQEDDSVPICIECSAGCGRTGVICAI & 240 \\
\hline PEP & 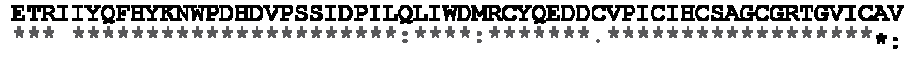 & 240 \\
\hline $\mathbf{P}$ & DYTWMLLFDGI IPENESVF SLIREMRTQRPSLVQTQEQYELVYLAVLLLFRROMDVIRDK & 300 \\
\hline PEP & 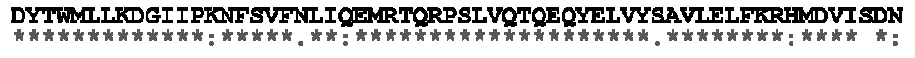 & 300 \\
\hline IE & HSGTESQAKRCIPEKANTLQADSYSPNLPKSTTKAAKMMNQ-- -QRTKMEIFESSSEDFR & 357 \\
\hline PEP & 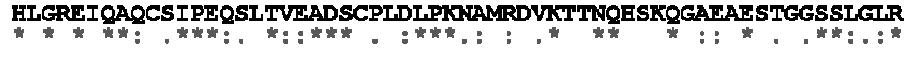 & 360 \\
\hline $\mathbf{P}$ & TSEI SAKEELVLERAKSSTSFDFLEINYSFDKNADTTMKWQTKAFPIVGE PLQKHQSIDI & 417 \\
\hline PEP & 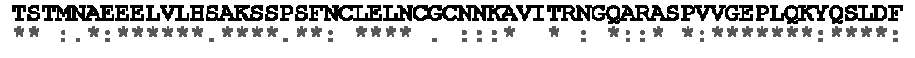 & 420 \\
\hline $1 \mathbf{x}$ & 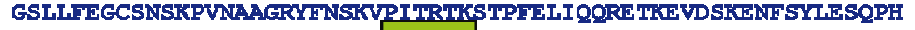 & 477 \\
\hline PEP & 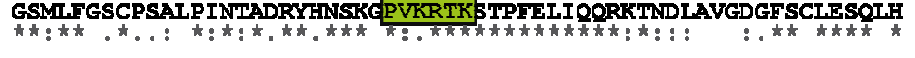 & 480 \\
\hline YP & DS-CFVEMDAOKVMEVSSAELNYSL.PYDSKHOI RHASSVKHEDSSALGVYSY I PLVENPY & 536 \\
\hline PEP & 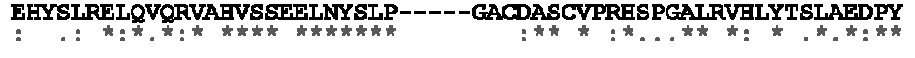 & 535 \\
\hline $\mathbf{Y Y}$ & FSSWPPSGTSSKMSLDLPERQDGTVFPSSILPTSSTSLFSYYNSEDSLSLNSPTNISSI & 596 \\
\hline PEP & 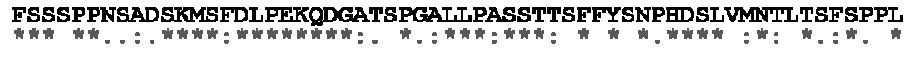 & 595 \\
\hline $\mathbf{Y P}$ & NQESAVLATAPRIDDEIPPPLPVRTPESFIVVEEAGEFSPNVPKSLSSAVKVKIGTSLETh & 656 \\
\hline PEP & 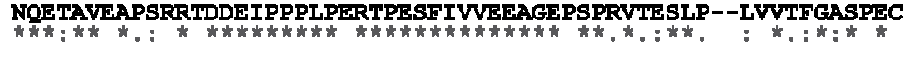 & 653 \\
\hline LYP & GGTSEPKKH'DDSVILRPSKSVKLRSPKSETHODRSSPPPPLPERTLESFFLADEDCMQAQ & 716 \\
\hline PEP & 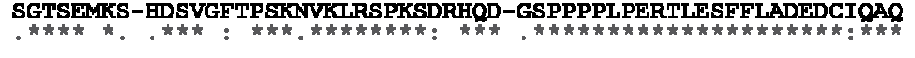 & 711 \\
\hline $\mathbf{Y P}$ & SIETYSTSYPDTMENSTSSRQTLKTPGKSF'IRSKSLKI LRNMKKS ICNSCPPNKPAESVQ & 776 \\
\hline PEP & 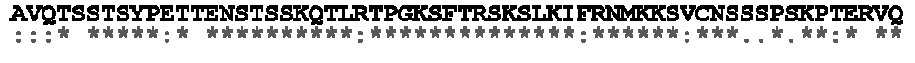 & 771 \\
\hline LYE & SMNSSSFLNTGFANRFSKPRGPRNPPPTWNI & \\
\hline & 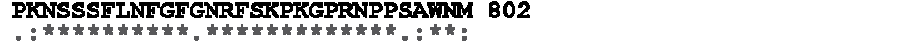 & \\
\hline
\end{tabular}




\subsubsection{Estructura: domino fosfatasa y dominio PEST.}

Lyp posee un dominio fosfatasa en el extremo amino-terminal, al igual que las otras fosfatasas de esta subfamilia, una región central de función desconocida y una región carbóxilo terminal, que contiene varios motivos ricos en prolina. En su dominio catalítico (aminoácidos 24289), Lyp presenta los aminoácidos esenciales para su función, la cisteína catalítica, C227, y la arginina R233, que forman parte del bucle $P$ (aminoácidos 226-233), bucle que en Lyp tiene la secuencia HC227SAGCGR233 (Figura 12 A y B). Para llevar a cabo la desfosforilación de la tirosina también es necesaria la colaboración del ácido aspártico D195 del motivo WPD (aminoácidos 193-204) y de la glutamina Q274 del bucle Q (aminoácidos 274-301) requerida para posicionar y activar una molécula de agua en el ataque nucleofílico.

Como se ha comentado anteriormente, la superficie del dominio catalítico de Lyp posee un potencial electrostático positivo, así como una hendidura profunda en el bolsillo catalítico que acoge al substrato fosforilado. Además de estas características, el dominio catalítico de Lyp posee dos zonas susceptibles de variar su conformación en función del estado de activación de está proteína (Figura 12 B recuadros rojos). Estas zonas son el bucle WPD y el inserto específico de Lyp. En concreto, la conformación y el movimiento de este inserto afecta al tamaño y la forma de los ligandos que pueden unirse al sitio activo (Tsai et al. 2009). Hasta el momento se han obtenido cinco estructuras del dominio catalítico de Lyp:

PDB 2QCT (cocristalizado con el inhibidor IC-11, un compuesto salicílico ácido-base competitivo y reversible para Lyp, donde una parte de este compuesto ocupa el sitio activo de Lyp mientras que la otra interacciona hidrofóbicamente con la región cercana al segundo bolsillo de interacción de fosfotirosinas) (Yu et al. 2007) y PDB 2QCJ, correspondiente al dominio fosfatasa en ausencia del inhibidor, obtenidas ambas en el mismo laboratorio (Yu et al. 2007).

PDB 2P6X (Barr et al. 2009) describe un WPD abierto.

PDB 3BRH (cocristalizado con un fosfopéptido de Lck) (Seidel 2007) presenta una conformación cerrada.

PDB 3H2X presenta una conformación intermedia (Tsai et al. 2009). Está última estructura es la única que presenta un puente disulfuro entre la cisteína catalítica C227 y la adyacente C192, que además también establece contacto con la C231. Presumiblemente, ambas cisteínas ejercen una función contraria, de modo que actúan impidiendo o favoreciendo la oxidación de la cisteína catalítica y regulando de esta manera la actividad de Lyp (Tsai et al. 2009). 
A

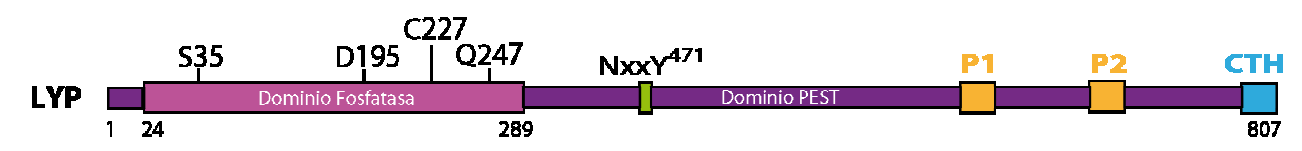

B

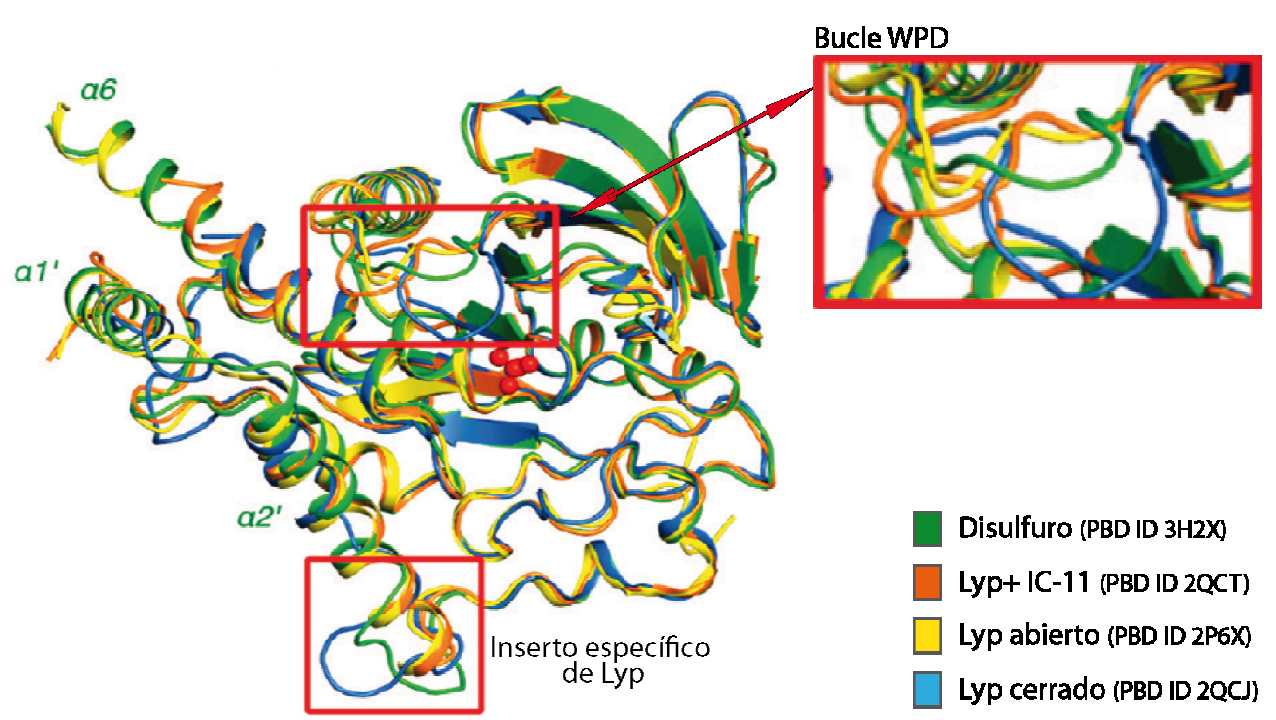

Figura 12: Estructura de Lyp. (A) Estructura lineal de Lyp. En ella se muestran algunos aminoácidos importantes para su función. En el dominio fosfatasa, la Ser 35, el Asp 195, la Cys 227 y la Glu 247 del bucle $Q$ y, en el dominio PEST, las secuencias ricas en prolinas P1, P2, el motivo CTH y el motivo NxxY, cuya tirosina es susceptible de fosforilación. (B) Superposición de las estructuras conocidas del dominio catalítico de Lyp. Se han enmarcado en rojo las dos áreas donde la variación entre las estructuras es mayor, el bucle WPD y el inserto específico. En verde se representa la estructura del dominio catalítico de Lyp con un puente disulfuro entre la Cys del dominio catalítico y una Cys adyacente (PDB 3H2X), en naranja la estructura obtenida junto con el inhibidor IC-11 (PDB 2QCT), en azul la correspondiente estructura sin el inhibidor (PDB 2QCJ) y en amarillo se representa la estructura de Lyp sola (PDB 2P6X). Por último, los iones fosfato están representados como bolas rojas. Modificado de Tsai et al. (Tsai et al. 2009).

En general, la variación en la posición del bucle WPD observada en las estructuras descritas sugiere un posible papel de este bucle en la regulación de Lyp. Por otra parte, el inserto específico de las fosfatasas PEST, situado entre las hélices a2' y a1 de Lyp también cambia de conformación, pudiendo encontrarse como un bucle o como una hélice (Figura $12 \mathrm{~B}$ ). En las estructuras obtenidas por Yu, et al. se observa que, en la conformación helicoidal, la Ser 35 se orienta hacia el interior de la estructura, formando un enlace de hidrógeno con la Arg 266 de la hélice $\alpha 5$, en el fondo del segundo bolsillo de unión a fosfatos. Así, la Ser 35 contribuiría al 
mantenimiento de la conformación helicoidal, de forma que, cuando se fosforila, esta hélice pierde su conformación haciendo que los aminoácidos que forman parte del segundo sitio de unión a fosfotirosinas pierdan su afinidad por el sustrato. Se ha observado que no por ello Lyp pierde su capacidad intrínseca para desfosforilar el sustrato pNPP (4-Nitrophenyl phosphate) pero sí se observa un aumento en la activación de los linfocitos $T$ debido a la incapacidad de Lyp para inactivar las kinasas de la familia Src (Yu et al. 2007).

Dada la variabilidad de las conformaciones, no se puede concluir claramente que combinacion de las conformaciones del WPD y del inserto específico es óptima para el funcionamiento de Lyp. En la tabla 2 se resumen las características observadas en todas las estructuras.

\begin{tabular}{l|c|c}
\multirow{2}{*}{ 2QCJ } & WPD & Inserto especifico \\
\cline { 2 - 3 } 2QCT & Abierto & Bucle \\
\hline 2P6X & Abierto & Hélice \\
\hline 3H2X & Intermedio & Hélice \\
\hline 3BRH & Cerrado & Hucle \\
\hline
\end{tabular}

Tabla 2: Conformaciones del bucle WPD y del inserto específico en las distintas estructuras de Lyp.

En cuanto a la región no catalítica, o dominio PEST, de Lyp existen varios motivos a través de los cuales Lyp podría interaccionar con otras proteínas. El motivo $\mathrm{N}^{468} \mathrm{XXY}$ (Figura $12 \mathrm{~A}$ ) contiene una tirosina (Y471) susceptible de ser fosforilada, que de este modo podría ser reconocida por los motivos PTB (phosphotyrosine binding domain) (Laminet et al. 1996) presentes en proteínas como por ejemplo IRS (Insulin receptor substrate), la proteína adaptadora Shc (Src homology 2 domain containing transforming protein 1) y Cbl (Cohen et al. 1999). Además, en esta región, Lyp tiene tres secuencias ricas en prolina, denominadas P1, P2 y CTH. Hasta ahora la interacción de Lyp mejor caracterizada es la que se establece entre el motivo $\mathrm{P} 1$, que es un motivo rico en prolinas de clase II, y el dominio SH3 de Csk. La secuencia P2 presenta un motivo de clase I y un motivo de clase II, mientras que en PEP esta secuencia solo presenta un motivo de clase II, debido a la ausencia de la arginina que aparece como una inserción en Lyp. La secuencia del motivo de clase II del P2 y del motivo P1 son similares como puede verse en el alineamiento de estos motivos (Figura 13). 


\title{
P1 (LYP) 610 DDEIP PPLPVRTPESFIVVEE 630 \\ P1 (PEP) 609 DDEIPPPLPERTPESFIVVEE 629
}

$\begin{array}{lll}\text { P2 (LYP) } & 690 & \text { RSSPPPPLPERTLESF'HADE } 710 \\ \text { P2 (PEP) } & 685 & \text { DGSPPPPLPERTLESFFLADE } 705\end{array}$

\author{
Px $\psi$ PxR (Clase II) \\ $\operatorname{Rx} \psi \mathbf{P x x P}$ (Class I)
}

Figura 13: Alineamiento de los motivos P1 y P2 de Lyp y PEP. Ambas proteínas presentan motivos de prolinas de clase II tanto en la secuencia P1 como en la P2, sin embargo, sólo Lyp presenta dentro de su secuencia P2 un motivo rico en prolinas de clase I.

\subsubsection{Interacción con Csk.}

La interacción de PEP con Csk está mediada por el dominio SH3 de Csk y el motivo P1 (PPPLPERTPESFIV) de la región no catalítica de PEP (Cloutier y Veillette 1996; Gregorieff et al. 1998), también descrito en su homólogo humano Lyp (Cohen et al. 1999) (Figura 14). Los aminoácidos hidrofóbicos 1625 y V626 de este motivo son esenciales para la interacción ya que estabililizan la unión (Ghose et al. 2001).

Cloutier y Veillette han descrito que aproximadamente el $25 \%-50 \%$ de todas las moléculas de PEP están asociadas constitutivamente con Csk y que aproximadamente el $5 \%$ de Csk está participando del complejo Csk-PEP en linfocitos T (Cloutier y Veillette 1996), dato que se desconoce para la interacción entre Lyp y Csk. La estequiometría con la que interaccionan PEP y CSK es muy alta lo que sugiere que esta interacción ha de tener una función importante.

En 1996, Cloutier et al. descartaron la posibilidad de que la interacción de PEP y Csk produjera modificaciones en las mismas como cambios de fosforilación o de conformación. Sin embargo, recientemente Barr et al. observaron que el dominio fosfatasa de Lyp puede desfosforilar in vitro un péptido que contiene la Y184 de Csk. (Barr et al. 2009). 


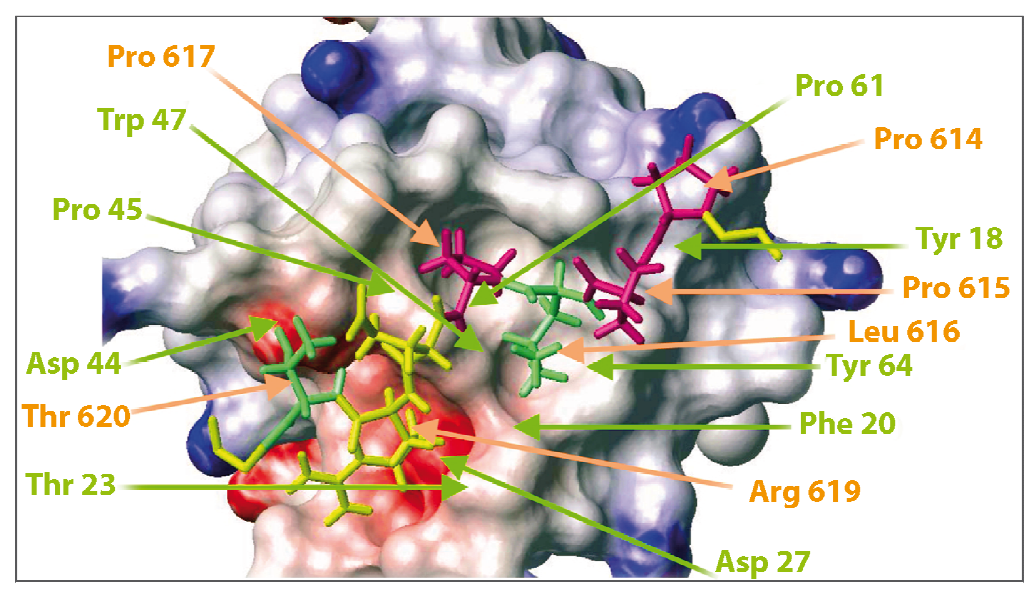

Figura 14: Estructura obtenida por NMR del domino SH3 de Csk con un péptido que contiene el motivo P1 de PEP (PDB PEP-3BP1). En esta imagen se muestra como encaja el péptido del dominio P1 de PEP en el dominio SH3 de Csk (parte globular). En naranja se representan los aminoácidos del péptido $S^{607}$ RRTDDEIPPPLPVRTPESFIVV ${ }^{627}$ de PEP, donde en rosa se representa el motivo PxxP, en verde los aminoácidos hidrofóbicos L616 y T617 y en amarillo la R619, involucrada en la interacción con el D27 de Csk. Los aminoácidos que forman la superficie del dominio SH3, principalmente aromáticos, Y18, F20, W47 y la Y64, se muestran rotulados en verde (Ghose et al. 2001).

Según el modelo propuesto por Veillette, la interacción entre Lyp y Csk permitiría que estas proteínas actuaran de forma cooperativa en la inhibición de las kinasas de la familia Src Lck y Fyn, que se expresan en los linfocitos T. De esta forma, Lck sería regulada negativamente por la fosforilación de su tirosina 505 por acción de Csk, a la vez que Lyp desfosforilaría la fosfotirosina 394 de activación de Lck (Figura 15) (Cloutier et al. 1995).

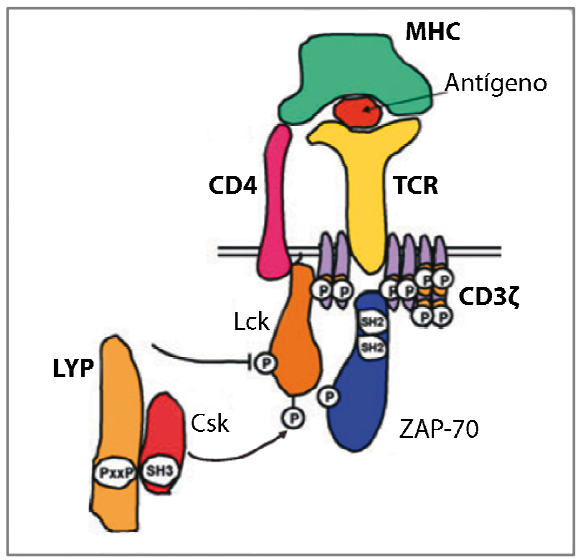

Figura 15: Esquema de la acción conjunta de Lyp y Csk en la inhibición de Lck. Modificada de Veillette (Veillette et al. 2009). 


\subsubsection{Interacción con proteínas y posibles substratos.}

La búsqueda de substratos de Lyp o de su homólogo murino, PEP, ha permitido identificar algunas proteínas como posibles substratos de Lyp (Tabla 1). Por el momento solo Lck, Fyn, Zap70 y la cadena $\zeta$ asociada al TCR han sido descritos como substratos directos de Lyp. También se ha propuesto que Cbl podría ser su substrato, dado que interaccionan en linfocitos $T$ y se ha comprobado una reducción en la fosforilación de Cbl cuando se sobreexpresa Lyp (Cohen et al. 1999). En el caso de Lck, Lyp desfosforila la Y394 que se encuentra en el bucle de activación (Palacios y Weiss 2004; Wu et al. 2006) al igual que hace con la Y417 de Fyn (Cloutier y Veillette 1999), mientras que en Zap70 desfosforila la Y493 que es importante para su activación.

Wu y colaboradores, además de identificar Lck, Zap70 y la cadena $\zeta$ asociada al TCR por espectrometría de masas, han identificado también otras proteínas que interaccionan con Lyp como Vav (factor intercambiador de nucleótidos de guanina), CD3 $\varepsilon$ y VCP (valosin containing protein), proteínas cruciales para la señalización del TCR (Wu et al. 2006) y que podrían o no ser substratos de Lyp. Por otra parte, Hill et al. han descrito la interacción de Lyp con Grb2 (Growth factor receptor bound protein 2) mediante inmunoprecipitación a partir de lisados de células HEK293 transfectadas con plásmidos que expresan Grb2 y Lyp. Asimismo, en este trabajo, observan que Lyp actúa como regulador negativo sobre la actividad transcripcional en la señalización del TCR iniciada por la activación del receptor CD3 y/o CD28 (Hill et al. 2002). Grb2 podría dirigir a Lyp hacia sus substratos, pero Bottini et al. no han observado una gran estequiometría de interacción por lo que esta interacción es de una dudable relevancia fisiológica (Bottini et al. 2006).

\subsubsection{Regulación.}

La actividad de Lyp puede ser regulada por distintos mecanismos, tanto transcripcionales como post-transcripcionales. Así, entre los primeros, se ha descrito la regulación de la expresión del ARNm de Lyp por el micro RNA miR-181a (Li et al. 2007), que también regula la expresión de otras fosfatasas de tirosina en los linfocitos T maduros, como DUSP5, DUSP6 y SHP2. Así, un aumento en la expresión de este micro-ARN bloquea moderadamente la expresión de Lyp, produciéndose un incremento en la señalización a través del TCR que conduce a una inducción de la producción de citoquina IL-2 y a un aumento en la sensibilidad durante el reconocimiento de péptidos antigénicos por parte del linfocito, favoreciendo así tanto la selección positiva como negativa de los linfocitos $\mathrm{T}$.

En cuanto a los mecanismos post-transcripcionales, Lyp, al igual que PTP-PEST, se regula por fosforilación en la Ser35, situada en el inserto característico de estas fosfatasas, de 
forma que su fosforilación por la PKC disminuye la actividad catalítica de Lyp provocando una mayor activación de los linfocitos T (Yu et al. 2007). Por otro lado, la deleción de la región Cterminal no-catalítica aumenta la actividad enzimática de PEP (Gjorloff-Wingren et al. 1999). Posiblemente, este efecto sea debido a interacciones intramoleculares que reducen la actividad de Lyp en condiciones basales. En un trabajo reciente, Bottini et al. (Liu et al. 2009) han propuesto que la región de 300 aminoácidos situada entre el dominio fosfatasa y el motivo P1 sería la región que interaccionaría con el dominio fosfatasa, inhibiendo su función. Por último, la formación de puentes disulfuro entre la cisteína catalítica y dos cisteínas adyacentes observada en la estructura PDB 3H2X del dominio fosfatasa de Lyp, podría regular la actividad de esta fosfatasa (Tsai et al. 2009).

\subsubsection{Polimorfismos de Lyp.}

\subsubsection{Estudio del polimorfismo R620W.}

En el año 2004 se describió la existencia del polimorfismo rs2476601 de Lyp y su asociación con un aumento en el riesgo de padecer diabetes tipo I, una enfermedad autoinmune (Bottini et al. 2004). Posteriormente, se ha confirmado esta asociación en numerosos estudios genéticos y se ha aumentado el número de enfermedades autoinmunes con las que está asociado. Así, se ha descrito que este polimorfismo también está asociado con artritis reumatoide, artritis idiopática juvenil (Begovich et al. 2004; Criswell et al. 2005; Hinks et al. 2005; Lee et al. 2005; Orozco et al. 2005; Viken et al. 2005), lupus eritematoso sistémico (Kyogoku et al. 2004; Criswell et al. 2005; Orozco et al. 2005), enfermedad de Graves (Smyth et al. 2004; Velaga et al. 2004), miastenia grave (Vandiedonck et al. 2006), vitíligo generalizado (Canton et al. 2005) y granulomatosis de Wegener (Jagiello et al. 2005). También se ha demostrado que no se encuentra asociado con otras enfermedades autoinmunes como la esclerosis múltiple (Begovich et al. 2005; Criswell et al. 2005; Hinks et al. 2005), enfermedades inflamatorias del intestino como la enfermedad de Crohn (Martin et al. 2005; van Oene et al. 2005) o la colitis ulcerosa (Martin et al. 2005; Prescott et al. 2005), enfermedad celiaca (Rueda et al. 2005; Viken et al. 2005), colangitis esclerosante primaria (Viken et al. 2005), cirrosis biliar primaria (Milkiewicz et al. 2006), psoriasis y artritis psoriática (Hinks et al. 2005). En general, el polimorfismo de Lyp parece estar relacionado con un grupo de enfermedades autoinmunes caracterizadas por la presencia de autoanticuerpos circulantes. Los individuos que muestran más susceptibilidad a desarrollar dichas enfermedades suelen ser individuos homocigotos o heterocigotos que portan esta mutación, aunque es muy poco probable que por si mismo este polimorfismo cause autoinmunidad, y por tanto, sería necesaria la participación de otros factores genéticos, especialmente los que afectan al MHC, además de factores ambientales. 
La distribución mundial de este polimorfismo muestra un gradiente geográfico. Las poblaciones que presentan con más frecuencia este polimorfismo se encuentran en el norte de Europa ( $8 \%$ Reino Unido, $12 \%$ en Suecia y un 15\% en Finlandia). En cambio, la presencia de este polimorfismo es relativamente rara en el sur de Europa ( $2 \%$ Italia y un $6 \%$ España) y casi inexistente en poblaciones africanas, americanas y asiáticas. Estos datos sugieren que el origen 0 la selección de este polimorfismo es europeo (Vang et al. 2008).

El polimorfismo rs2476601 de nucleótido simple que presenta esta fosfatasa produce el cambio de un nucleótido de citosina por una timina en la posición 1858 (C1858T). Esta sustitución provoca un cambio de aminoácido en Lyp, de manera que se sustituye la arginina en posición 620 por un triptófano $(\mathrm{R} 620 \mathrm{~W})$. Este cambio altera la región $\mathrm{P} 1$ rica en prolinas (DDEIPPPLPVR620TPESFIVVEE) implicada en la interacción con Csk, impidiendo la asociación entre ambas proteínas (Bottini et al. 2004). Esta sustitución no produce ningún cambio en la localización subcelular de la proteína Lyp W620 con respecto a Lyp R620 (Bottini et al. 2006). Estudios funcionales de las dos variantes de Lyp han mostrado que Lyp-W620 es un mutante de ganancia de función, ya que presenta una mayor actividad que la variante Lyp-R620, dando lugar a una mayor inhibición de la cascada de señalización del TCR (Vang et al. 2005; Rieck et al. 2007).

Rieck et al. en 2007 estudiaron las características que muestran los linfocitos T portadores del polimorfismo R620W, observando una menor fosforilación de la cadena $\zeta$ asociada al TCR, Lck (Y394), Erk2 y LAT, y por lo tanto, una mayor inhibición de la señalización y una disminución de la respuesta del linfocito $T$ al estimular el TCR y el CD3. También se observó un aumento en el número de linfocitos $\mathrm{T} \mathrm{CD}^{+}$de memoria pero no una mayor cantidad de IL-10 como era de esperar. De hecho, la cantidad de IL-10, conocido supresor natural de la respuesta inflamatoria (Davidson et al. 1996; Anderson et al. 2004), se ve reducida. En general, la presencia del polimorfismo de Lyp en los linfocitos de sujetos heterocigotos C1858T no produce una reducción global de la producción de citoquinas pero sí una alteración en el balance de producción de las mismas después de la activación (Rieck et al. 2007). La reducida cantidad de IL10 podría producir una pérdida de regulación, una expansión de los linfocitos T de memoria y una predisposición hacia la autoinmunidad debido a la reducción de la selección negativa en el timo, dejando escapar así linfocitos con capacidad autorreactiva (Figura 16). 


\section{LYP R620}
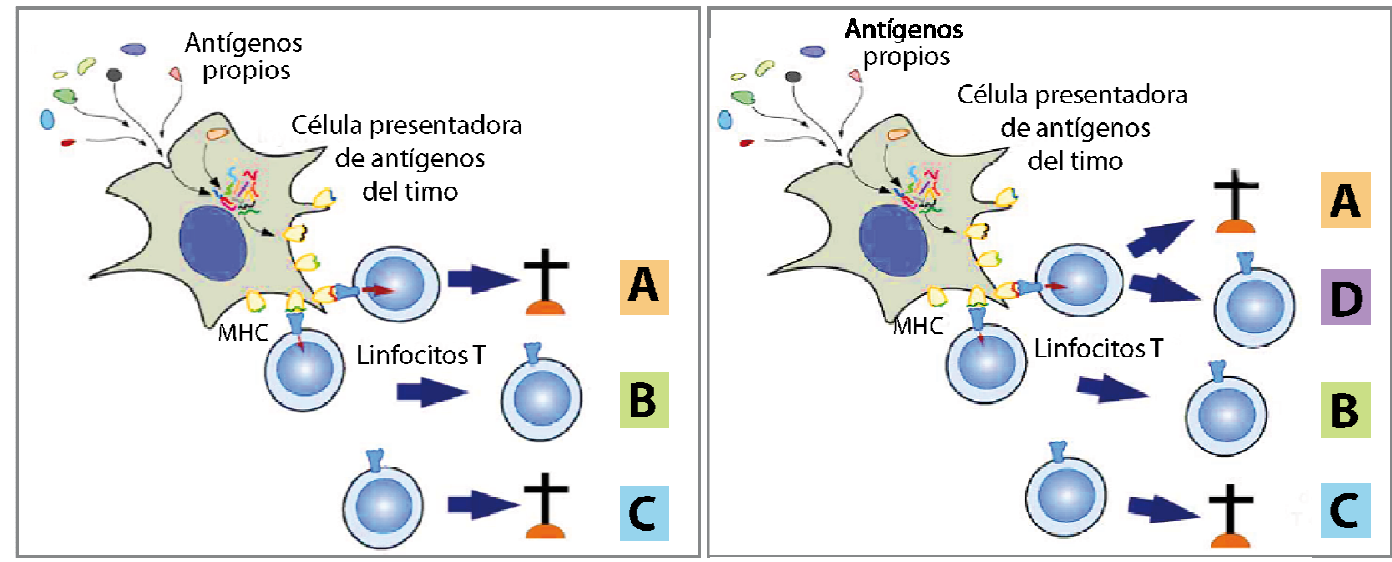

A Apoptosis de linfocitos T autorreactivos con respuesta desmesurada.

C Selección negativa de linfocitos T sin afinidad por MHC propios.

B Selección positiva de linfocitos T con baja Selección positiva de linfocitos T autorreactivos que presentan una moderada afinidad por MHC propios.

Figura 16: Diferencias en la selección clonal de linfocitos que presentan la variante Lyp R620 y su polimorfismo Lyp W620. En la imagen de la izquierda se representan los posibles destinos de un linfocito que porta la variante normal de Lyp cuando la intensidad de respuesta ante antígenos propios es o no adecuada (ver tamaño de las flechas rojas en el interior del linfocito) y en el esquema de la derecha en el caso de presentar la variante polimórfica de Lyp.

La presencia de autoanticuerpos en las enfermedades a las que el polimorfismo está asociado puede ser debida a una pérdida de la tolerancia de los linfocitos $\mathrm{T}$, aunque el polimorfismo de Lyp puede contribuir también a la autoinmunidad vía linfocitos B. Hasegawa et al. en 1999 demostraron que PEP regulaba la señalización del BCR en linfocitos $B$ inmaduros mediante el uso de cDNA antisentido de PEP (Hasegawa et al. 1999). En este estudio, observaron que la reducción de la expresión de PEP rescataba parcialmente la inhibición de la síntesis de ADN mediada por el BCR después de ser estimulado con IgM, y también se inhibía el bloqueo en fase G1 y la apoptosis, eventos cruciales para la eliminación de los linfocitos $B$ inmaduros autorreactivos. Más recientemente, se ha descrito que los linfocitos B portadores del polimorfismo R620W poseen una baja capacidad de respuesta al estimular el BCR, lo que puede afectar a la maduración, a la selección y a la función de dichos linfocitos (Rieck et al. 2007; Arechiga et al. 2009).

Por otra parte, en ratones knockout para PEP (Hasegawa et al. 2004) se ha observado un fenotipo menos severo de lo esperado. En estos ratones, la señalización a través del TCR se 
mantiene intacta en los linfocitos inmaduros, siendo la fosforilación de las proteínas kinasas de la familia Src completamente normal tanto en su tirosina reguladora como en la inhibidora. Sólo se observó un incremento marginal de la expresión de CD5 en linfocitos doble positivos CD4/CD8, sugiriendo un papel inhibitorio de PEP en la selección positiva pero no en la negativa. Únicamente una segunda estimulación de los linfocitos $T$ (efectores y de memoria) mostró algunos de los efectos esperados como el mantenimiento del estado fosforilado así como una hiperactivación de los linfocitos $\mathrm{T}$, que como hemos mencionado no se produce en los linfocitos $\mathrm{T}$ inmaduros. Estos resultados indican que PEP no es crítico para la señalización del TCR en linfocitos inmaduros, aunque esto podría ser debido al efecto redundante de otras fosfatasas de tirosina como PTPPEST que compensen la ausencia de PEP.

Según aumenta la edad de los ratones, se observa un mayor número de linfocitos $T$ efectores y de memoria, desarrollando a los 6 meses de vida una marcada linfoadenopatía y esplenomegalia, apareciendo con el tiempo acúmulos de linfocitos $B$ en los centros germinales del bazo y en las placas de Peyer, aunque tanto las respuestas de los linfocitos $B$ maduros como la señalización a través de los receptores BCR no están alteradas. Serológicamente, los niveles de lgG1, IgG2 e IgE son elevados y aunque los compartimentos de células $T$ y $B$ parecen no estar regulados, estos ratones no muestran incremento de autoanticuerpos o daño de órganos relacionados con autoinmunidad (Hasegawa et al. 2004). Este fenotipo no es debido a una alteración en la selección tímica de los linfocitos $\mathrm{T}$, sino que puede ser causado por el aumento de las respuestas inducidas por el TCR de los linfocitos T maduros.

Debido a que en el knockout de PEP no se observa un desarrollo de autoinmunidad claro, se ha desarrollado un modelo animal que represente la situación genética del polimorfismo Lyp R620W. Arthur Weiss y su equipo (datos no publicados) han generado una mutación equivalente en PEP, R619W, observando que el polimorfismo, en este caso, podría comprometer la habilidad de PEP para inhibir la activación de los linfocitos T (Veillette et al. 2009). Aún hay que estudiar en más profundidad este caso, en el que se propone que la mutación provoca la pérdida de función en vez de la ganancia de función como en el caso de Lyp R620W. Estas diferencias podrían ser debidas a los diferentes porcentajes de identidad entre los dominios PEST de PEP y de Lyp.

La gran paradoja de estos hallazgos es que la autoinmunidad en el caso de Lyp W620 se produce por una hiporreactividad de los linfocitos $T$ inmaduros que evitan de esta forma la selección negativa y no por una hiperactivación de los mismos (Rieck et al. 2007).

Según los antecedentes mencionados, la función de Lyp es regular negativamente la señalización a través del TCR (Gjorloff-Wingren et al. 1999) y mantener así en homeostasis a las células $\mathrm{T}$ de memoria. Asimismo, otros estudios sugieren un papel crítico no sólo para la regulación de la señalización sino también en el desarrollo del sistema inmune (Bottini et al. 2006) 


\subsubsection{Estudio del polimorfismo R263Q.}

Recientemente se ha descrito otro polimorfismo de nucleótido simple, en este caso se produce la sustitución de una arginina por una glutamina (R263Q) en el dominio catalítico, lo que provoca una pérdida de función, el efecto opuesto al polimorfismo R620W.

El polimorfismo R263Q (G788A, rs33996649) (Orru et al. 2009) tendría una función de protección ante el desarrollo de enfermedades autoinmunes como por ejemplo el lupus eritematoso sistémico. Esta función protectora viene dada por una reducción en la actividad fosfatasa, siendo así menos efectiva en la reducción de la señalización del TCR.

La estructura del dominio catalítico de Lyp con este polimorfismo (Q263) es semejante al recientemente descrito por Yu et al. (Yu et al. 2007) para el alelo normal (R263). Sin embargo, se observa un desplazamiento de la hélice a2' debido a que el cambio de Arg a Gln produce la pérdida del contacto que se da normalmente entre la R263 de la hélice a5 y la glutamina Q34 de hélice a2'. Esta sustitución también provoca un cambio en la conformación, de bucle a hélice, en el inserto específico, dejando en el exterior de la superficie la serina 35, crítica para la regulación de Lyp, y cambiando la conformación de la hendidura catalítica, lo que reduce la efectividad en el procesamiento de substratos. El motivo WPD adquiere en el caso del polimorfismo Q263 una conformación abierta con respecto a la conformación medio cerrada de la fosfatasa normal R263. Por último, al comparar las superficies electrostáticas entre R263 y Q263, se observa que ambas preservan una naturaleza electropositiva de la hendidura de unión al sustrato, pero la conformación y profundidad de ésta es diferente entre ambas proteínas, lo que podría interrumpir la catálisis. De hecho, comprobaron que el inhibidor específico de Lyp I-C11 es menos potente cuando actúa sobre Lyp Q263 (Orru et al. 2009).

Comparando la secuencia de Lyp con homólogos de otras especies, llama la atención que la arginina en posición 263 está únicamente presente en humanos y no en las demás especies, las cuales han conservado el aminoácido glutamina. Esto demuestra que la enzima ancestral codificaba una glutamina en lugar de una arginina (Figura 17).

Sería interesante determinar si el alelo R263 en humanos se elevó con gran frecuencia como resultado de una presión selectiva positiva. Desde este punto de vista, podría ser considerado como una "ganancia de función" en comparación con el alelo ancestral Q263. Aunque actualmente el alelo R263 predispone a enfermedades autoinmunes, se podría pensar que la pérdida de función del polimorfismo Q263 tenga un efecto contrario (Orru et al. 2009). 


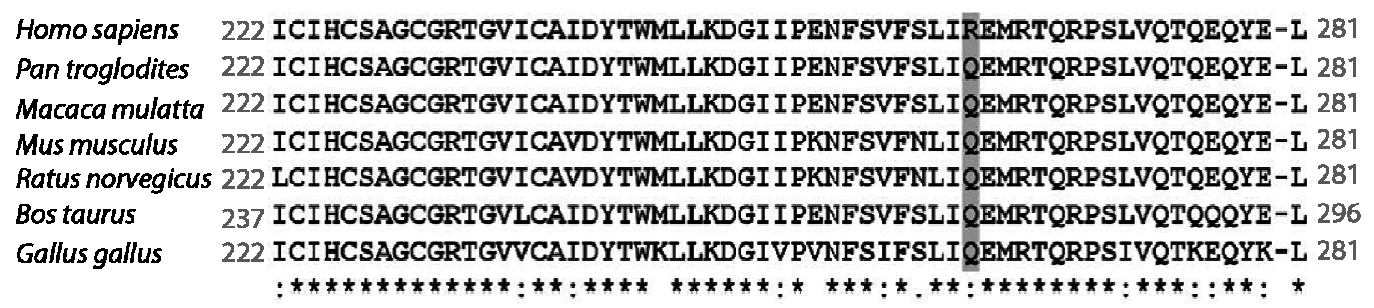

Figura 17: El alelo Q263 define la variante ancestral de Lyp. Alineamiento del domino fosfatasa de Lyp de distintas especies: Homo sapiens (gi:48928054), Pan troglotides (gi:114558717), Macaca mulatta (gi:109014421), Mus musculus (gi:6679555), Rattus Norvegicus (gi:157824150), Bos taurus (gi:119889627) and Gallus gallus (gi:118102481). El alelo Q sombreado en gris define una variante ancestral.

Los polimorfismos R620W y el R263Q no son sinónimos y están presentes en diferentes haplotipos (Carlton et al. 2005; Zoledziewska et al. 2008), es decir se heredan en distintos bloques. Son variantes independientes y no tienen el mismo efecto en cuanto a la susceptibilidad a padecer lupus eritematoso sistémico. 


\section{Objetivos}



En el contexto definido por los antecedentes descritos, el objetivo general del presente estudio fue profundizar en el conocimiento del los mecanismos de acción molecular de la fosfatasa de tirosina, Lyp.

Este objetivo general se puede desglosar en los siguientes objetivos específicos:

1. Estudiar la interacción de Lyp con Csk

1.1. Determinar la región de Lyp implicada en la interacción con Csk

1.2. Caracterizar los motivos de Pro de Lyp implicados en la interacción con Csk

1.3. Definir los aminoácidos de Csk implicados en la interacción con Lyp.

1.4. Estudiar la interacción de Lyp y Csk en linfocitos.

2. Analizar la colaboración de Lyp y Csk en la la regulación de la señalización del TCR.

2.1. Estudiar si la cooperación de Lyp y Csk es dependiente de su interacción.

2.2. Definir el papel de Lyp en la activación de diversas vías de señalización de linfocitos 

III. Material y métodos 



\section{Materiales.}

\subsection{Tampones y soluciones.}

\section{Tampones y Soluciones}

\begin{tabular}{|c|c|c|}
\hline Tampón fosfato salino (PBS) & \multicolumn{2}{|l|}{$\begin{array}{l}\mathrm{NaCl} 136 \mathrm{Mm} \\
\mathrm{KCl} 2,7 \mathrm{mM} \\
\mathrm{Na}_{2} \mathrm{HPO}_{4} 8 \mathrm{mM} \\
\mathrm{KH}_{2} \mathrm{PO}_{4} 1,5 \mathrm{mM} \\
\text { Se ajusta a pH 7,4 }\end{array}$} \\
\hline Tampón de transfección (HEBS) & \multicolumn{2}{|l|}{$\begin{array}{l}\text { HEPES } 50 \mathrm{mM} \\
\mathrm{KCl} 10 \mathrm{mM} \\
\text { D-Glucosa } 12 \mathrm{mM} \\
\mathrm{NaCl} 0,28 \mathrm{M} \\
\mathrm{Na}_{2} \mathrm{HPO}_{4} 1,5 \mathrm{mM}\end{array}$} \\
\hline Tampón de lisis celular (TNE 1X) & $\begin{array}{l}\text { Tris- } \mathrm{HCl} 20 \mathrm{mM} \quad \mathrm{pH}=7,4 \\
\mathrm{NaCl} 150 \mathrm{mM} \\
\text { EDTA } 5 \mathrm{mM} \\
\text { NP-40 } 1 \%\end{array}$ & 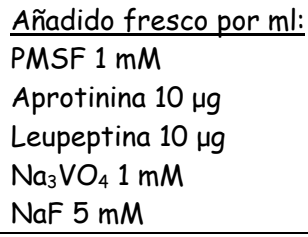 \\
\hline Tampón tris salino (TBS) & \multicolumn{2}{|l|}{$\begin{array}{l}\text { Tris-HCl } 10 \mathrm{mM}, \mathrm{NaCl} 135 \mathrm{mM} \\
\text { Se ajusta a pH 7,6 }\end{array}$} \\
\hline TBS-Tween (TTBS) & \multicolumn{2}{|l|}{$\begin{array}{l}\text { TBS } \\
\text { Tween-20 } 0,02 \%\end{array}$} \\
\hline Tampón de electroforesis & \multicolumn{2}{|l|}{$\begin{array}{l}\text { Tris } 25 \mathrm{mM} \\
\text { Glicina } 0,2 \mathrm{M} \\
\text { SDS } 1 \%(\mathrm{p} / \mathrm{v}) \text { a pH } 8.3\end{array}$} \\
\hline Tampón de transferencia & \multicolumn{2}{|l|}{$\begin{array}{l}\text { Tris } 25 \mathrm{mM} \\
\text { Glicina } 0,2 \mathrm{M} \\
\text { SDS } 1 \%(\mathrm{p} / \mathrm{v}) \\
\text { Metanol } 20 \%(\mathrm{v} / \mathrm{v}) \\
\end{array}$} \\
\hline Tampón de Laemmli 5X & \multicolumn{2}{|l|}{$\begin{array}{l}\text { Tris } 65 \mathrm{mM} \mathrm{pH} 7.5 \\
\text { Glicerol } 10 \% \\
\text { SDS } 2 \% \\
\text { B-mercaptoetanol } 2 \% \\
\text { Azul de bromofenol } 0.05 \% \text { ) }\end{array}$} \\
\hline Tampón de lisis de eritrocitos & \multicolumn{2}{|l|}{$\begin{array}{l}\mathrm{NH}_{4} \mathrm{Cl} 0.15 \mathrm{M} \\
\mathrm{KHCO}_{3} 10 \mathrm{mM} \\
\text { EDTA } 0.1 \mathrm{mM} \\
\end{array}$} \\
\hline Tampón fosfatasa pH 6 & \multicolumn{2}{|l|}{$\begin{array}{l}\text { Acetato sódico } 100 \mathrm{mM} \\
\text { Tris } 50 \mathrm{mM} \\
\text { Bis-Tris } 50 \mathrm{mM} \\
\text { EDTA } 5 \mathrm{mM} \\
\text { DTT } 10 \mathrm{mM}\end{array}$} \\
\hline
\end{tabular}




\subsection{Reactivos.}

\section{Reactivos}

\begin{tabular}{|l|c|}
\hline Antibiótico G418 Gentamicina-sulfato & GIBCO \\
\hline Stripping Buffer & Pierce, Rockford \\
\hline Ortovanadato Sódico $\left(\mathrm{Na}_{3} \mathrm{VO}_{4} \quad 0,1 \mathrm{M}, \mathrm{H}_{2} \mathrm{O}_{2}\right.$ al 30\%) & SIGMA \\
\hline p-Nitrophenyl phosphate hexahidrate disodium salt (pNPP) & SIGMA \\
\hline
\end{tabular}

\subsection{Anticuerpos.}

Los anticuerpos utilizados en esta tesis y sus características principales se presentan en la siguiente tabla:

\begin{tabular}{|c|c|c|}
\hline \multicolumn{3}{|c|}{ Tabla de anticuerpos } \\
\hline \multicolumn{3}{|c|}{ Monoclonales (de ratón) } \\
\hline Antigeno & Clon & Origen \\
\hline Epítopo Myc & 9E10 & Santa Cruz Biotechnology \\
\hline Epítopo Hemaglutinina (HA) & 16B12 & COVANCE \\
\hline Epítopo Hemaglutinina $(H A)$ & $12 C A 5$ & Roche \\
\hline Anti-HA-AGAROSA & - & SIGMA \\
\hline Lck & $3 E 5$ & Santa Cruz Biotechnology \\
\hline Csk & 52 & BD Bioscience \\
\hline Fofotirosina (PY) & $4 G 10$ & Upstate BI \\
\hline Fosfotirosina (PY-20) & - & Santa Cruz Biotechnology \\
\hline Glutatión S-transferasa (GST) & B-14 & Santa Cruz Biotechnology \\
\hline \multicolumn{3}{|c|}{ Policlonales } \\
\hline Antigeno & Clon & Origen \\
\hline Lyp (cabra) & - & R\&D Systems \\
\hline Erk (conejo) & $C-14$ & Santa Cruz Biotechnology \\
\hline Fosfo-Erk (conejo) & - & Promega \\
\hline $\begin{array}{l}\text { P-Src } 416 \text { (conejo) reconoce el bucle de } \\
\text { activación conservado de todas las SFK } \\
(P-L C K 394)\end{array}$ & - & Cell Signalling \\
\hline Csk (conejo) & $C-20$ & Santa Cruz Biotechnology \\
\hline Anti-myc-AGAROSA & - & SIGMA \\
\hline \multicolumn{3}{|c|}{ Secundarios } \\
\hline Antígeno & Conjugado a & Origen \\
\hline IgG de ratón & HRP & GE Healthcare \\
\hline IgG de conejo & HRP & GE Healthcare \\
\hline IgG de cabra & HRP & Santa Cruz \\
\hline
\end{tabular}




\subsection{Plásmidos y mutagénesis.}

Para estudiar los mecanismos moleculares de interacción de Lyp disponemos de cDNAs de las proteínas de interés clonadas en distintos vectores de expresión en eucariotas como muestra la tabla 3.

Además, mediante el uso de técnicas de biología molecular, hemos generado, deleciones de Lyp (Figura 18) que contienen los distintos dominios funcionales, variantes catalíticamente inactivas y mutaciones puntuales introducidas con el kit de mutagénesis QuikChage Site Directed Mutagenesis de Stratagene (Tabla 3). Los oligonucleótidos cebadores se diseñaron de acuerdo con la mutación deseada de forma que fueran complementarios entre sí y con la cadena doble del plásmido. Todas las construcciones fueron verificadas mediante secuenciación de nucleótidos.

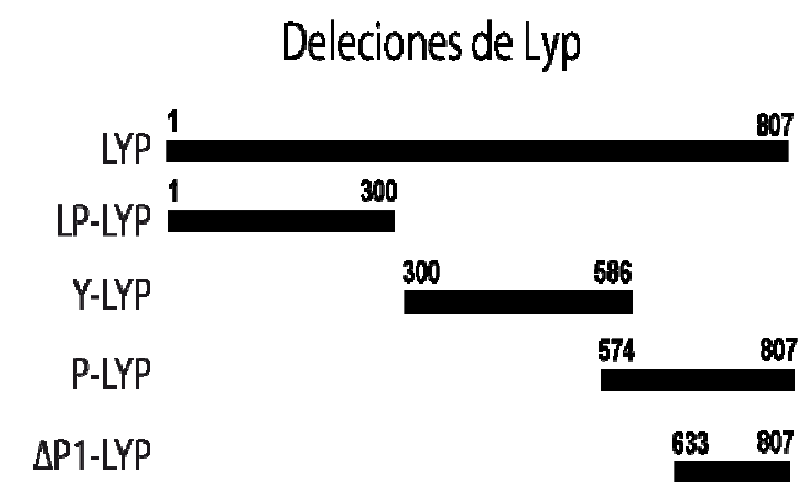

Figura 18: Deleciones de Lyp generadas para el estudio de interacción con Csk.

\begin{tabular}{|l|c|}
\hline \multicolumn{2}{|c|}{ Tabla de Plásmidos $y$ Mutaciones } \\
\hline \multicolumn{2}{|c|}{ Plás } \\
\hline Plásmido & Epitopo \\
\hline pEF & HA \\
\hline pEF3xHA & $3 \times H A$ \\
\hline pCDNA3 & Myc \\
\hline pEF3xmyc & $3 \times M y c$ \\
\hline pEBG & GST \\
\hline pEGFP-N3 (Aequoria victoria) & GFP \\
\hline Sh-Lyp 237; 238; 239; 240 & inhiben Lyp \\
\hline Sh-30001-GFP & inhibe GFP \\
\hline Sh-30002-LUC & inhibe la Luciferasa \\
\hline Sh-GFP-30003 ne. & no inhibe GFP \\
\hline 30001 pRS & plásmido vacío \\
\hline
\end{tabular}




\begin{tabular}{|c|c|}
\hline \multicolumn{2}{|c|}{ Mutagénesis dirigida } \\
\hline Proteina codificada & Mutaciones Puntuales \\
\hline \multirow{4}{*}{ Lyp R } & $(\mathrm{D} 195 \mathrm{~A})$ \\
\cline { 2 - 2 } Lyp W & $(\mathrm{C227S})$ \\
\cline { 2 - 2 } & $(\mathrm{P} 615 \mathrm{~A}, \mathrm{P} 618 \mathrm{~A}, \mathrm{P} 695 \mathrm{~A})$ \\
\cline { 2 - 2 } & $(\mathrm{S624A})$ \\
\cline { 2 - 2 } & $(\mathrm{I} 626 \mathrm{~A})$ \\
\cline { 2 - 2 } & $(\mathrm{V} 627 \mathrm{~A})$ \\
\hline \multirow{3}{*}{ Csk } & $(\mathrm{Q} 26 \mathrm{~A})$ \\
\cline { 2 - 2 } & $(\mathrm{D} 27 \mathrm{~A})$ \\
\cline { 2 - 2 } & $(\mathrm{W} 47 \mathrm{~A})$ \\
\hline & $(\mathrm{R} 107 \mathrm{M})$ \\
\hline
\end{tabular}

Tabla 3: Listado de plásmidos y mutaciones utilizadas para el estudio.

\section{Métodos experimentales.}

\subsection{Cultivos de líneas celulares.}

Las células Jurkat son una línea celular de linfocitos humanos derivados de una leucemia linfoblástica aguda de tipo $T$ y han sido obtenidas de la ATCC (№ ATCC: TIB-152 ${ }^{\text {TM }}$ ). Se cultivaron en atmósfera con $5 \%$ de $\mathrm{CO}_{2}$ y a $37^{\circ} \mathrm{C}$ de temperatura en suspensión en medio RPMI 1640 suplementado con $10 \%(\mathrm{v} / \mathrm{v})$ de suero bovino fetal previamente inactivado, $100 \mathrm{U} / \mathrm{ml} \mathrm{de}$ penicilina-streptomicina, y L-glutamina $2 \mathrm{mM}$, a lo que denominamos medio RPMI completo.

Las células HEK293 son una línea celular embrionaria derivada de riñón humano, son células fibroblásticas adherentes y se cultivan en medio DMEM suplementado con $10 \%(\mathrm{v} / \mathrm{v})$ de suero bovino fetal inactivado, $1 \%$ de penicilina-estreptomicina y $2 \mathrm{mM} \mathrm{L-glutamina} \mathrm{(medio} \mathrm{DMEM}$ completo), incubadas bajo las mismas condiciones de temperatura y $\mathrm{CO}_{2}$ que las anteriores.

En este trabajo también se han utilizado linfocitos de sangre periférica humana o PBLs (periferal blood lymphocytes). Estas células se obtuvieron a partir de bolsas de concentrados leucocitarios o buffy coats que provienen de sangre de cinco donantes sanos. Este material de trabajo ha sido amablemente cedido por el Centro Regional de Hemodonación y Hemoterapia de Castilla y León durante todo el proyecto.

El contenido sanguíneo se diluyó en proporción 1:1 con PBS a pH 7,4 y posteriormente se añadió sobre una solución de Ficoll-Paque manteniendo la proporción de sangre-PBS/FicollHipaque 3:1. Esta mezcla se centrifugó a $725 \times \mathrm{g}$, sin freno, durante 30 minutos. Tras la centrifugación, se forman varias fases: en la parte superior se sitúa la fase acuosa (plasma y PBS), seguida de un anillo de células mononucleares, de una fase de Ficoll-Paque y células polimorfonucleares y en el fondo del tubo se sitúan los eritrocitos. Las células obtenidas de los anillos de células mononucleares se incubaron a $37^{\circ} \mathrm{C}$ y $5 \% \mathrm{CO}_{2}$ durante dos horas para 
favorecer la adherencia de los monocitos y poder recoger los linfocitos del sobrenadante, éstos fueron tratados con el tampón de lisis de eritrocitos para eliminar los eritrocitos y posteriormente se lavaron con PBS. Por último se incubaron en medio RPMI completo a $37^{\circ} \mathrm{C}$ y $5 \%$ de $\mathrm{CO}_{2}$ hasta su uso el día siguiente.

\subsection{Métodos de transfección transitoria.}

\section{Transfección con fosfato cálcico}

Este método se basa en la obtención de un precipitado de fosfato cálcico que facilita la entrada del ADN en las células y se utilizó para transfectar células HEK293. Se sembraron $3.5 \times 10^{6}$ células en placas de $10 \mathrm{~cm}$ de diámetro la víspera de la transfección con el fin de obtener una confluencia del $80 \%$ al día siguiente. Dos horas antes de transfectar se cambió el medio a las células dejándolas en $5 \mathrm{ml}$ de DMEM completo. Se preparó una mezcla de ADN plasmídico de 5 $10 \mu \mathrm{g}$ y $500 \mu \mathrm{l}$ de una solución de $\mathrm{CaCl}_{2}(2,5 \mathrm{M})$ diluído 1:10 en agua, sobre la que se añadieron, gota a gota, $500 \mu \mathrm{l}$ de una solución HEBS $2 X$. Esta mezcla se incubó a temperatura ambiente 10 minutos. Posteriormente se añadió, gota a gota, a las células adheridas a la placa y las células se incubaron de $24-48$ horas a $37^{\circ} \mathrm{C}$ y $5 \%$ de $\mathrm{CO}_{2}$.

\section{Transfección por electroporación}

Las células Jurkat fueron transfectadas por electroporación usando un electroporador Gene pulser de Bio-Rad. Por cada condición experimental se usaron aproximadamente $20 \times 10^{6}$ células resuspendidas en un volumen final de $400 \mu \mathrm{l}$ de medio RPMI sin suero que se mezclaron con 5-50 $\mu \mathrm{g}$ de ADN plasmídico total. La mezcla se introdujo en cubetas de electroporación de 0.4 $\mathrm{cm}$ y se sometieron a pulsos eléctricos de $240 \mathrm{~V}$ y $950 \mu \mathrm{F}$. A continuación, las células se diluyeron en medio completo y se mantuvieron de $24-48$ horas a $37^{\circ} \mathrm{C}$ en atmósfera al $5 \%$ de $\mathrm{CO}_{2}$.

\subsection{Obtención de líneas estables.}

Generamos líneas estables transfectando $15 \times 10^{6}$ células Jurkat por el procedimiento de electroporación descrito anteriormente, estas líneas expresan las formas silvestres y mutantes de Lyp, pEF-HA-Lyp-R, pEF-HA-Lyp-RD195A, pEF-HA-Lyp-W, como plásmido control se usó pEFHA vacío. La línea parental fue crecida en medio RPMI 1640 suplementado con 10\% (v/v) de suero bovino fetal previamente inactivado, $100 \mathrm{U} / \mathrm{ml}$ de penicilina-streptomicina, y L-glutamina 2 $\mathrm{mM}$. A las 24 horas de la transfección se centrifugaron las células a $1500 \mathrm{rpm}$ durante 5 min y se resuspendieron las células en medio RPMl completo más $10 \mathrm{mM}$ de HEPES y $3 \mathrm{mg} / \mathrm{ml}$ de antibiótico gentamicina G418 para someter a las células a selección clonal. La dosis de G418 se fue variando durante los sucesivos pases usando en los últimos sólo $2 \mathrm{mg} / \mathrm{ml}$. Aproximadamente después de un mes seleccionándose se sometió a las células a una centrifugación con FicollPaque con el fin de retirar restos celulares y mantener en crecimiento, en frascos T-75, y con 2 
$\mathrm{mg} / \mathrm{ml} \mathrm{G} 418$ únicamente los linfocitos. En este punto se prepararon viales con parte de las células para mantener en nitrógeno líquido, también se realizó western blot para comprobar que la expresión de las proteínas transfectadas era correcta. Tras comprobar la expresión se separaron las células en placas de 96 pocillos a razón de 0.2 células por pocillo, con $2 \mathrm{mg} / \mathrm{ml} \mathrm{G} 418$, para así seleccionar y obtener clones aislados. Los clones positivos para la expresión de la proteína recombinante en cada caso, fueron aislados y analizados de nuevo por western blot con anticuerpos específicos y por citometría de flujo en el citómetro Beckman Coulter Epics XL-MCL Todas las líneas celulares fueron crecidas a $37^{\circ} \mathrm{C}$ y $5 \%$ de $\mathrm{CO}_{2}$ y ninguna mostró alteraciones en su morfología celular, pero sí se observó un crecimiento más lento en comparación con las células Jurkat silvestres.

\subsection{Análisis de proteínas mediante inmunodetección (western blotting).}

Para realizar el análisis de los niveles de expresión de las proteínas, las células fueron recogidas y lisadas en tampón de lisis TNE $1 \mathrm{X}$ al que se añadieron los inhibidores de proteasas: PMSF $1 \mathrm{mM}$, aprotinina $10 \mu \mathrm{g} / \mathrm{ml}$ y leupeptina por $10 \mu \mathrm{g} / \mathrm{ml}$. El lisado fue incubado durante 15 minutos a $4^{\circ} \mathrm{C}$ y posteriormente centrifugado 10 minutos a $4^{\circ} \mathrm{C}$ y $13.200 \mathrm{rpm}$. El sobrenadante se recogió y se midió la concentración de proteína mediante el método BCA. El sobrenadante se mezcló con tampón de Laemmli $4 \mathrm{X}$ y se hirvió durante 5 minutos. Las proteínas del lisado celular desnaturalizadas se separaron mediante electroforesis en geles de acrilamida/poliacrilamida (SDS-PAGE). La electroforesis fue llevada a cabo en el tampón de electroforesis a $120 \mathrm{~V}$. Posteriormente las proteínas se transfirieron del gel a una membrana de nitrocelulosa en condiciones húmedas durante 1,5 horas a $400 \mathrm{~mA}$ en el tampón de transferencia. Una vez acabada la transferencia, las membranas de nitrocelulosa se bloquearon durante 1 hora a temperatura ambiente con una solución de TBS-Tween de leche desnatada en polvo al $5 \%(\mathrm{p} / \mathrm{v}) 0$ de BSA al 3\% $(p / v)$, dependiendo del anticuerpo primario a utilizar. A continuación se incubaron las membranas con las soluciones de los anticuerpos primarios correspondientes durante toda la noche a $4^{\circ} \mathrm{C}$. Al día siguiente se realizaron tres lavados de 10 minutos de duración con TBSTween y después se incubó durante 1 hora, a temperatura ambiente con un anticuerpo secundario anti-lgG conjugado con peroxidasa de rábano (HRP) a una dilución 1:3000 en leche al $5 \%$. Tras 5 lavados de 5 minutos con TBS-Tween se procedió a la detección de los inmunocomplejos formados mediante una reacción de quimioluminiscencia utilizando el sustrato de la peroxidasa de rabano con el kit ECL (Amersham) y utilizando películas Hiperfilm (Amersham) sensibles a este método. La cuantificación de las bandas reveladas se realizó mediante densitometría utilizando el software Quantity One de Bio-Rad.

Posteriormente las membranas que debían ser reveladas con otro anticuerpo, eran sometidas a un lavado del anticuerpo primario mediante la solución Stripping Buffer . 


\subsection{Valoración de la concentración de proteína.}

La concentración de la proteína total obtenida de los extractos celulares se cuantificó según el método colorimétrico $\mathrm{BCA}$ con el kit $\mathrm{BCA}^{\mathrm{TM}}$ Protein Assay Kit distribuido por Pierce. El ácido bicinconínico (BCA) es un compuesto capaz de formar un complejo púrpura intenso con el catión $\left(\mathrm{Cu}^{1+}\right)$ en medio alcalino. Este método combina la reducción del ión cúprico $\left(\mathrm{Cu}^{2+}\right)$ a ión cuproso $\left(\mathrm{Cu}^{1+}\right)$ en un medio alcalino (reacción de Biuret) y la detección de este catión $\left(\mathrm{Cu}^{1+}\right)$ usando un reactivo que contiene el ácido bicinconínico.

La estabilidad del producto hidrosoluble final (dos moléculas de BCA unidas al ión cuproso) (Smith et al. 1985) proporciona un método para la cuantificación de proteínas que es sencillo, rápido, muy sensible, y que muestra una gran tolerancia a compuestos que afectan a otros métodos. Se realizó también una recta de calibrado con diluciones crecientes de albúmina de suero bovino (BSA) y la absorbancia fue medida a una longitud de onda de $562 \mathrm{~nm}$ en placas de 96 pocillos en el espectrofotómetro VERSAmax (Molecular Devices) (Figura 19).

\section{Proteína+ $\mathrm{Cu}^{2+} \rightarrow \mathrm{Cu}^{1+}$ \\ $\mathrm{Cu}^{1+}+\mathrm{BCA} \rightarrow \mathrm{BCA}-\mathrm{Cu}^{1+}-\mathrm{BCA}$ (color violeta)}

Figura 19: Ensayo de BCA para la detección de proteínas.

\subsection{Ensayos de Inmunoprecipitación (IP).}

Para realizar estos ensayos se lisaron las células en tampón de lisis TNE $1 \mathrm{X}$ con los inhibidores de proteasas, antes mencionados, durante $30 \mathrm{~min}$ a $4^{\circ} \mathrm{C}$. Posteriormente se centrifugaron a $13.200 \mathrm{rpm}$ durante $10 \mathrm{~min}$ a $4^{\circ} \mathrm{C}$. Los sobrenadantes obtenidos se inmunoprecipitaron durante toda la noche, en agitación y a $4^{\circ} \mathrm{C}$ junto con el anticuerpo de interés y $50 \mu \mathrm{l}$ de proteína G-Sefarosa 1:5 en PBS más $0.002 \%$ de azida sódica. En otros casos se utilizaron anticuerpos unidos covalentemente a las bolas de proteína $G$, obtenidos comercialmente o preparados en nuestro laboratorio.

Los inmunoprecipitados se lavaron 2 veces en tampón de lisis TNE 1X, una vez retirado todo el sobrenadante, las bolas se resuspendieron en $42 \mu \mathrm{l}$ de tampón de Laemmli $1 \mathrm{X}$, se hirvieron durante $5 \mathrm{~min}$ y se separaron en geles de acrilamida/bis-acrilamida en condiciones desnaturalizantes (SDS-PAGE) para su detección mediante Western Blot.

\subsection{Ensayos de luciferasa.}

Los ensayos de luciferasa se realizaron en células Jurkat mediante transfección transitoria de nuestros plásmidos de interés junto con los plásmidos que expresan el gen de la luciferasa de la luciérnaga bajo el control de distintos promotores como NFAT-AP-1, NF-kB, GAL4-ELK e IL-2. La enzima luciferasa no necesita modificaciones postraduccionales para ser catalíticamente activa 
y oxidar a la luciferina (substrato) hasta oxiluciferina en una reacción bioluminiscente. La técnica se basa en cuantificar la expresión de la luciferasa a través de la reacción de bioluminiscencia que esta cataliza (Figura 20 A). La reacción es lineal en un amplio rango de concentraciones, dentro del cual la cantidad de luz emitida será proporcional a la expresión de la luciferasa. La actividad luciferasa puede normalizarse para corregir diferencias debidas a la eficiencia de la transfección, para ello se cotransfecta el vector pRL-0 (Promega) que expresa la luciferasa de Renilla reniformis que cataliza una reacción luminiscente (Figura 20 B) y que es muy diferente a la luciferasa en cuanto a estructura y requerimientos de sustratos debido a su distinto origen evolutivo. Estas diferencias hacen posible discriminar eficazmente entre la señal de uno u otro enzima de forma que podemos medir la actividad luciferasa y posteriormente bloquear dicha reacción y medir la actividad renilla luciferasa en el mismo tubo evitando la dispersión provocada por errores de pipeteo.

A las 24 horas de transfección parte de las células se estimularon por triplicado durante 5 horas con anticuerpos para el TCR (se usó el sobrenadante purificado del hibridoma C305), en el caso de NFAT, o con anticuerpos que reconocen el TCR, el CD28 y un anticuerpo rabbit anti mouse (RaM) en el caso de NF-kB e IL-2. Transcurrido este tiempo, se recogieron las células y se lisaron en $100 \mu \mathrm{l}$ del tampón de lisis Passive Lysis Buffer 1X (Promega). Del extracto celular se tomaron $50 \mu \mathrm{l}$ para realizar el ensayo de luciferasa en placa de 96 pocillos con el Dual-Luciferase Assay System (Promega) siguiendo las instrucciones del fabricante, mientras que al resto del extracto se le añadió tampón de Laemmli $4 \mathrm{X}$ y se hirvió para su posterior electroforesis y Western Blot con el fin de comprobar la expresión de las proteínas transfectadas. Los resultados muestran la inducción o represión de la actividad transcripcional de los diferentes factores de transcripción utilizados expresada como veces de activación, tomado como unidad la actividad de las células trasnfectadas con pEF sin estimular.

A

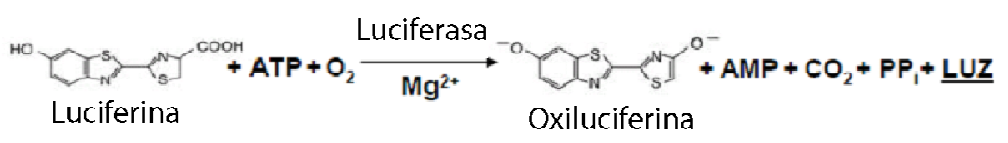

B

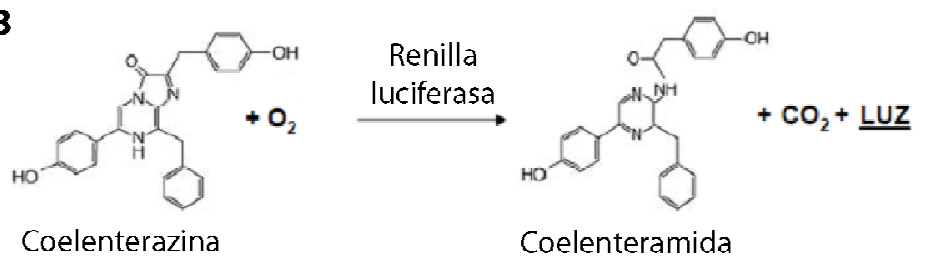

Figura 20: Esquema representativo de la reacción Luciferasa y Renilla. 


\subsection{Ensayos de fosfatasa.}

Los ensayos para medir la actividad fosfatasa de Lyp se realizaron con el sustrato artificial para-nitrofenil fosfato (pNPP) de Sigma en tampón fosfatasa (acetato sódico $100 \mathrm{mM}$, Tris $50 \mathrm{mM}$, Bis-Tris $50 \mathrm{mM}$, EDTA $5 \mathrm{mM}$ y DTT $10 \mathrm{mM}$ a pH 6), tanto el EDTA como el DTT junto con el pNPP 20 mM eran añadidos justo antes de realizar los ensayos. La reacción se llevó a cabo a $37^{\circ}$ $C$ en tubos eppendorf con Lyp inmunoprecipitada a partir de distintas células. La reacción se llevó a cabo en $250 \mu \mathrm{l}$ del tampón fosfatasa, tomando lecturas en el espectrofotómetro durante periodos de tiempo comprendidos entre 1 y 5 horas deteniendo la reacción con $25 \mu \mathrm{l}$ de $\mathrm{NaOH}$ $0.5 \mathrm{~N}$. La hidrólisis del pNPP se midió por absorbancia a una longitud de onda de $405 \mathrm{~nm}$ en una placa de ELISA y en un lector de placas de ELISA (Versamax microplate reader Molecular Devices). Los datos obtenidos se restan de la actividad que se produce en un control que contiene bolas unidas al anticuerpo anti-myc pero sin haber estado en contacto con lisado celular. 

IV. Resultados 



\section{Interacción de Lyp con otras proteínas.}

Se comenzó este estudio realizando un grupo de experimentos enfocados al estudio de la interacción de Lyp con distintas proteínas. En estos experimentos, se probaron proteínas cuya interacción con Lyp había sido descrita previamente en la literatura, como es el caso de Csk (Cohen et al. 1999), Zap70 (Wu et al. 2006), Grb2 (Hill et al. 2002) y p85, la subunidad reguladora de la fosfoinositol 3 kinasa (PI3K) de clase I, la cual actúa en las vías de señalización activadas por citoquinas, receptores antigénicos (TCR, BCR, FcR) y receptores Toll (Koyasu 2003; Hazeki et al. 2007). Para el estudio de la interacción in vivo se utilizaron los mutantes atrapadores de substratos (D/A), tanto de la fosfatasa Lyp R620, como de la variante polimórfica, Lyp W620, y se transfectaron células HEK293 con los plásmidos que codifican para las proteínas anteriormente descritas. Sólo se consiguió detectar una interacción clara con Csk (Figura 21, paneles superiores), así como una leve interacción con Zap70 (calles 5 y 6 del panel superior). Sin embargo, no se observó interacción con p85, ni con Grb2 (datos no mostrados). La interacción con Csk se produjo con ambas proteínas, Lyp R D/A y Lyp W D/A, aunque se ha descrito extensamente que Lyp-W620 es incapaz de interaccionar con Csk (Bottini et al. 2004). No obstante, otros investigadores, como Begovich et al. (Begovich et al. 2004), también han observado esta interacción aunque en menor medida que con la proteína silvestre.

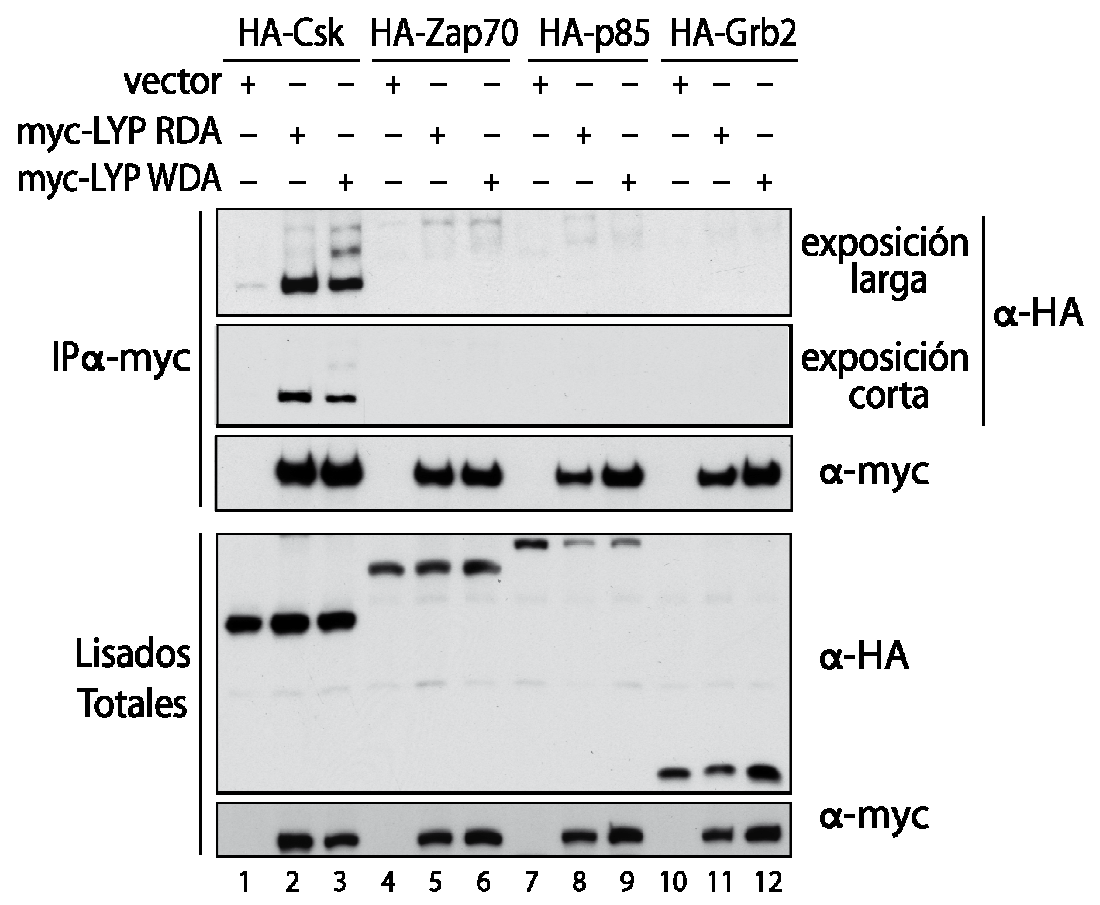

Figura 21: Interacción de Lyp con otras proteínas. Interacción de Lyp R D/A y Lyp W D/A con distintas proteínas como Csk, Zap70, p85 y Grb2. Se transfectaron células HEK293 con plásmidos de expresión en mamíferos para Lyp con el epítopo -myc y los demás plásmidos con el epítopo -HA, también se usó un 
vector vació ( $\mathrm{pEF}-\mathrm{HA})$ como control. Después de 24 horas se trataron las células con Pervanadato sódico (PV) durante $5 \min$ a $37^{\circ} \mathrm{C}$, posteriormente se lisaron y el lisado total se inmunoprecipitó con anticuerpo antimyc (tres primeros paneles). Las inmunoprecipitaciones se analizaron por SDS-PAGE seguido de una transferencia a membrana de nitrocelulosa, se bloqueó y se incubó con anticuerpos anti-myc y anti-HA. Los dos paneles inferiores muestran el lisado total para comprobar la expresión de todas las proteínas transfectadas utilizando los anticuerpos mencionados.

\section{Estudio de la interacción entre Lyp y Csk.}

Tras los resultados obtenidos en el experimento mostrado en la figura 21, se estudió en detalle la interacción entre Lyp y Csk. En primer lugar, se confirmó la interacción observada entre Lyp W y Csk realizando varios experimentos en células HEK293 (Figura 22). Además, con el objeto de comprobar esta interacción en un sistema de estudio más apropiado, se realizaron experimentos en la línea celular Jurkat, tanto con las proteínas endógenas (Lyp y Csk) como con las proteínas transfectadas (Figura 23), y se estudió la interacción entre Lyp y Csk en linfocitos humanos de sangre periférica o PBLs (Figura 24).

En el primer caso, se cotransfectaron las dos variantes de Lyp ( $R$ y W) y sus mutantes atrapadores de substratos (D/A) junto con Csk en células HEK293. Para comprobar si la interacción era dependiente de activación se usó el pervanadato (PV), un compuesto que produce una gran activación celular basada en su potente acción como inhibidor de fosfatasas de tirosina. Como se muestra en el panel superior de la figura 22, Csk interacciona tanto con la proteína Lyp silvestre como con Lyp W. Sin embargo, la interacción con esta última es menor que con la proteína normal, observándose un comportamiento similar cuando usamos los mutantes D/A atrapadores de substratos. En todos los casos, el efecto del PV incrementa la interacción entre Lyp y Csk.

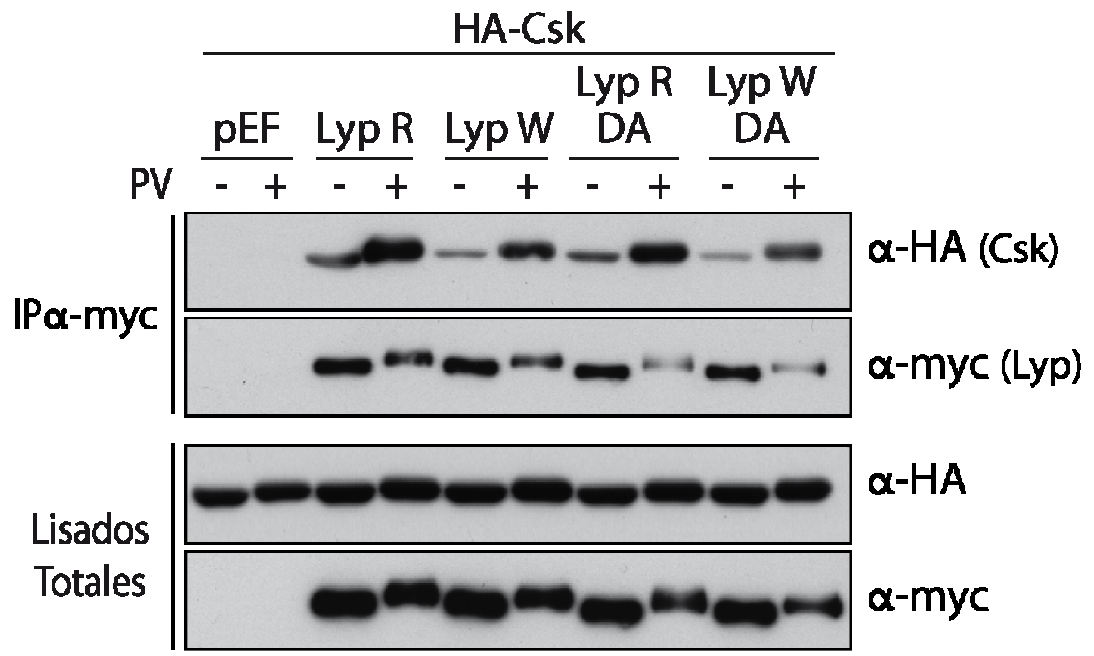

Figura 22: Interacción de Lyp R, Lyp W y sus mutantes D/A con Csk. Se transfectaron células HEK293 con las cuatro variantes de Lyp clonadas en el plásmido pCDNA3 con el epítopo -myc junto con HA- 
Csk y como control, el plásmido vacio pEF-HA. 24 horas después se trataron las células con pervanadato (PV) como activador de la señalización celular, según se detalla en el apartado de material y métodos, y se inmunoprecipitó el lisado total con anticuerpo anti-myc (los dos primeros paneles). Los lisados y las inmunoprecipitaciones se separaron en gel SDS-PAGE al 10\% y posteriormente se incubó la membrana con anticuerpos anti-myc y anti-HA. La expresión de Lyp y de Csk se muestra en los dos paneles inferiores.

A continuación, nos planteamos estudiar la interacción entre las proteínas Lyp y Csk endógenas en células Jurkat, tanto tratadas con PV como estimuladas con anticuerpos que reconocen el TCR y el CD28. Para ello, se realizaron inmunoprecipitaciones cruzadas en un lisado total de células Jurkat. Como se muestra en la figura $23 \mathrm{~A}$, al inmunoprecipitar Csk (calle 1) observamos que Lyp interacciona con Csk prácticamente de igual manera al usar PV que al estimular las células a través de los receptores TCR y CD28, sin embargo no se produce interacción en células en reposo. Al realizar la inmunoprecipitación reversa, es decir inmunoprecipitando Lyp (calle 2), se observa que Csk interacciona con Lyp en mayor medida cuando las células son tratadas con PV que cuando son estimuladas a través de los receptores TCR y CD28, no observándose tampoco interacción cuando las células están en reposo. En la tercera calle se representa una inmunoprecipitación control con proteína G-Sefarosa utilizando un anticuerpo no relevante. En conjunto, estos experimentos indican que la cantidad de Csk que está asociada con Lyp en las células en reposo es muy pequeña, lo cual no está de acuerdo con datos anteriores que sugerían que está asociación era constitutiva (Veillette et al. 2009). Además, la activación celular incrementa esta asociación, siendo por tanto susceptible de ser regulada durante la estimulación de los linfocitos $T$.

Se obtuvieron datos similares al sobreexpresar las dos variantes de Lyp en su versión atrapadora de substratos (D/A) junto con Csk en la línea celular Jurkat (Figura 23 B). Al igual que en las células HEK, la interacción entre Lyp W y Csk sigue siendo menor que cuando se utiliza Lyp $R$ y esta interacción aumenta cuando se tratan las células con PV. 
A

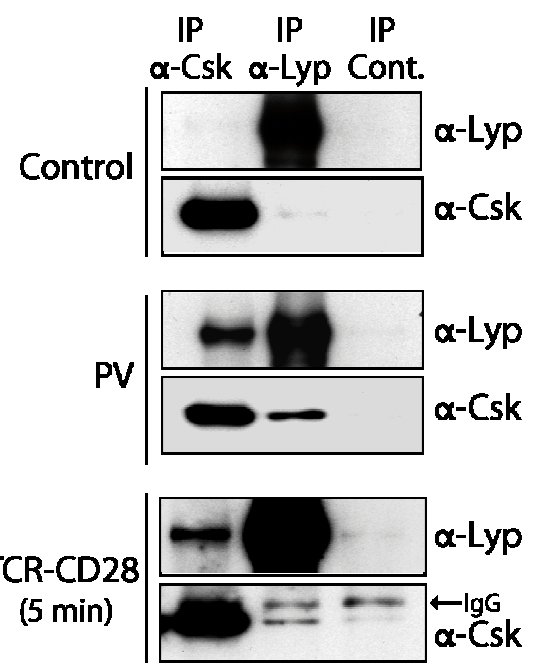

B

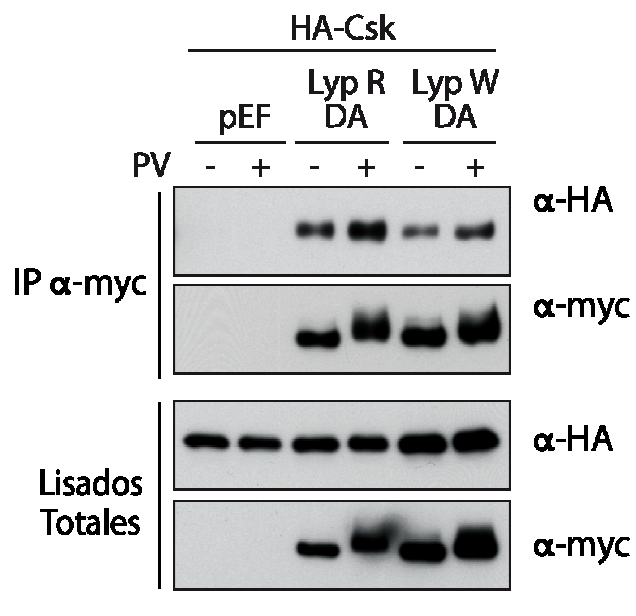

Figura 23: Interacción entre Lyp y Csk en células Jurkat. (A) Se probó una coinmunoprecipitación cruzada de las proteínas endógenas con las células Jurkat en tres condiciones: en estado de reposo, bajo el efecto del PV y estimulando los linfocitos con anticuerpos anti-TCR (C305) junto con CD28 mediante el anticuerpo $\mathrm{RaM}$ (conejo contra ratón) durante $5 \mathrm{~min}$ a $37^{\circ} \mathrm{C}$ como se describe en el apartado de materiales y métodos. En todas las condiciones se utilizó la misma cantidad de proteína total. En las tres condiciones se realizaron inmunoprecipitaciones de: Csk (carril 1), de Lyp (carril 2) y una inmunoprecipitación control (carril 3), con un anticuerpo no relevante junto con proteína G-Sefarosa. El western blot se realizó con los anticuerpos específicos para cada proteína. El doblete observado en el panel inferior de la figura es debido al anticuerpo anti- RaM utilizado en la estimulación que es revelado también por el secundario utilizado para anti-Csk. (B) Ensayo de interacción cotransfectando la línea celular Jurkat. Se utilizaron Lyp R D/A y Lyp W D/A clonadas en el plásmido pEF3xmyc- cotransfectando con HA-Csk, 24 horas después se trataron o no con PV (-/+PV), se lisaron y se inmunoprecipitó Lyp con anticuerpo anti-myc.

Por último se estudió la interacción entre ambas proteínas en linfocitos humanos de sangre periférica o PBLs obtenidos de buffy coats. En este caso, los linfocitos proceden de un pool de cinco donantes diferentes que podrían o no presentar el polimorfismo. Cuando estas células son estimuladas con anticuerpos anti-CD3 y anti-CD28, aumenta la asociación de Csk con Lyp, asociación que se mantiene hasta el minuto 30 para volver a las condiciones de reposo a los 60 minutos (Figura 24). 


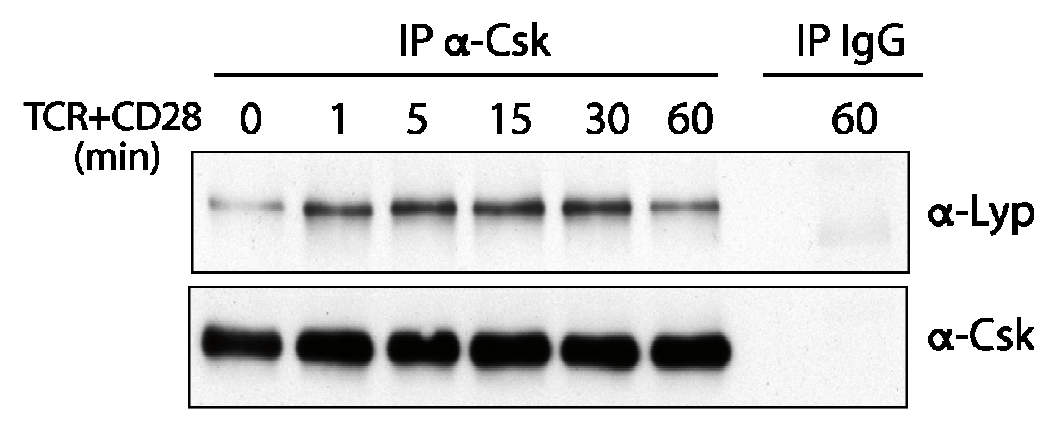

Figura 24: Cinética de interacción Lyp-Csk en linfocitos humanos de sangre periférica. Los linfocitos de sangre periférica se obtuvieron de dos buffy coats y 24 horas después de su obtención fueron estimulados a través de los receptores CD3 y CD28 con anticuerpos específicos, junto con un anticuerpo secundario anti-ratón para producir la agregación de los receptores durante los tiempos indicados. Se utilizaron $250 \times 10^{6}$ linfocitos por condición, se lisaron en tampón de lisis TNE, posteriormente se inmunoprecipitó el lisado total con $2 \mu \mathrm{g}$ anticuerpo anti-Csk de conejo unido de forma covalente a proteína ASefarosa, el lisado total del control a 60 min se inmunoprecipitó con un anticuerpo de conejo no relevante junto con bolas de proteína G-Sefarosa. Después de separar las proteínas mediante SDS-PAGE se analizaron mediante western blot con los anticuerpos específicos para Lyp y Csk (de ratón).

\subsection{Dominios de Lyp implicados en la interacción con Csk.}

Para profundizar en el estudio de la interacción de Lyp con Csk, se realizaron deleciones de distintos dominios de Lyp para comprobar cuales de ellos estaban implicados en la interacción con Csk (Figura $25 \mathrm{~A}$ ). Las construcciones generadas han sido: LP-Lyp, que consta únicamente del dominio fosfata; Y-Lyp, que posee en la posición 468 la secuencia NxxY de unión a proteínas con dominios PTB o a dominios SH2 si la tirosina se encuentra fosforilada; P-Lyp, que posee los dominios ricos en prolina $\mathrm{P} 1, \mathrm{P} 2$ y $\mathrm{CTH}$, y $\triangle \mathrm{P} 1$-Lyp, que carece del dominio $\mathrm{P} 1$.

Como se puede observar en el panel superior de la figura $25 \mathrm{~B}$, Csk es capaz de interaccionar con Lyp R, con la deleción P-Lyp y más importante aún con la deleción $\triangle \mathrm{P} 1$-Lyp. Estos resultados excluyen la posibilidad de que la interacción entre ambas proteínas se esté produciendo por el dominio catalítico de Lyp (LP-Lyp) y demuestran que la interacción no se da exclusivamente por el dominio $\mathrm{P} 1$ rico en prolinas como se ha descrito en varias ocasiones (Begovich et al. 2004; Vang et al. 2005), sino que también puede producirse por el domino P2. 
A

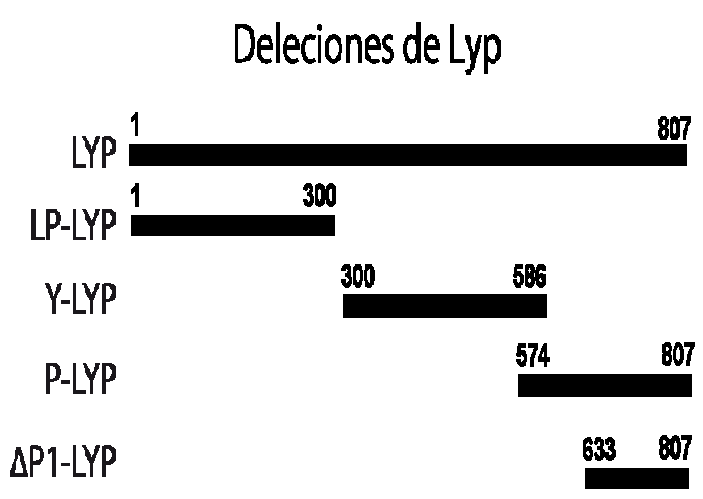

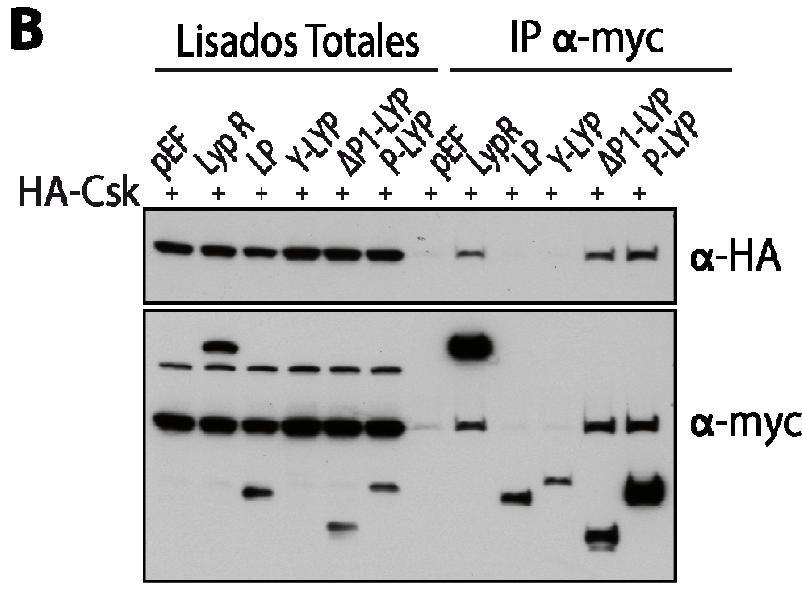

Figura 25: Identificación de las regiones de Lyp implicadas en la interacción con Csk. (A) Esquema representativo de las deleciones de Lyp generadas y utilizadas en este ensayo de interacción con Csk, donde cada fragmento consta de los siguientes aminoácidos: Lyp silvestre 1-807 aminoácidos (aa), LP-Lyp 1-300 aa, Y-Lyp 300-586 aa, P-Lyp 574-807 aa y $\triangle \mathrm{P} 1$-Lyp 633-807 aa. (B) Células HEK293 fueron cotransfectadas con las deleciones de Lyp en plásmidos pCDNA3myc junto el plásmido pEF-HA-CSK, se inmunoprecipitaron las construcciones de Lyp mediante el anticuerpo anti-myc unido a bolas de agarosa, las proteínas se separaron en gel de poliacrilamida al $12 \%$ y se detectaron mediante inmunoblot con anticuerpos contra los epítopos HA para ver Csk y anti-myc para ver Lyp, como se puede observar en el panel inferior además de las construcciones de Lyp vuelve a mostrarse Csk debido a que ambos anticuerpos (anti-myc y anti-HA) comparten el mismo anticuerpo secundario de ratón unido a peroxidada.

\subsubsection{Análisis del $\mathbf{P 1 .}$}

Después de observar que la interacción no se produce exclusivamente a través del motivo P1 de Lyp como estaba descrito, quisimos estudiar en detalle las bases moleculares del mecanismo de reconocimiento e interacción de Csk con los dominios ricos en prolina de Lyp (P1, P2 y CTH). Para ello generamos una serie de mutantes puntuales (Figura 26) en estos motivos ricos en Pro.

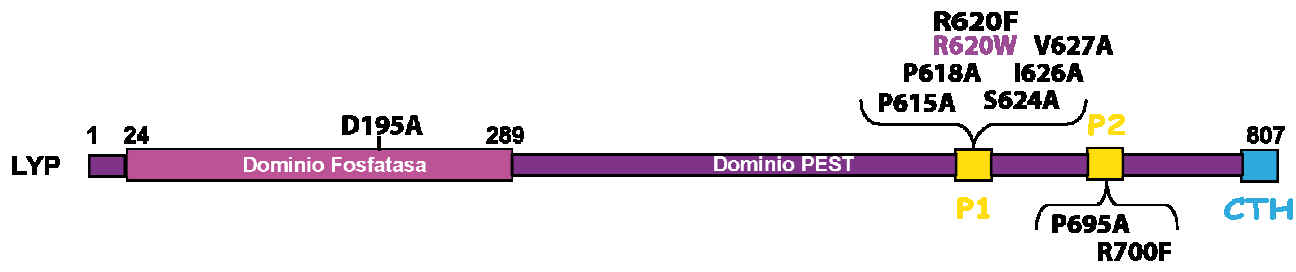

Figura 26: Mutaciones puntuales generadas en Lyp para estudiar la interacción con Csk. 
Las estructuras de proteínas obtenidas NMR (Nuclear Magnetic Resonance) aportan una manera única de estudiar no solo la estructura, sino también la dinámica de estas biomoléculas en solución en una amplio rango de escalas de tiempo (Kay 1998). Basándonos en los datos obtenidos mediante esta técnica de la estructura del dominio $\mathrm{SH} 3$ de Csk junto con un péptido que contiene el motivo P1 rico en Pro de PEP (Ghose et al. 2001) y en los estudios bioquímicos previos realizados por Veillette et al. con PEP (Cloutier y Veillette 1996), se realizaron mutaciones puntuales de varios aminoácidos del motivo P1 de Lyp (SRRTDDEIPPPLPVR620TPESFIVV). Concretamente, se sustituyeron por alaninas las prolinas 615 y 618 (P615A y P618A), la serina 624 (S624A), incluida en el estudio realizado entre PEP y el dominio SH3 de Csk (Gregorieff et al. 1998), y la isoleucina 626 junto con la valina 627 (IV626AA), ya que, como describieron Gregorieff y Ghose (Gregorieff et al. 1998), (Ghose et al. 2001), ambos aminoácidos ayudan a estabilizar la interacción.

En el primer grupo de experimentos dirigidos al estudio de los aminoácidos del P1 de Lyp implicados en la interacción con Csk (Figura $27 \mathrm{~A}$ ), se puede observar que las mutaciones puntuales (P615A, P618A y P615A+P618A) de Lyp $R$ reducen la interacción con Csk de modo muy parecido a lo observado con Lyp W620. Por otra parte, la mutación de la S624A afecta también a la interacción con Csk (Figura $27 \mathrm{~B}$ ), apoyando los datos obtenidos de las estructuras NMR y la mutación conjunta de la IV626AA también reduce la interacción de Lyp con Csk (Figura 27 C), corroborando los datos publicados por Ghose et al. (Ghose et al. 2001). 
A
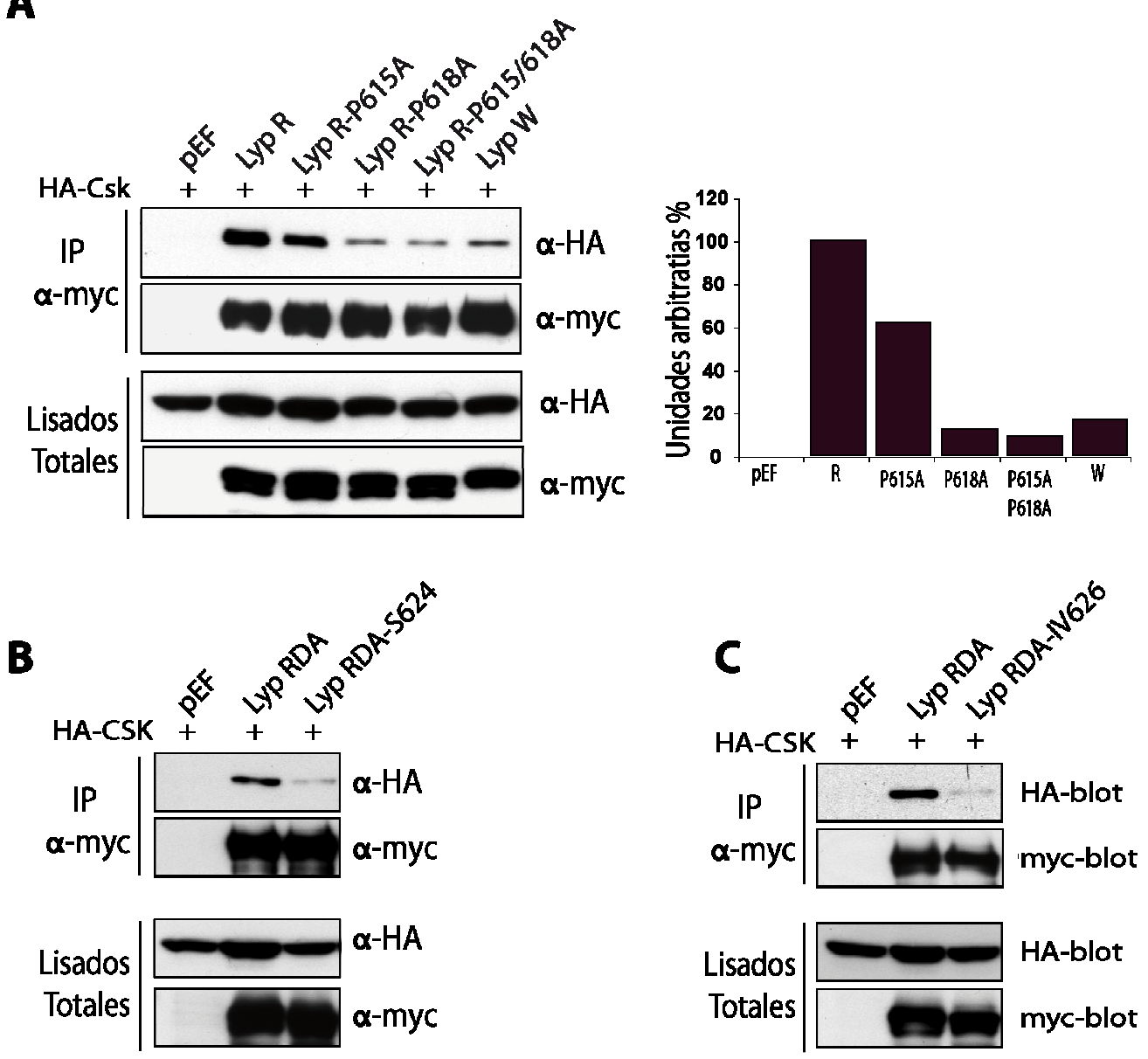

Figura 27: Análisis del motivo P1 de Lyp en interacción con Csk. (A) Para estudiar la implicación de las prolinas 615 y 618 en la interacción con Csk se transfectaron células HEK293 con las construcciones pertinentes, tras 24 horas se lisaron y se inmunoprecipitó con anticuerpo anti-myc, realizando western blot con los anticuerpos anti-HA y anti-myc para ver la interacción. En la gráfica se muestra un análisis del volumen de la bandas del blot correspondiente al anticuerpo anti-HA. (B) En este caso se utilizó la variante atrapa substratos de Lyp con la mutación en la serina 624 del mismo modo que para la figura A. (C) Igualmente se utilizó la misma metodología para el estudio de la isoleucina y la valina del P1. 


\subsubsection{Análisis comparativo entre $\mathbf{P 1}$ y $\mathbf{P 2}$.}

A continuación, tratamos de determinar la contribución del motivo P2 a la interacción de

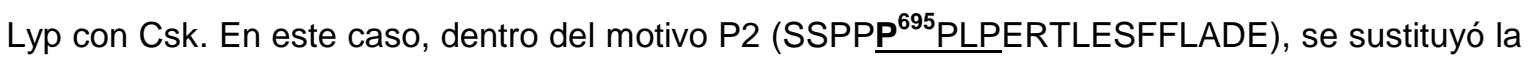
prolina 695 por una alanina (P695A), tanto en la variante normal $\mathrm{R}$ como en el polimorfismo W. Esta mutación en el motivo P2 disminuye la interacción de Lyp con Csk (calle 4, figura 28), aunque en menor medida que la variante polimórfica W620 (calle 7, figura 28). Además, la mutación conjunta del motivo P1 y P2 hace inviable la interacción de estas dos proteínas, lo que se observa con distintos mutantes del motivo P1+P2: Lyp R-P615A+P618A+P695A (calle 5, figura 28) o W-P695A (calle 7, figura 28), corroborando de esta manera que el motivo rico en prolinas P2 también es necesario para la interacción entre ambas proteínas.

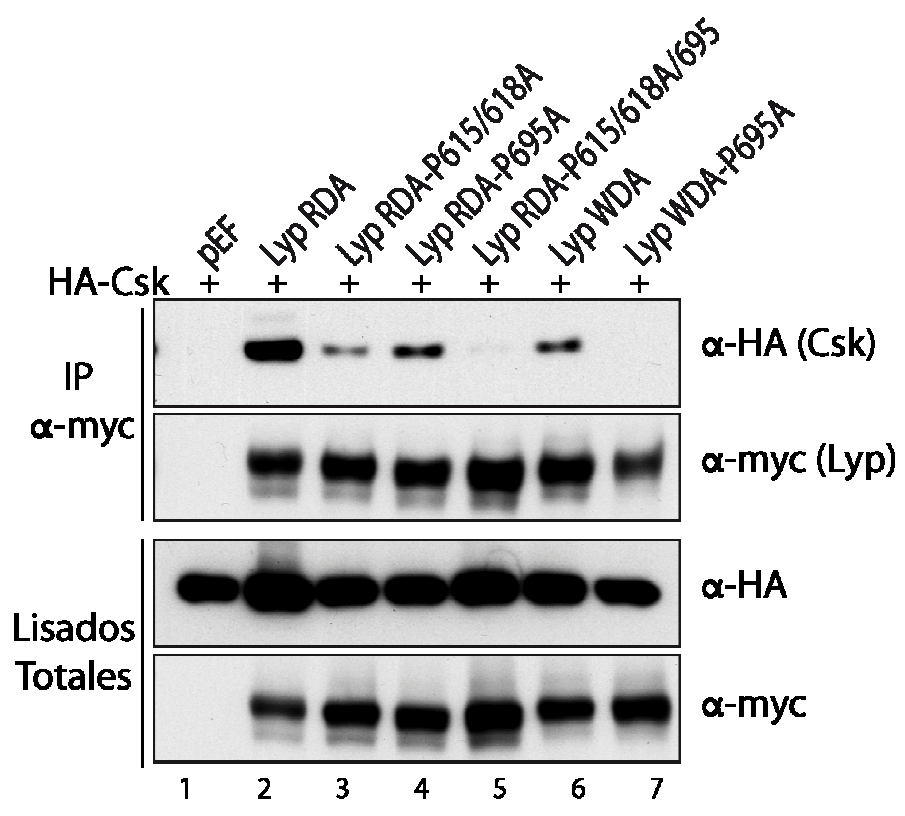

Figura 28: Análisis de interacción con los motivos P1 y P2 de Lyp. Siguiendo la metodología usada se cotransfectaron células HEK293 con HA-Csk y las mutaciones en los diferentes motivos de Lyp, P1, P2 o en ambos con el epítopo myc. Se inmunoprecipitaron las construcciones de Lyp con el anticuerpo anti-myc y se reveló con los anticuerpos anti-HA y anti-myc, en los dos paneles superiores se muestra la inmunoprecipitación y en los dos interiores el extracto total de proteínas.

\subsubsection{Implicación de las argininas de los motivos $P 1$ y $P 2$ en la interacción con Csk.}

Además de las mutaciones puntuales en los motivos P1 y P2 ya citadas, se sustituyeron las argininas que forman parte de esos motivos, la arginina 620 del P1 y la arginina 700 del P2, 
por fenilalaninas (R620F y R700F), ya que según la base de datos ADAN (http://adanembl.ibmc.umh.es) estos aminoácidos eran los menos favorables para esta interacción.

Como se puede observar, cuando se produce el cambio R620F (calle 3, figura 29) la interacción con Csk disminuye drásticamente en comparación con la interacción control (calle 2). Sin embargo, la mutación en el P2 (R700F) tan solo disminuye moderadamente esta interacción (calle 4). Por último, cuando Lyp contiene ambas mutaciones (R620/700F) la interacción con Csk no se produce, lo que apoya la implicación del P2 en la interacción con Csk (calle 5).

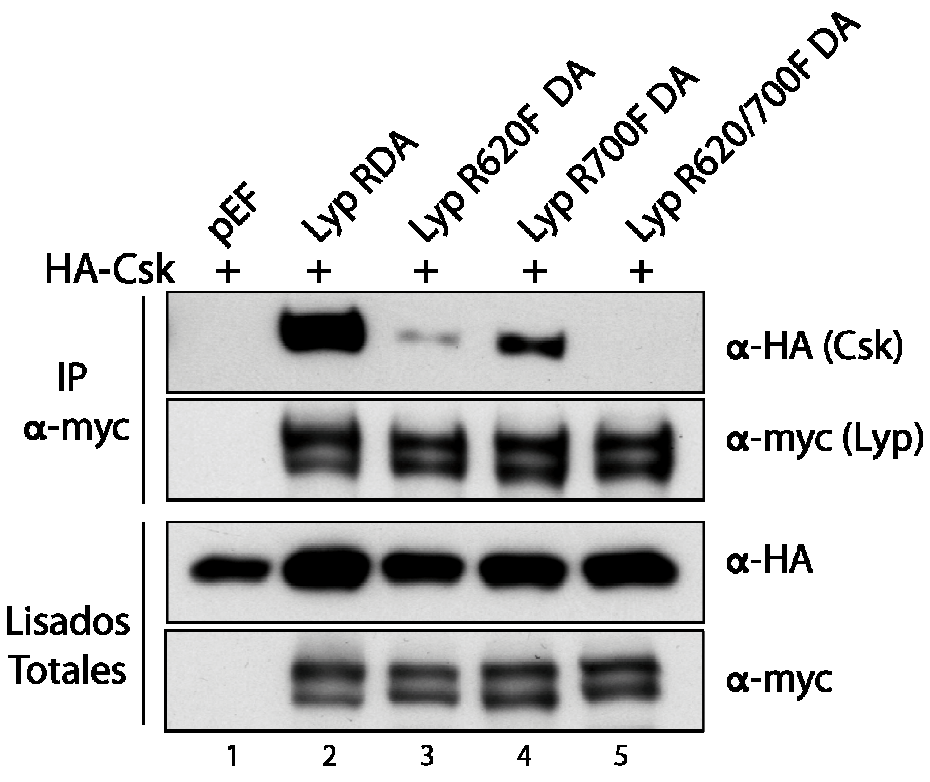

Figura 29: Análisis de las mutaciones R620F y R700F en los motivos P1 y P2 de Lyp en la interacción con Csk. Siguiendo la misma metodología que en los experimentos anteriores, se transfectaron células HEK293 con los plásmidos que codifican para Csk y para Lyp R en su versión atrapa substratos (D/A) junto con las mutaciones puntuales R620F, R700F o ambas a la vez. Se inmunoprecipitaron los lisados con anticuerpo anti-myc y posteriormente se analizó mediante western blot.

\subsubsection{Importancia del dominio CTH.}

Para comprobar si el motivo del extremo carboxilo terminal de Lyp (CTH), que contiene un dominio rico en prolinas, estaba implicado en la interacción con Csk, generamos una deleción de Lyp que carecía de los últimos 25 aminioácidos ( $\triangle \mathrm{CTH}$ ) (FLNFGFANRFSKP ${ }^{795}$ KGPRNPPPTWNI). Como se puede comprobar, la eliminación del dominio carboxilo terminal $(\triangle \mathrm{CTH})$ no impide la interacción entre Lyp y Csk (calle 3, figura 30). 


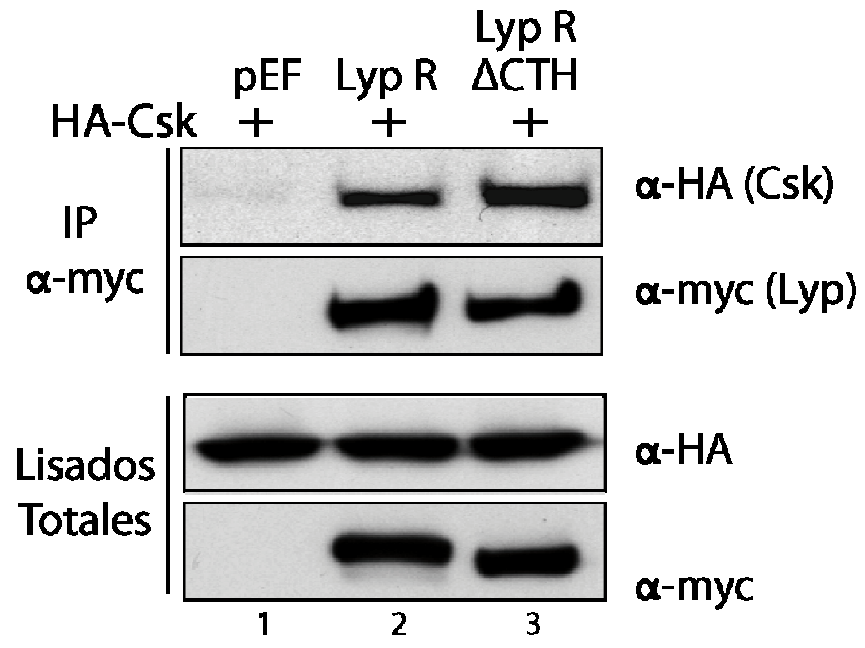

Figura 30: Interacción entre Csk y de Lyp- $\mathbf{A C T H}$. Las células HEK293 se transfectaron con los plásmidos que codifican para las proteínas de fusión HA-Csk y myc-Lyp, tanto silvestre como con la deleción del carboxilo terminal. A las 24 horas de transfección se lisaron y los lisados resultantes se inmunoprecipitaron con anticuerpo anti-myc unido a bolas de agarosa, se realizó western blot utilizando los anticuerpos específicos para cada epítopo.

\subsection{Dominios de CSK implicados en la interacción.}

Csk posee un dominio $\mathrm{SH} 3$ en el extremo amino terminal capaz de interaccionar con motivos ricos en prolinas y un dominio $\mathrm{SH} 2$ capaz de interaccionar con tirosinas fosforiladas. Con el fin de estudiar la implicación de estos dominios de Csk en la interacción de esta proteína con Lyp, se generaron mutaciones de ciertos aminoácidos en estos dominios. (Figura 31). De esta menera, para estudiar la implicación del dominio $\mathrm{SH} 3$, se sustituyó el ácido aspártico en posición 27 por una alanina (D27A) dado que, según la estructura del dominio SH3 de Csk y el motivo P1 de Lyp, este aminoácido interacciona directamente con la arginina R620 (Ghose et al. 2001). Asimismo, se mutó la glutamina adyacente en posición 26 (Q26A) ya que esta glutamina podría participar en la interacción con la arginina R620 del dominio P1 (Ghose et al. 2001). Por último, se realizó una sustitución del triptófano en posición 47 por una alanina (W47A), puesto que este aminoácido es el responsable de la interacción con la P618 del motivo P1 de Lyp (Ghose et al. 2001). Además, para estudiar la posible implicación del dominio SH2 en la interacción de Csk con Lyp, se mutó la arginina 107 por una metionina (R107M), ya que esta arginina juega un papel crítico en la unión del domino SH2 con las tirosinas fosforiladas de otras proteínas. 


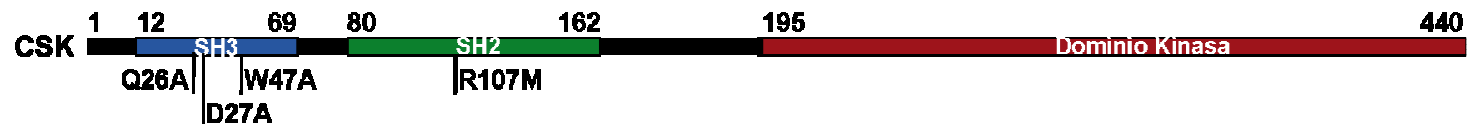

Figura 31: Mutaciones generadas en los dominios de CSK para el estudio de interacción con Lyp.

\subsubsection{Efecto de las mutaciones de Csk sobre la señalización celular.}

Con el fin de observar el comportamiento de los mutantes de Csk anteriormente descritos en la señalización a través del TCR, se realizaron ensayos de luciferasa en la línea celular Jurkat (Figura 32). Como se muestra, Csk bloquea la señalización celular, y las mutaciones introducidas en está kinasa no parecer afectar a su función en la señalización a través del TCR.

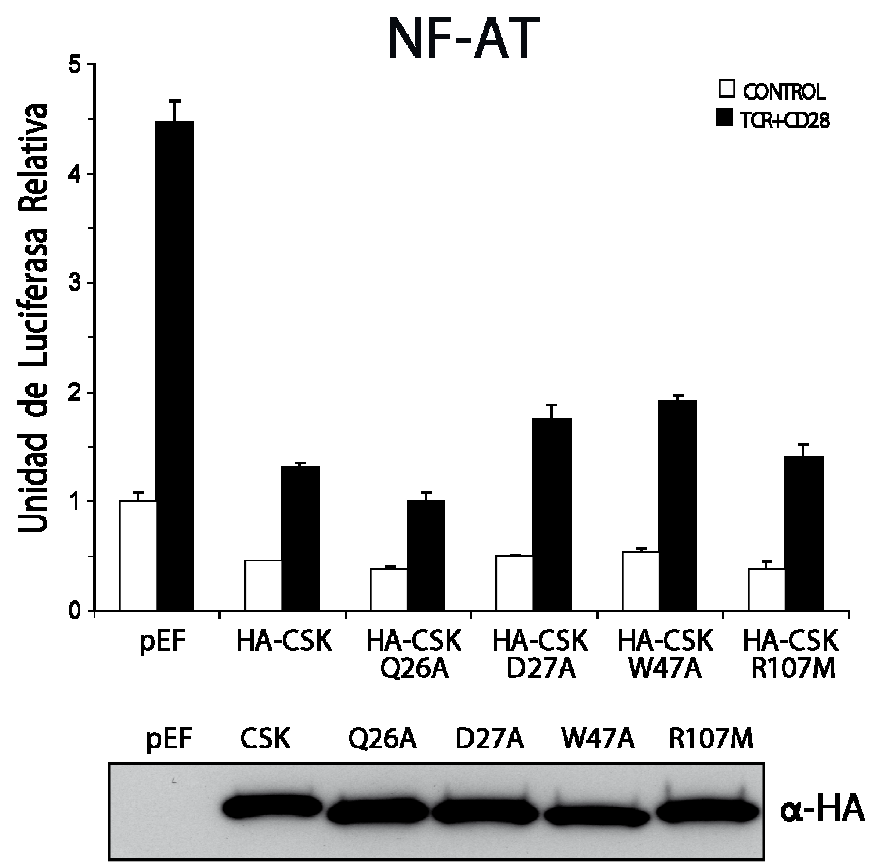

Figura 32: Ensayo de luciferasa de las distintas mutaciones de Csk sobre la actividad de NFAT. Se transfectaron células Jurkat con el plásmido que expresa la enzima luciferasa bajo el control de un promotor que presenta sitios de unión para el factor de transcripción NFAT ( $3 \mu \mathrm{g})$, junto con un plásmido control que expresa la enzima luciferasa de Renilla reniformis (250 ng) RL-O y los plásmidos que expresan los distintos mutantes de Csk clonadas con el epítopo de la hemaglutinina (HA). Tras 24 horas de transfección las células se trataron como se describe en el apartado de material y métodos y se determinó la actividad transcripcional de NFAT mediante la medida de la actividad de la luciferasa en el lisado celular. La figura 
muestra uno de tres experimentos independientes con resultados similares. En la parte inferior se muestra la expresión de los mutantes de Csk utilizados, detectados mediante Western blot con anticuerpo anti-HA.

\subsubsection{Análisis del dominio SH3.}

Una vez comprobado el efecto funcional de las distintas mutaciones del dominio $\mathrm{SH} 3$ de Csk, se estudió su posible efecto en la interacción de Csk con Lyp. Para ello, se cotransfectaron células Jurkat con los mutantes Q26A, D27A y W47A de Csk junto con la variante atrapadora de substratos de Lyp R. En estos ensayos se puso de manifiesto la ausencia de interacción entre Lyp y Csk cuando ésta contiene las mutaciones D27A y W47A en el dominio SH3 (Figura 33). También se puede observar como la mutación Q26A afecta a la interacción, aunque en menor medida que las mutaciones de Csk Q27A y W47A.

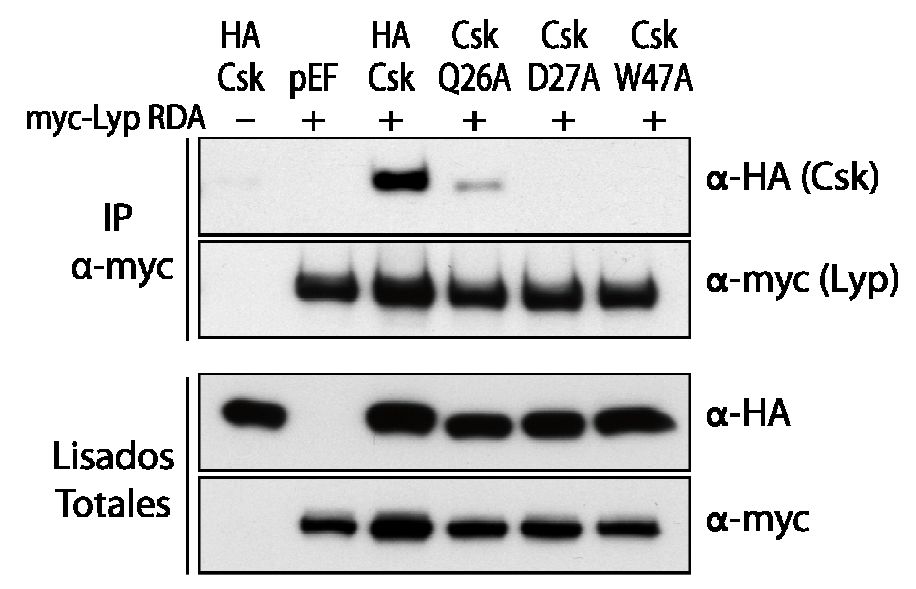

Figura 33: Análisis de la interacción de los mutantes del dominio SH3 de Csk, Q26A, D27A y W47A con Lyp. Al igual que en experimentos anteriores se transfectaron células Jurkat con las correspondientes construcciones, las proteínas sobreexpresadas se inmunoprecipitaron con anticuerpo anti-myc, finalmente los precipitados y los lisados celulares se detectaron mediante Western Blot con un anticuerpo contra los epítopos HA y myc.

\subsubsection{Análisis del dominio SH2.}

Para comprobar el efecto de la mutación R107M del domino SH2 de Csk en la interacción con Lyp, tanto R D/A como W D/A, (Figura 34), se trataron las células con PV. Como se puede observar, la mutación de Csk R107M disminuye la interacción con Lyp R con respecto a Csk y esto se produce tanto en células en reposo como en células tratadas con PV, hecho que se hace más evidente cuando estudiamos la interacción con Lyp W. 


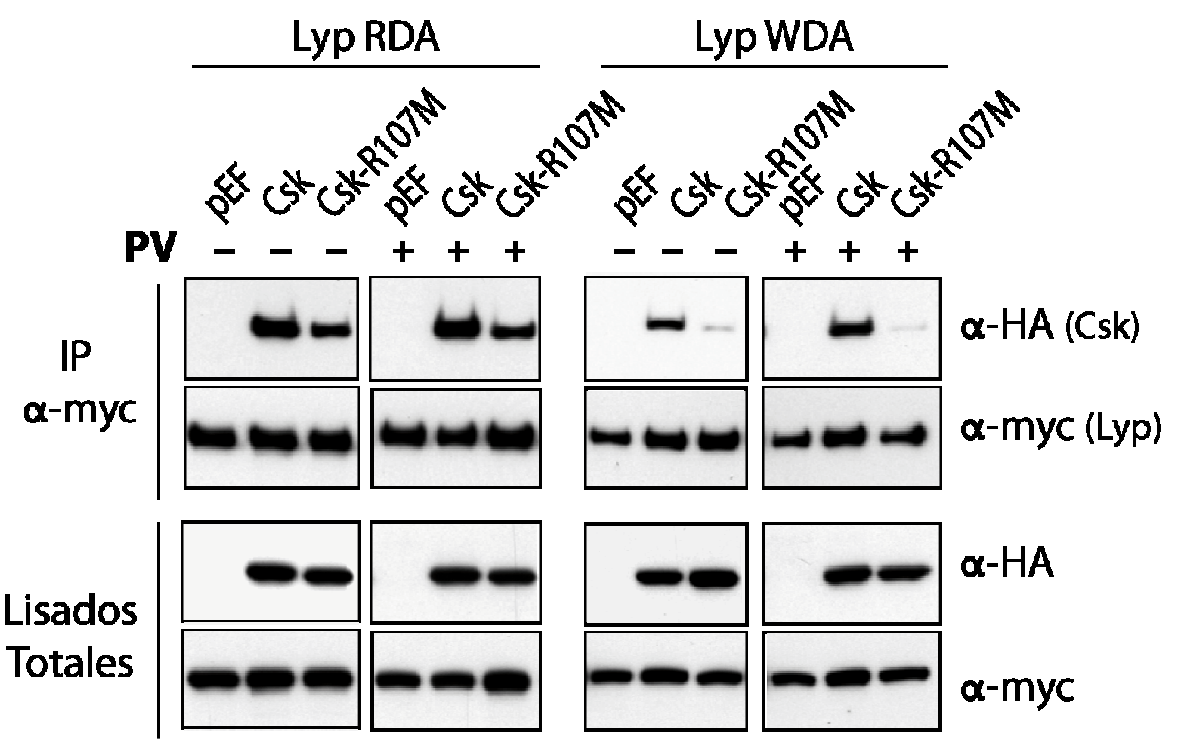

Figura 34: Asociación de Csk con Lyp a través de su dominio SH2. Las células HEK293 se transfectaron con plásmidos pCDNA3myc- que codifican para las versiones atrapa substratos de Lyp (R D/A y W D/A) junto con plásmidos pEF-HA de Csk y su mutante R107M. Antes de lisar las células, unas condiciones se dejaron sin tratar y otras se trataron con PV durante 5 min a $37^{\circ} \mathrm{C}$, una vez lisadas se realizó una inmunoprecipitación con anticuerpo anti-HA, se separaron los lisados y las inmunoprecipitaciones en geles SDS-PAGE y se realizó western blot con los anticuerpos anti-myc y anti-HA.

\section{Efecto de lyp sobre la señalización celular.}

\subsection{Efecto de Lyp sobre la activación de los factores de transcripción NFAT, NFkB y ELK.}

Para determinar cómo la fosfatasa Lyp afecta a la señalización in vivo a través del receptor de linfocitos $T$ (TCR), se sobreexpresaron las proteínas Lyp R y Lyp W en células Jurkat junto con los plásmidos reporteros que expresan el gen de la luciferasa bajo el control de diferentes promotores relevantes en la activación de los linfocitos T: NFAT, NF-kB y GAL4-ELK.

En todos los casos se obtuvieron resultados similares (Figura 35). Por un lado, no se observaron grandes cambios entre la variante normal y el polimorfismo de Lyp y, por otro, ambas variantes reducían de una manera similar la señalización a través del TCR. 


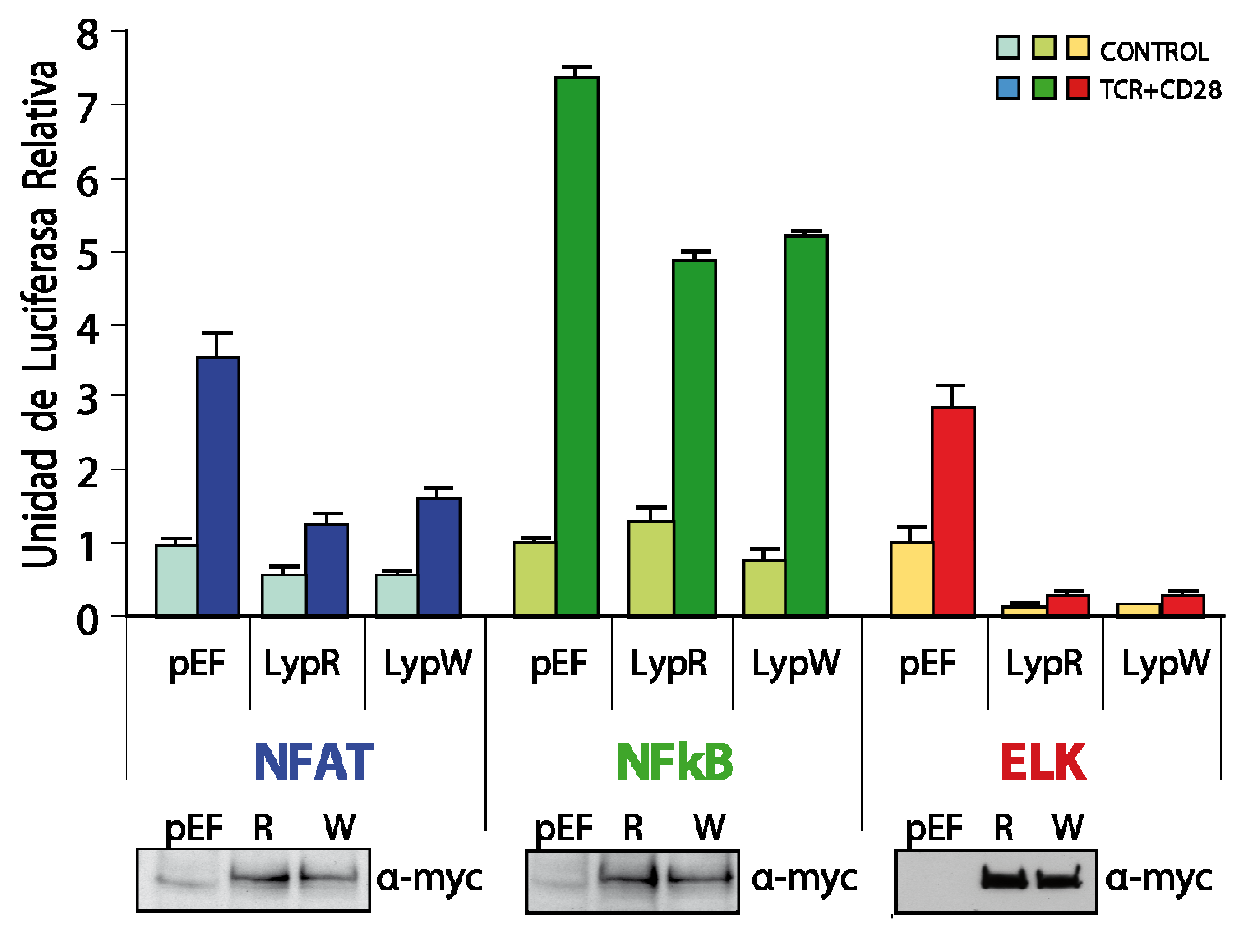

Figura 35: Efecto sobre la actividad transcripcional de las variantes Lyp $\mathbf{R}$ y Lyp W. $15 \times 10^{6}$ células Jurkat fueron transfectadas con un plásmido vació pEF, con Lyp R y con Lyp W junto los plásmidos que codifican para la enzima luciferasa con los genes reporteros $(3 \mu \mathrm{g})$ NFAT, $(3 \mu \mathrm{g})$ NFkB y $(500 \mathrm{ng})$ GAL4-ELK además del control (250 ng) RL-O de renilla. 24 horas después se estimularon como se describe en el apartado de ensayos de luciferasa de material y métodos y se midió la actividad luciferasa en las tres condiciones con NFAT, con NFkB y con GAL4-ELK y parte del lisado se utilizó para comprobar la expresión de Lyp en todos los casos. Se representa la media de tres experimentos independientes por triplicado.

Para confirmar que Lyp regula negativamente la activación de los linfocitos $T$, transfectamos células Jurkat con plásmidos que expresan Sh-RNA (short hairpin RNA) para suprimir la expresión de Lyp. En el estudio funcional realizado mediante ensayos de luciferasa se comprobó que en todos los casos (Figura 36) el silenciamiento de Lyp provoca un aumento de la señalización a través del TCR. 


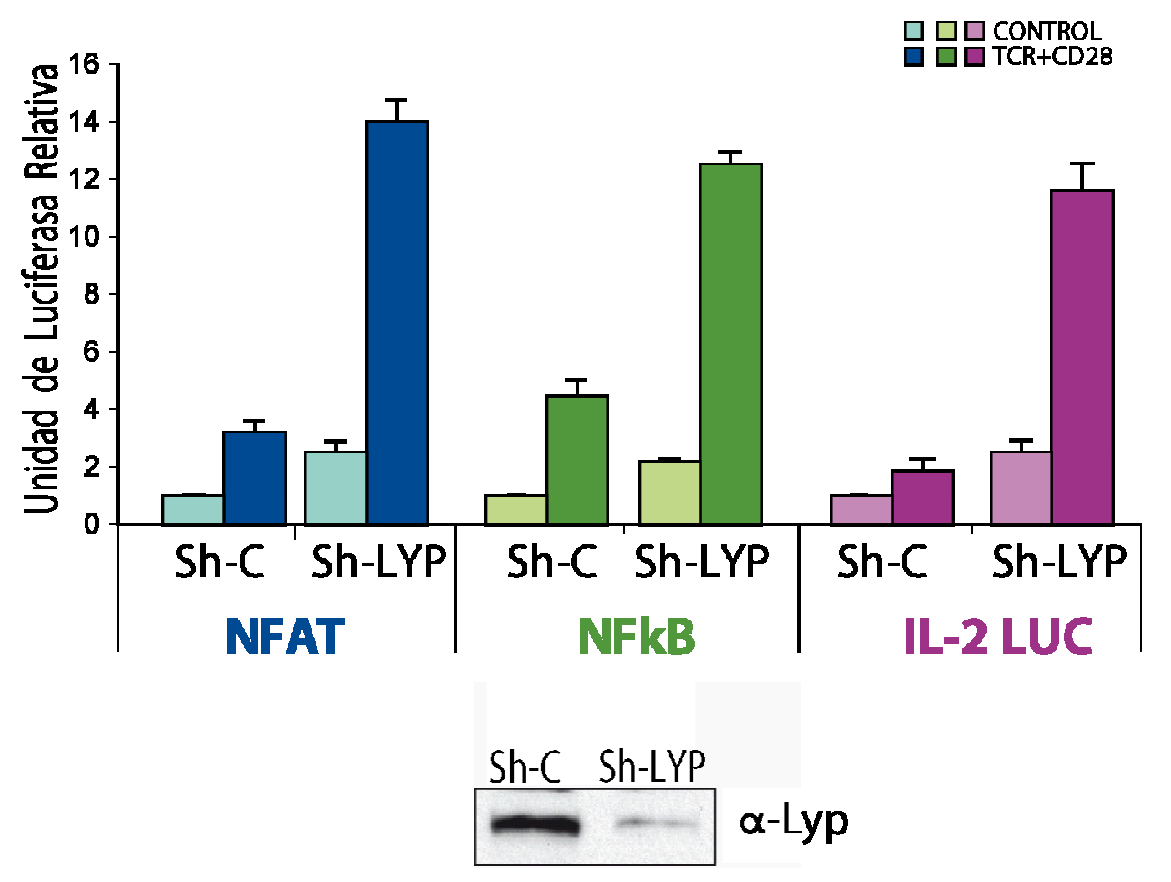

Figura 36: Efecto de la inhibición de Lyp sobre la señalización celular. Ensayos de luciferasa con células Jurkat transfectadas con el plásmido control Sh-C (Sh-30001-GFP) y el plásmido Sh-Lyp 38 que bloquea la expresión de Lyp junto con los plásmidos que codifican para la enzima luciferasa con los genes reporteros: NFAT, NFkB e IL-2 junto con el control de renilla RL-O. Las medidas presentadas corresponden a la media de tres experimentos independientes por triplicado. En la parte inferior se representa el blot correspondiente a la expresión de Lyp en estos ensayos.

\subsection{Efecto de Lyp en la desfosforilación de Lck.}

Una vez comprobado que Lyp inhibía la señalización a través del TCR, tratamos de verificar si Lyp actuaba sobre Lck. Para ello transfectamos células Jurkat con los plásmidos que codifican para Lck y para Lyp $R$ y estimulamos estas células a través de los receptores CD3 y CD28. En estas condiciones, observamos que Lck era desfosforilada por Lyp R (Figura 37), confirmando así que Lyp R es capaz de desfosforilar la tirosina 394 de Lck. 


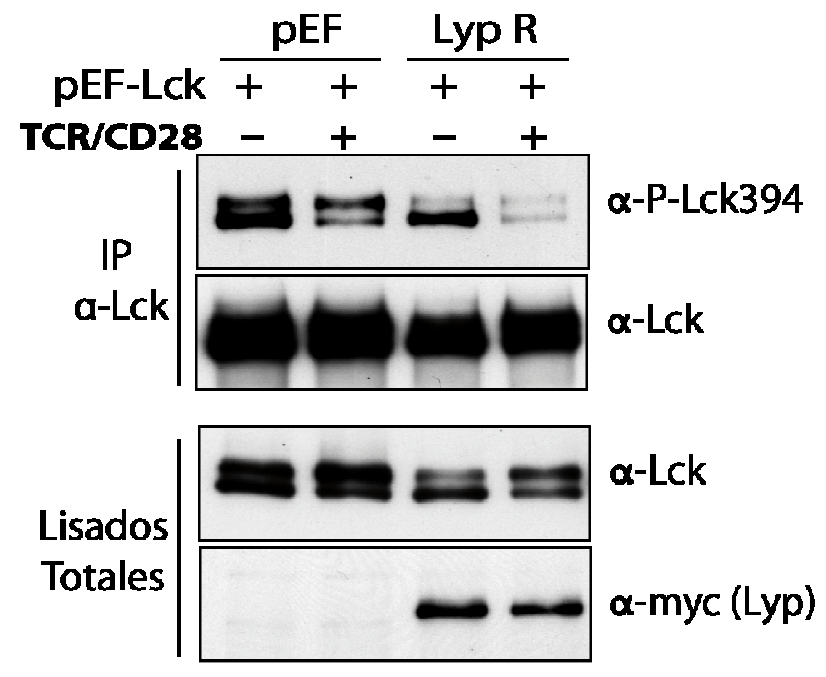

Figura 37: Desfosforilación de Lck por Lyp R. Células Jurkat fueron tranfectadas con los plásmidos para Lyp R y para Lck. Antes de lisar las células se estimularon con anticuerpos anti-CD3 y anti-CD28 durante 10 min a $37^{\circ} \mathrm{C}$. Los lisados se inmunoprecipitaron con anticuerpo anti-Lck, posteriormente se realizó western blot con los anticuerpos anti-fosfo-Src 416, que reconoce la secuencia de la tirosina 394 de Lck, con anti Lck y anti-myc.

\subsection{Efecto cooperativo de Lyp y Csk.}

Con el fin de determinar si la interacción de Lyp con Csk es necesaria para la regulación de la señalización iniciada por el TCR, se realizaron ensayos de luciferasa para estudiar la actuación conjunta de ambas proteínas en la señalización celular. Los datos obtenidos en estos experimentos (Figura 38 A) muestran que tanto Lyp R como Lyp W son capaces de cooperar con Csk en la regulación de la señalización del TCR, por tanto la interacción de Lyp con Csk no sería estrictamente necesaria para controlar la activación de los linfocitos T por antígenos. Se observó el mismo efecto (Figura 38 B) cuando se utilizó el mutante de Csk W47A, que como se ha descrito anteriormente no interacciona con Lyp (Figura 33). 
A

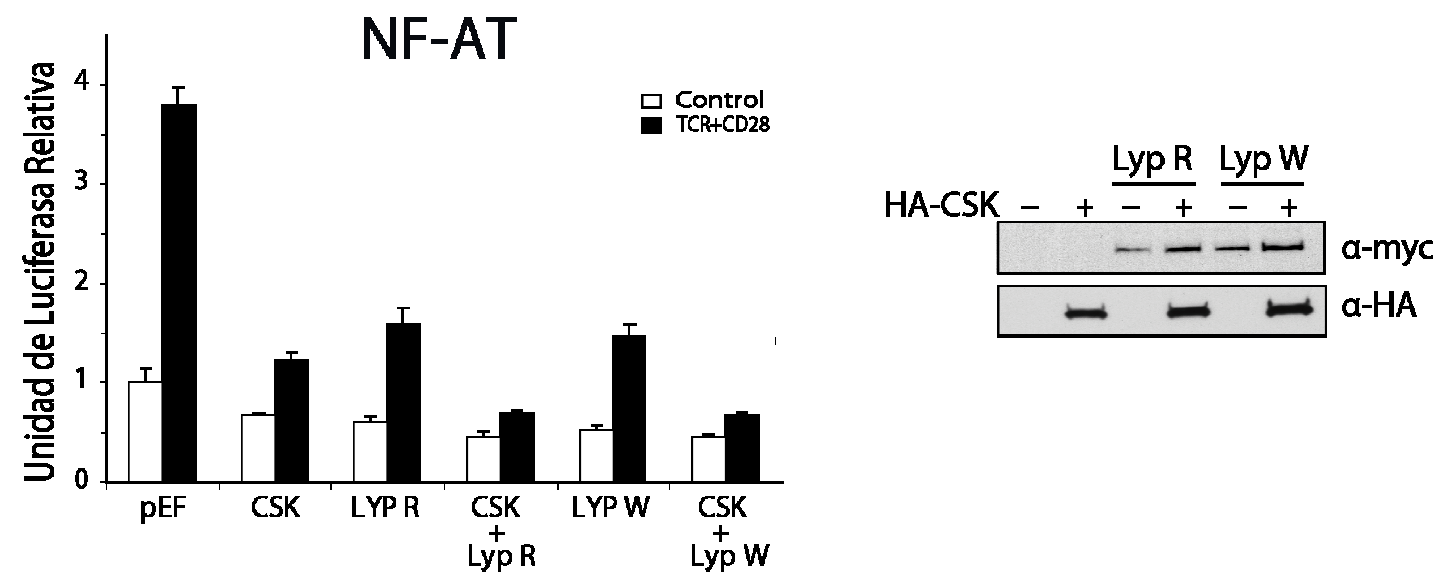

$\mathbf{B}$

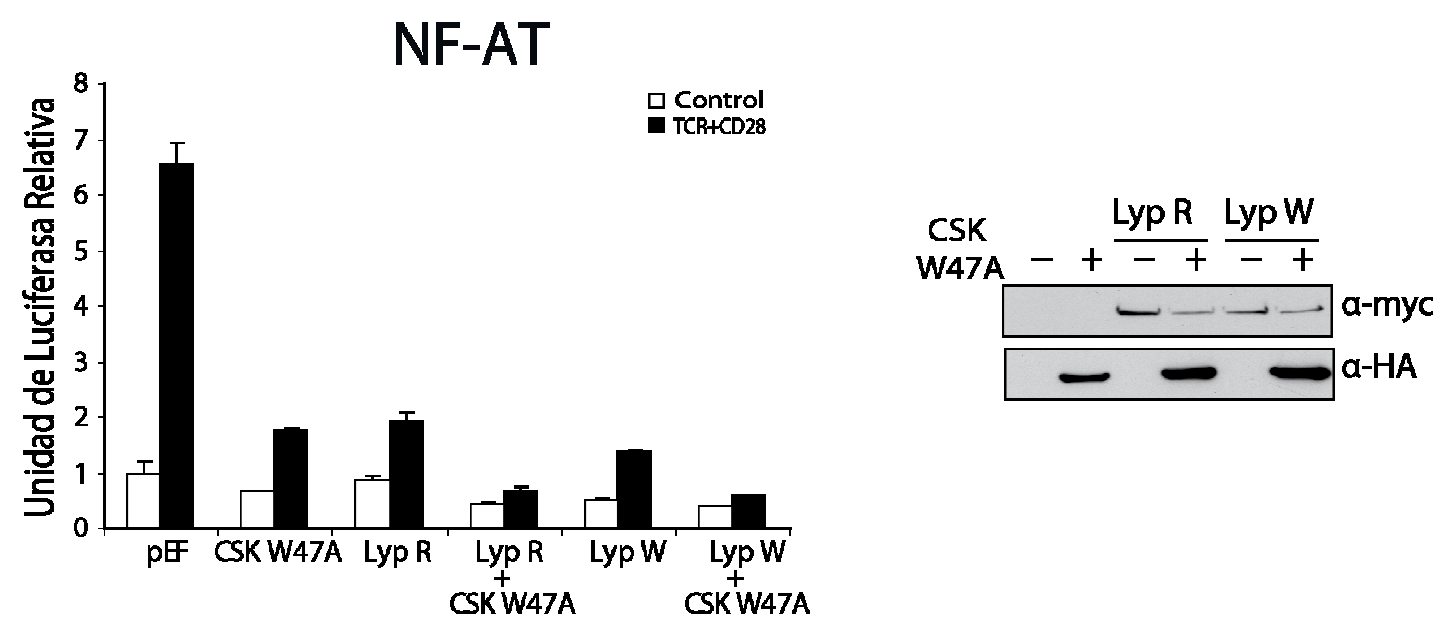

Figura 38: Cooperación de Lyp y Csk en la regulación de NFAT. (A) Se transfectaron células Jurkat con Lyp R y W junto con Csk y se realizaron los ensayos de luciferasa como se ha indicado anteriormente. (B) En este caso se cotranfectaron Lyp, tanto R como W con el mutante del dominio SH3 de Csk (HA-Csk W47A) para comprobar si la falta de interacción produce algún efecto a nivel de señalización celular.

Por otro lado, para corroborar los datos obtenidos en ensayos de luciferasa, quisimos determinar la activación de la MAP kinasa Erk en presencia de Lyp y Csk, Para ello se cotransfectaron células Jurkat con HA-ERK, myc-Lyp R o W y GST-CSK (Figura 39). Los resultados de estos experimentos indican de nuevo que el efecto sumatorio de Lyp, tanto de $R$ como de W, con Csk, cuando las células han sido estimuladas por el TCR y el CD28, produce una 
disminución en el estado de fosforilación de Erk (panel superior, octava y duodécima calle). Además, se puede observar que en presencia de Lyp R (calle 6) la desfosforilación de Erk es menor que en las células transfectadas con Lyp W (calle 10), siendo por tanto más eficiente en este ensayo Lyp W.

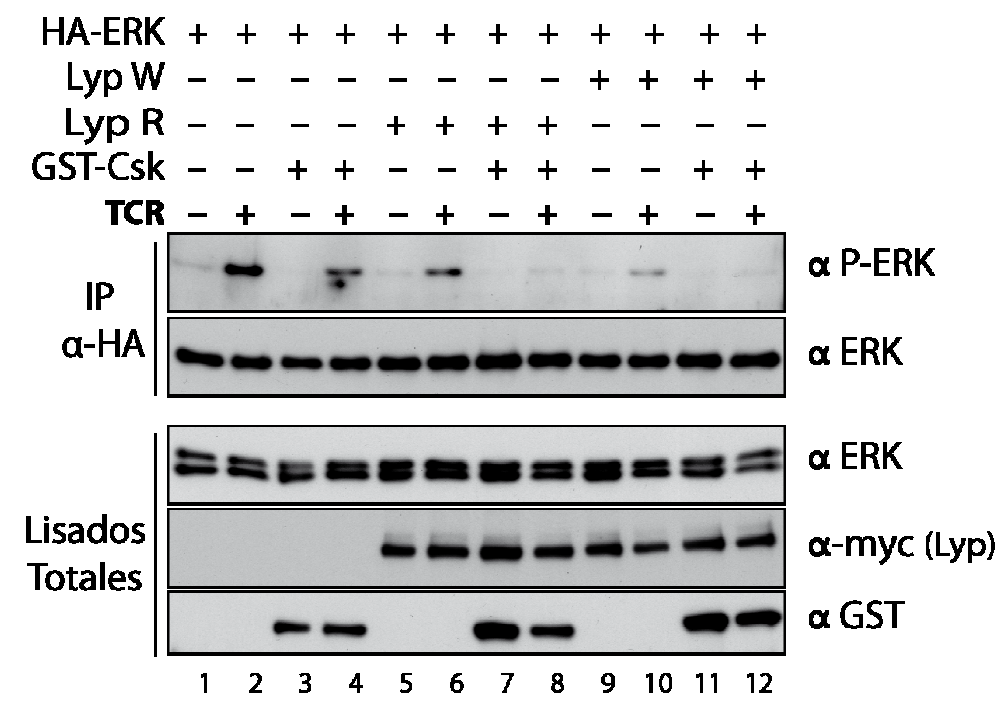

Figura 39: Efecto de la sobreexpresión de Lyp y Csk en la activación de ERK. Se transfectaron células Jurkat con pEF3xmyc-Lyp R y Lyp W junto al ADN codificante para GST-CSK y HA-ERK. Después de su estimulación por el TCR durante 5 minutos, Erk se inmunoprecipitó de los lisados de estas células con anticuerpo anti-HA y la activación de Erk se detectó mediante Western blot con un anticuerpo específico para su bucle de activación fosforilado, anti-fosfo ERK, seguido de un blot anti-Erk para comprobar que se inmunoprecipitó la misma cantidad de Erk en todas las condiciones. Además, también se determinó mediante Western blot con anticuerpos, anti-ERK y anti-GST y anti-myc, que las células se habían transfectado con cantidades similares de las proteínas indicadas.

\section{Actividad fosfosfatasa de Lyp.}

Se realizaron ensayos fosfatasa in vitro con las proteínas Lyp $R$ y su variante Lyp W purificadas mediante inmunoprecipitación a partir de transfecciones transitorias en células Jurkat o de clones estables de células Jurkat que expresaban ambas proteínas. Se analizó la capacidad de ambas fosfatasas para desfosforilar un sustrato artificial de fosfatasas de tirosina, el paranitrofenilfosfato (pNPP), el cual es desfosforilado a para-nitrofenol (pNP) produciendo un color amarillo medible a una longitud de onda de $405 \mathrm{~nm}$. En estos ensayos, observamos que, efectivamente, como se ha publicado (Bottini et al. 2004), la actividad fosfatasa de Lyp $R$ es un $31.1 \%$ menor que la de Lyp W (Figura $40 \mathrm{~A}$ ). Cuando las células fueron estimuladas a través del 
TCR y del CD28, la actividad de Lyp disminuyó, lo que nos indujo a medir la actividad de Lyp en una cinética de estimulación por estos receptores (Figura 40 B). En este caso, se utilizó Lyp W por ser la más activa de las dos variantes y, al igual que en el experimento anterior, la estimulación produjo una disminución de la actividad de esta fosfatasa, siendo mayor la inhibición cuanto mayor es el tiempo de estimulación.

A

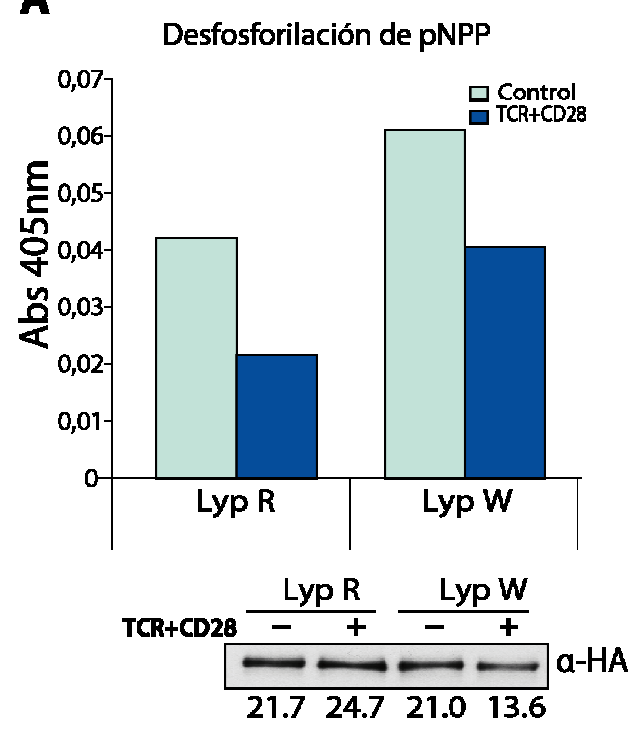

B
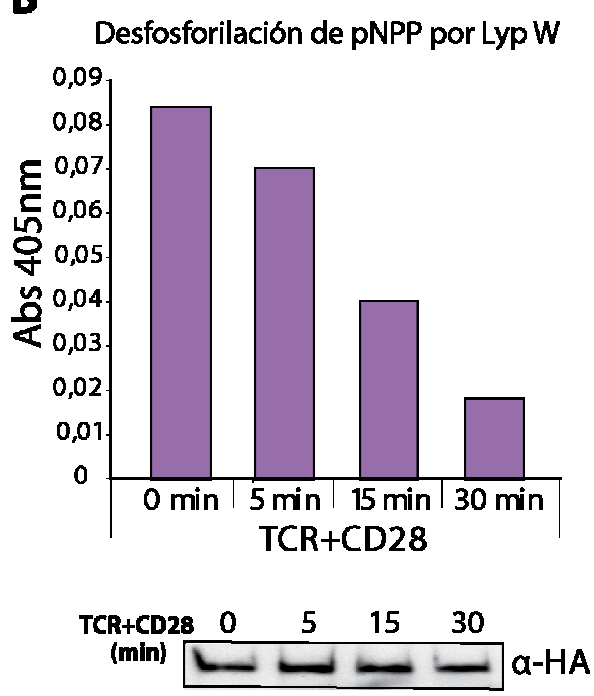

Figura 40: Actividad catalítica intrinseca de Lyp R y su polimorfismo W. (A) Células del clon estable de Jurkat que codifica para Lyp R ( $70.10^{6}$ /punto) y para el clon Lyp W (140.10\% punto) fueron tratadas durante 15 min con TCR y CD28 antes de lisarlas e inmunoprecipitar su extracto total de proteínas con anticuerpo anti-HA. El precipitado se utilizó para medir la actividad fosfatasa en presencia de $20 \mathrm{mM}$ de pNPP y a $37^{\circ} \mathrm{C}$, se realizaron medidas de absorbancia a una longitud de onda de $405 \mathrm{~nm}$ a las 5 horas. Los datos mostrados de la actividad fosfatasa de Lyp R y de Lyp W son el resultado de la diferencia de la actividad de las fosfatasas con respecto a la actividad mostrada por un control de bolas unidas al anticuerpo anti-myc en el mismo tampón fosfatasa. En el panel inferior se muestra el western blot de los inmunoprecipitados utilizados para el ensayo fosfatasa. (B) Cinética de activación del clon Lyp W (150.10\% /punto) estimulados con TCR y CD28 durante 5, 15 y 30 minutos, el ensayo se realizó igual que en el caso anterior mostrándose los datos de absorbancia obtenidos a $405 \mathrm{~nm}$. 
V. Discusión 



\section{Lyp interacciona principalmente con Csk.}

En este estudio hemos analizado la interacción de Lyp con distintas proteínas cuya asociación con esta fosfatasa había sido previamente descrita, como es el caso de Csk (Cohen et al. 1999), Zap70 (Wu et al. 2006) y de Grb2 (Hill et al. 2002) y con otras proteínas como p85, la subunidad reguladora de la $\mathrm{PI} 3 \mathrm{~K}$, que contiene un dominio $\mathrm{SH} 3$ y participa en la señalización del TCR. Los resultados obtenidos en nuestro laboratorio muestran que Lyp interacciona claramente con Csk, no así con las otras proteínas, Zap70, Grb2, o p85.

En el caso de Zap70, no solo se ha descrito la interacción con esta proteína sino que también se ha propuesto que es substrato de Lyp (Wu et al. 2006). En este trabajo, se detectó la interacción de estas dos proteínas en ensayos de pull-down con el dominio fosfatasa de Lyp. En cambio, nosotros hemos estudiado la interacción utilizando la proteína completa en ensayos de inmunoprecipitación, tanto de proteínas expresadas ectopicamente como de proteínas endógenas, en células en reposo o activadas con diversos estímulos, y no hemos obtenido datos que apoyen la existencia de esta asociación entre Lyp y Zap70. La discrepancia en los resultados puede deberse a los diferentes métodos utilizados en ambos laboratorios. En cualquier caso, el hecho de que Wu y colaboradores detecten interacción entre Lyp y Zap70 utilizando solamente el dominio fosfatasa de Lyp indicaría que la interacción tendría lugar entre el dominio fosfatasa de Lyp y el bucle de activación de Zap-70 y sería, por tanto, una asociación transitoria que se deshace tan pronto como la fosfatasa hidroliza el fosfato.

La falta de interacción entre Lyp y Grb2 observada en este estudio concuerda con el trabajo publicado por Cloutier y Veillete (Cloutier y Veillette 1996), donde muestran que el dominio SH3 de Grb2 no interacciona con el motivo P1 de PEP, aunque Hill et al. mostraron que esta interacción se produce a través del dominio SH3 del extremo amino terminal de Grb2 (Hill et al. 2002). En cuanto a la subunidad reguladora de la PI3K, p85, recientemente se ha descrito la interacción de su dominio SH3 con la fosfatasa de tirosina PTPN4 o MEG1, perteneciente al grupo de fosfatasas citosólicas o no receptoras. Dicha fosfatasa posee un dominio rico en prolinas de clase I y de clase II en su secuencia, a través de los cuales se estaría produciendo la interacción según comentan Wu y colaboradores (Wu et al. 2007). Sin embargo, nosotros no hemos observado interacción entre p85 y Lyp, aunque Lyp posee un dominio rico en prolinas de clase I.

La interacción contemplada entre Lyp y Csk ha sido descrita por varios laboratorios que han trabajado tanto con PEP (Cloutier y Veillette 1996) como con Lyp (Cohen et al. 1999). (Bottini et al. 2004) (Begovich et al. 2004). Aunque se considera que Lyp W no interacciona con Csk, como muestran Vang et al. (Vang et al. 2005), nosotros hemos observado que esta interacción es posible, aunque más débil que con Lyp R, lo cual también había sido observado por Begovich et al. (Begovich et al. 2004), aunque no había sido estudiado en detalle. En otro trabajo, pese a 
observarse cierta asociación, aunque débil, entre las dos proteínas, se concluye que la interacción no se produce (Bottini et al. 2004).

\section{Estudio de la interacción de Lyp y Csk.}

Los datos en que se basa el conocimiento actual acerca de la interacción ente Lyp y Csk han sido obtenidos fundamentalmente en el laboratorio del Dr. Veillette, utilizando PEP, el homologo de Lyp en ratón. A partir de estos trabajos, Veillette propuso un modelo según el cual Lyp y Csk actúan de forma cooperativa en la regulación de la señalización temprana del TCR. En este modelo, Lyp y Csk interaccionan de forma constitutiva, de hecho el propio Veillette señala que en condiciones basales el 25-50\% de PEP está asociado con Csk y sólo el 5\% de Csk está unida a PEP (Cloutier y Veillette 1996), siendo está asociación indispensable para la regulación de la señalización iniciada por el TCR. Este modelo permitiría explicar como el cambio de una R por un W, que impide la asociación de estas dos proteínas, conduciría a un aumento en la señalización por el TCR, lo que podría explicar la existencia de linfocitos autorreactivos que condujeran a la aparición de una enfermedad autoinmune. Sin embargo, otros trabajos han cuestionado este modelo, ya que muestran que Lyp W es una variante de ganancia de función, es decir, con mayor actividad fosfatasa y, por tanto, con mayor capacidad de inhibir la señalización del TCR (Vang et al. 2005). Para poder explicar la aparición de una enfermedad autoinmune en células con menor capacidad de señalización frente a antígenos, se ha propuesto que la presencia del polimorfismo podría favorecer que linfocitos autorreactivos escapasen a los mecanismos de selección negativa que tratan de eliminar estas células que reconocen antígenos propios. Aunque distintos trabajos muestran que Lyp W presenta una mayor actividad, que se corresponde con una mayor inhibición de la señalización temprana del TCR (Vang et al. 2005; Rieck et al. 2007), no está muy claro cuales son los efectos a los que conduce está inhibición de la señalización. En este sentido, se ha publicado que Lyp W conduce a una reducción de la producción de IL-2 (Vang et al. 2005), dato que discrepa con el publicado por Rieck et al, donde no observan una diferencia significativa en la producción de IL-2 (Rieck et al. 2007), aún tratándose de estudios realizados con muestras de pacientes con diabetes tipo I. Sin embargo, otro trabajo realizado con muestras de pacientes con miastenia grave, ha mostrado que Lyp W conduce a un aumento de la producción de IL-2 (Lefvert et al. 2008).

Este trabajo es el primero en el que se lleva a cabo un análisis detallado de la interacción de Lyp con Csk. A partir de los datos obtenidos en este trabajo podemos concluir que Lyp apenas interacciona con Csk en condiciones basales, y que su asociación se ve incrementada por la activación celular, ya sea con potentes activadores como el pervanadato, ya sea a través de estímulos fisiológicos como el TCR. 
Los datos aquí presentados muestran que Lyp puede interaccionar con Csk no solo por el motivo P1 sino que también puede hacerlo por el motivo P2, lo cual era de esperar dada la similitud de la secuencia entre estos 2 motivos ricos en Pro. No obstante, a pesar de esta similitud, la afinidad del motivo P1 por Csk es mayor que la del motivo P2. Esto se ve claramente al mutar estos dos motivos de forma independiente, ya que la alteración del motivo P2 disminuye la asociación entre estas 2 proteínas en menor medida que la alteración del motivo P1.

Los estudios de Veillette fueron realizados en su mayoría utilizando el dominio $\mathrm{SH} 3$ de Csk y el motivo P1 de Lyp de forma aislada y, cuando usan la proteína completa, lo hacen en células COS, donde Lyp o PEP no se expresan de forma natural (Gregorieff et al. 1998). Sus resultados presentan algunos datos contradictorios, pues la mutación de los aminoácidos de PEP correspondientes a la P615, la P618 y la R620 impiden la asociación de PEP con Csk (Gregorieff et al. 1998), sin embargo, en clones estables realizados en células de un hibridoma de linfocitos $T$ de ratón, $\mathrm{BI}-141$, la deleción del motivo P1 no conduce a la pérdida de la interacción entre las dos moléculas (Cloutier y Veillette 1999). En nuestro estudio, hemos analizado la interacción de las dos moléculas mediante el uso de mutaciones puntuales en las moléculas completas y hemos utilizado, en gran número de experimentos, células Jurkat, las cuales expresan Lyp de forma endógena. Nuestros resultados muestran una reducción de la interacción cuando se mutan los aminoácidos que definen el motivo P1 como un motivo rico en Pro de clase II, la P615, la P618 y la R620 de Lyp, indicando que estos aminoácidos participan en la interacción con Csk. La mutación conjunta de esos aminoácidos no es capaz de impedir la interacción de Lyp con Csk. Además, se ha comprobado la contribución de los distintos aminoácidos del motivo P1 de Lyp a la asociación con el domino SH3 de Csk. En este sentido, como ya mostró Veillette (Gregorieff et al. 1998), la R620 de Lyp, que interacciona con el D27 de Csk, es esencial en esta interacción, al igual que la P618 que interacciona con el W47 de Csk. La mutación de cualquiera de estos aminoácidos de Lyp reduce la asociación de las dos proteínas de manera similar. La mutación de otros aminoácidos dentro del motivo P1 junto con la P618 o con W620 no contribuye a disminuir su interacción. Asimismo, la sustitución por Ala de la $\$ 624$ o de la 1625 y la V626 reducen la interacción pero sin impedirla totalmente. Además, añadimos al estudio de interacción la sustitución de la S624 por una Ala, demostrando que también es un aminoácido necesario para la interacción con Csk, aunque la sustitución en su homólogo en PEP (S623A) no tuvo ningún impacto en la interacción (Gregorieff et al. 1998). Así, se puede concluir que la mutación del motivo P1 en uno o varios aminoácidos no es suficiente para impedir la asociación entre Lyp y Csk. Estos datos y los ensayos que muestran que el péptido $\Delta \mathrm{P} 1$ interacciona con Csk y que la deleción del CTH no modifica la asociación con Lyp, apoyarían la existencia de una interacción entre Lyp y Csk a través del motivo P2. La interacción de Csk con Lyp-W620, la variante 
polimórfica de Lyp, sugeriría la existencia de un fenotipo menos dramático que el propuesto en el que hay una ausencia total de unión entre las dos moléculas.

Para demostrar la implicación del motivo P2 directamente, se realizaron mutaciones puntuales en este motivo, P695A o R700F. Los ensayos de interacción mostraron que dichas mutaciones reducen la asociación con Csk, aunque en menor medida que las mutaciones equivalentes en el motivo P1. Además, la mutación conjunta del motivo P2, junto con la W620 o la P618 del motivo P1, permitió reducir la asociación de las 2 proteínas a niveles basales, lo que indicaría que el motivo P2 es el responsable de la unión que se observa cuando se muta el motivo P1. Con estos experimentos, mostramos que Csk se puede unir a Lyp a través del motivo P1 o del motivo P2. Este hecho sugiere la posibilidad de que Lyp una dos moléculas de Csk, una por el motivo P1 y otra por el motivo P2, pero los experimentos que hemos planteado en esta línea de trabajo no han demostrado esta hipótesis (resultaos no mostrados). Por tanto, en la actualidad, creemos que solo una molécula de Csk se une a una molécula de Lyp, bien por el motivo P1 o bien por el motivo P2, que tiene una afinidad menor. En cualquier caso, la unión de Csk a Lyp por uno de estos motivos debe impedir la unión de una segunda molécula de Csk por el otro motivo. Entre los mecanismos que pueden bloquear la interacción de una segunda molécula de Csk con Lyp estarían el impedimento estérico ocasionado por la propia molécula de Csk unida o bien un cambio conformacional en Lyp ocasionado por la interacción.

Aunque los datos obtenidos al resolver la estructura del dominio $\mathrm{SH} 3$ de Csk con el motivo P1 de PEP (Ghose et al. 2001) ya indicaban qué aminoácidos del dominio SH3 de Csk eran críticos en la interacción, el D27 de Csk, que interacciona con la R620, y el W47 que interacciona con la P618, no había datos experimentales que lo demostraran. Por ello, mutamos Csk en estos 2 aminoácidos y cualquiera de estas 2 mutaciones, D27A o W47A, impiden la unión de Csk a Lyp.. Esto excluiría que otros dominios de Csk participaran en la interacción. No obstante, para comprobarlo, se mutó el dominio SH2 de Csk, lo cual disminuyó la asociación entre estas moléculas, tanto en reposo como después de la activación con pervanadato. Estos resultados podrían ser debidos a que se ve afectado el reclutamiento de Csk a la membrana a través de PAG/Cbp (phosphoprotein associated with GEMs/Csk-binding protein), de acuerdo con lo postulado por Veillette y colaboradores (Veillette et al. 2002).

\section{Lyp R y Lyp W reducen la activación transcripcional de una manera similar en células Jurkat.}

El hecho de que Lyp W muestre una mayor actividad fosfatasa, también observada en nuestro laboratorio, $y$, por tanto, sea una variante de ganancia de función, ha hecho pensar que podría inhibir la señalización iniciada por el TCR en mayor medida que Lyp $R$, y así se ha mostrado en algunos trabajos (Vang et al. 2005; Rieck et al. 2007). Sin embargo, los efectos en la 
función de los linfocitos no están claros. En nuestro caso, utilizando ensayos de luciferasa, no hemos conseguido observar que Lyp W muestre una mayor inhibición en la activación de distintos factores de transcripción, como NF-AT/AP1, NF-kB o el promotor de la IL-2. En cambio, cuando estudiamos la activación de Erk, sí observamos una mayor eficiencia de Lyp $W$ en la desfosforilación de esta kinasa. Recientemente, Zikherman et al. han obtenido resultados diferentes a los de Vang et al. y a los nuestros en cuanto a la señalización celular. En este caso, han comparado el efecto de PEP, de Lyp y de sus polimorfismos R619W y R620W, respectivamente, demostrando que tanto PEP como Lyp normales inhiben más eficientemente la señalización que sus respectivos polimorfismos, por lo que en este caso no podría decirse que el polimorfismo provoca una ganancia de función de la fosfatasa sino todo lo contrario, una pérdida de función (Zikherman et al. 2009).

\section{La cooperación de Lyp y Csk en la señalización no depende de su asociación.}

Desde un principio se ha descrito que Csk y PEP son grandes supresores de la señalización del TCR (Cloutier y Veillette 1999), (Gjorloff-Wingren et al. 1999). En nuestro laboratorio, hemos demostrado que tanto Lyp R como Lyp W cooperan con Csk en la inhibición de la señalización hasta en el doble de lo observado para cada proteína de forma individual. Sin embargo, es la primera vez que se describe que esta cooperación no depende de su interacción, ya que el mutante del dominio SH3 de Csk (W47A), incapaz de interaccionar con Lyp, también ejerce la misma inhibición de la señalización.. De la misma manera, el efecto cooperativo de ambas moléculas también queda demostrado en el ensayo de desfosforilación de Erk. Estos datos cuestionan la validez del modelo cooperativo propuesto por Veillete y demuestran que la interacción entre las dos moléculas no es necesaria para su función en la regulación de la señalización del TCR. Por todo esto, suponemos que debe haber algún otro mecanismo que permita explicar como actúan estas proteínas de forma independiente de su posible interacción y, de la misma manera, en estos momentos no se conoce cual es el propósito de esta interacción. En este sentido, se ha postulado que el polimorfismo podría cambiar el espectro de las proteínas con las que interacciona Lyp normal o producir fallos en las interacciones proteína-proteína, como sucede con Csk (Vang et al. 2008). Sin embargo, los substratos de ambas variantes de Lyp deberían seguir siendo los mismos ya que el dominio catalítico no ha sido modificado por lo tanto deberían tener la misma especificidad intrínseca por los substratos (Bottini et al. 2006).

Actualmente, nuestro laboratorio continúa estudiando cómo las dos variantes de Lyp cooperan con Csk en la inhibición de Lck, datos que arrojarán luz para comprender como contribuye la variante Lyp W a la etiopatogenésis de las enfermedades autoinmunes. Los efectos de Lyp sobre las cascadas de señalización del TCR y sobre otras vías de señalización en los 
linfocitos $T$, al igual que en otras líneas celulares del sistema inmune, donde también se expresa Lyp, están pobremente definidas. En este sentido, habría que determinar el repertorio de substratos de Lyp en los distintos tipos celulares, su localización subcelular durante la activación celular y las cascadas de señalización en las que Lyp está implicada, además de definir los efectos que produce en las células del sistema inmune la variante polimórfica en comparación con Lyp R y como contribuye el polimorfismo a la aparición de las enfermedades autoinmunes con las que está asociado. 

A la vista de los resultados obtenidos podemos concluir que:

1. Lyp apenas interacciona con Csk en células linfoides en reposo. Sin embargo, esta interacción se incrementa de forma clara con la activación celular.

2. La mutación de los motivos P1 y P2 de Lyp produce una proteína incapaz de interaccionar con Csk y la mutación del SH3 de Csk produce una proteína incapaz de interaccionar con Lyp.

3. La asociación de Lyp con Csk se produce entre el dominio SH3 de Csk y los motivos P1 y P2 de Lyp, no interviniendo en dicha asociación ni el dominio CTH de Lyp ni el dominio SH2 de Csk.

4. El motivo P1 de Lyp interacciona con Csk con mayor afinidad que el motivo P2.

5. La variante polimórfica de Lyp que posee un $\mathrm{W}$ en lugar de una $\mathrm{R}$ en la posición 620 es capaz de interaccionar con Csk, y lo hace a través del motivo P2.

6. Lyp W presenta mayor actividad fosfatasa que Lyp R. Asimismo, Lyp W presenta mayor actividad que Lyp $R$ en la inhibición de la activación de Erk. Sin embargo, tanto Lyp R como Lyp W reducen la activación transcripcional de una manera similar en células Jurkat.

7. Lyp y Csk cooperan inhibiendo la señalización del TCR, sin embargo esta cooperación es independiente de su asociación. 



\section{Referencias Bibliográficas}



Alonso, A.Sasin, J.Bottini, N.Friedberg, I.Osterman, A., et al. (2004). "Protein tyrosine phosphatases in the human genome." Cell 117(6): 699-711.

Andersen, J. N.Jansen, P. G.Echwald, S. M.Mortensen, O. H.Fukada, T., et al. (2004). "A genomic perspective on protein tyrosine phosphatases: gene structure, pseudogenes, and genetic disease linkage." FASEB J 18(1): 8-30.

Anderson, A. C.Reddy, J.Nazareno, R.Sobel, R. A.Nicholson, L. B., et al. (2004). "IL-10 plays an important role in the homeostatic regulation of the autoreactive repertoire in naive mice." J Immunol 173(2): 828-34.

Angers-Loustau, A.Cote, J. F.Charest, A.Dowbenko, D.Spencer, S., et al. (1999). "Protein tyrosine phosphatase-PEST regulates focal adhesion disassembly, migration, and cytokinesis in fibroblasts." J Cell Biol 144(5): 1019-31.

Aoki, N.Ueno, S.Mano, H.Yamasaki, S.Shiota, M., et al. (2004). "Mutual regulation of protein-tyrosine phosphatase 20 and protein-tyrosine kinase Tec activities by tyrosine phosphorylation and dephosphorylation." J Biol Chem 279(11): 10765-75.

Aoki, N., Yamaguchi-Aoki, Y. y Ullrich, A. (1996). "The novel protein-tyrosine phosphatase PTP20 is a positive regulator of PC12 cell neuronal differentiation." J Biol Chem 271(46): 29422-6.

Arechiga, A. F.Habib, T.He, Y.Zhang, X.Zhang, Z. Y., et al. (2009). "Cutting edge: the PTPN22 allelic variant associated with autoimmunity impairs B cell signaling." J Immunol 182(6): 3343-7.

Arimura, Y., Vang, T., Tautz, L., Williams, S. y Mustelin, T. (2008). "TCR-induced downregulation of protein tyrosine phosphatase PEST augments secondary T cell responses." Mol Immunol 45(11): 3074-84.

Badour, K.Zhang, J.Shi, F.Leng, Y.Collins, M., et al. (2004). "Fyn and PTP-PEST-mediated regulation of Wiskott-Aldrich syndrome protein (WASp) tyrosine phosphorylation is required for coupling T cell antigen receptor engagement to WASp effector function and T cell activation." J Exp Med 199(1): 99-112.

Barr, A. J.Ugochukwu, E.Lee, W. H.King, O. N.Filippakopoulos, P., et al. (2009). "Large-scale structural analysis of the classical human protein tyrosine phosphatome." Cell 136(2): 352-63.

Begovich, A. B.Caillier, S. J.Alexander, H. C.Penko, J. M.Hauser, S. L., et al. (2005). "The R620W polymorphism of the protein tyrosine phosphatase PTPN22 is not associated with multiple sclerosis." Am J Hum Genet 76(1): 184-7.

Begovich, A. B.Carlton, V. E.Honigberg, L. A.Schrodi, S. J.Chokkalingam, A. P., et al. (2004). "A missense single-nucleotide polymorphism in a gene encoding a protein tyrosine phosphatase (PTPN22) is associated with rheumatoid arthritis." Am J Hum Genet 75(2): 330-7.

Bottini, N.Musumeci, L.Alonso, A.Rahmouni, S.Nika, K., et al. (2004). "A functional variant of lymphoid tyrosine phosphatase is associated with type I diabetes." Nat Genet 36(4): 337-8.

Bottini, N., Vang, T., Cucca, F. y Mustelin, T. (2006). "Role of PTPN22 in type 1 diabetes and other autoimmune diseases." Semin Immunol 18(4): 207-13.

Bubeck Wardenburg, J.Fu, C.Jackman, J. K.Flotow, H.Wilkinson, S. E., et al. (1996). "Phosphorylation of SLP-76 by the ZAP-70 protein-tyrosine kinase is required for T-cell receptor function." J Biol Chem 271(33): 19641-4.

Canton, I.Akhtar, S.Gavalas, N. G.Gawkrodger, D. J.Blomhoff, A., et al. (2005). "A single-nucleotide polymorphism in the gene encoding lymphoid protein tyrosine phosphatase (PTPN22) confers susceptibility to generalised vitiligo." Genes Immun 6(7): 584-7.

Carlton, V. E.Hu, X.Chokkalingam, A. P.Schrodi, S. J.Brandon, R., et al. (2005). "PTPN22 genetic variation: evidence for multiple variants associated with rheumatoid arthritis." Am J Hum Genet 77(4): 567-81.

Cloutier, J. F., Chow, L. M. y Veillette, A. (1995). "Requirement of the SH3 and SH2 domains for the inhibitory function of tyrosine protein kinase p50csk in T lymphocytes." Mol Cell Biol 15(11): 5937-44.

Cloutier, J. F. y Veillette, A. (1996). "Association of inhibitory tyrosine protein kinase p50csk with protein tyrosine phosphatase PEP in T cells and other hemopoietic cells." EMBO J 15(18): 4909-18.

Cloutier, J. F. y Veillette, A. (1999). "Cooperative inhibition of T-cell antigen receptor signaling by a complex between a kinase and a phosphatase." J Exp Med 189(1): 111-21. 
Cohen, S., Dadi, H., Shaoul, E., Sharfe, N. y Roifman, C. M. (1999). "Cloning and characterization of a lymphoid-specific, inducible human protein tyrosine phosphatase, Lyp." Blood 93(6): 2013-24.

Cote, J. F.Chung, P. L.Theberge, J. F.Halle, M.Spencer, S., et al. (2002). "PSTPIP is a substrate of PTPPEST and serves as a scaffold guiding PTP-PEST toward a specific dephosphorylation of WASP." J Biol Chem 277(4): 2973-86.

Criswell, L. A.Pfeiffer, K. A.Lum, R. F.Gonzales, B.Novitzke, J., et al. (2005). "Analysis of families in the multiple autoimmune disease genetics consortium (MADGC) collection: the PTPN22 620W allele associates with multiple autoimmune phenotypes." Am J Hum Genet 76(4): 561-71.

Charbonneau, H. y Tonks, N. K. (1992). "1002 protein phosphatases?" Annu Rev Cell Biol 8: 463-93.

Charest, A., Wagner, J., Shen, S. H. y Tremblay, M. L. (1995). "Murine protein tyrosine phosphatase-PEST, a stable cytosolic protein tyrosine phosphatase." Biochem J 308 ( Pt 2): 425-32.

Cheng, J., Daimaru, L., Fennie, C. y Lasky, L. A. (1996). "A novel protein tyrosine phosphatase expressed in lin(lo)CD34(hi)Sca(hi) hematopoietic progenitor cells." Blood 88(4): 1156-67.

Chong, Y. P., Ia, K. K., Mulhern, T. D. y Cheng, H. C. (2005). "Endogenous and synthetic inhibitors of the Src-family protein tyrosine kinases." Biochim Biophys Acta 1754(1-2): 210-20.

Chow, L. M., Fournel, M., Davidson, D. y Veillette, A. (1993). "Negative regulation of T-cell receptor signalling by tyrosine protein kinase p50csk." Nature 365(6442): 156-60.

Dang, C. V. y Lee, W. M. (1988). "Identification of the human c-myc protein nuclear translocation signal." Mol Cell Biol 8(10): 4048-54.

Davidson, D., Cloutier, J. F., Gregorieff, A. y Veillette, A. (1997). "Inhibitory tyrosine protein kinase p50csk is associated with protein-tyrosine phosphatase PTP-PEST in hemopoietic and non-hemopoietic cells." J Biol Chem 272(37): 23455-62.

Davidson, D. y Veillette, A. (2001). "PTP-PEST, a scaffold protein tyrosine phosphatase, negatively regulates lymphocyte activation by targeting a unique set of substrates." EMBO J 20(13): 3414-26.

Davidson, N. J.Leach, M. W.Fort, M. M.Thompson-Snipes, L.Kuhn, R., et al. (1996). "T helper cell 1-type CD4+ T cells, but not B cells, mediate colitis in interleukin 10-deficient mice." J Exp Med 184(1): 241-51.

den Hertog, J., Groen, A. y van der Wijk, T. (2005). "Redox regulation of protein-tyrosine phosphatases." Arch Biochem Biophys 434(1): 11-5.

Dosil, M., Leibman, N. y Lemischka, I. R. (1996). "Cloning and characterization of fetal liver phosphatase 1 , a nuclear protein tyrosine phosphatase isolated from hematopoietic stem cells." Blood $\mathbf{8 8}(12)$ : 4510-25.

Eswaran, J.von Kries, J. P.Marsden, B.Longman, E.Debreczeni, J. E., et al. (2006). "Crystal structures and inhibitor identification for PTPN5, PTPRR and PTPN7: a family of human MAPK-specific protein tyrosine phosphatases." Biochem J 395(3): 483-91.

Fischer, E. H., Charbonneau, H. y Tonks, N. K. (1991). "Protein tyrosine phosphatases: a diverse family of intracellular and transmembrane enzymes." Science 253(5018): 401-6.

Flint, A. J., Tiganis, T., Barford, D. y Tonks, N. K. (1997). "Development of "substrate-trapping" mutants to identify physiological substrates of protein tyrosine phosphatases." Proc Natl Acad Sci U S A 94(5): 1680-5.

Flores, E., Roy, G., Patel, D., Shaw, A. y Thomas, M. L. (1994). "Nuclear localization of the PEP protein tyrosine phosphatase." Mol Cell Biol 14(7): 4938-46.

Gandhi, T. K.Chandran, S.Peri, S.Saravana, R.Amanchy, R., et al. (2005). "A bioinformatics analysis of protein tyrosine phosphatases in humans." DNA Res 12(2): 79-89.

Garcia-Bustos, J., Heitman, J. y Hall, M. N. (1991). "Nuclear protein localization." Biochim Biophys Acta 1071(1): 83-101.

Garton, A. J., Flint, A. J. y Tonks, N. K. (1996). "Identification of p130(cas) as a substrate for the cytosolic protein tyrosine phosphatase PTP-PEST." Mol Cell Biol 16(11): 6408-18.

Garton, A. J. y Tonks, N. K. (1994). "PTP-PEST: a protein tyrosine phosphatase regulated by serine phosphorylation." EMBO J 13(16): 3763-71.

Garton, A. J. y Tonks, N. K. (1999). "Regulation of fibroblast motility by the protein tyrosine phosphatase PTP-PEST." J Biol Chem 274(6): 3811-8.

Ghose, R., Shekhtman, A., Goger, M. J., Ji, H. y Cowburn, D. (2001). "A novel, specific interaction involving the Csk SH3 domain and its natural ligand." Nat Struct Biol 8(11): 998-1004. 
Gjorloff-Wingren, A., Saxena, M., Williams, S., Hammi, D. y Mustelin, T. (1999). "Characterization of TCR-induced receptor-proximal signaling events negatively regulated by the protein tyrosine phosphatase PEP." Eur J Immunol 29(12): 3845-54.

Gregorieff, A., Cloutier, J. F. y Veillette, A. (1998). "Sequence requirements for association of proteintyrosine phosphatase PEP with the Src homology 3 domain of inhibitory tyrosine protein kinase p50(csk)." J Biol Chem 273(21): 13217-22.

Groen, A.Lemeer, S.van der Wijk, T.Overvoorde, J.Heck, A. J., et al. (2005). "Differential oxidation of protein-tyrosine phosphatases." J Biol Chem 280(11): 10298-304.

Habib, T., Herrera, R. y Decker, S. J. (1994). "Activators of protein kinase C stimulate association of Shc and the PEST tyrosine phosphatase." J Biol Chem 269(41): 25243-6.

Hardwick, J. S. y Sefton, B. M. (1995). "Activation of the Lck tyrosine protein kinase by hydrogen peroxide requires the phosphorylation of Tyr-394." Proc Natl Acad Sci U S A 92(10): 4527-31.

Hasegawa, K.Martin, F.Huang, G.Tumas, D.Diehl, L., et al. (2004). "PEST domain-enriched tyrosine phosphatase (PEP) regulation of effector/memory T cells." Science 303(5658): 685-9.

Hasegawa, K.Yajima, H.Katagiri, T.Ogimoto, M.Arimura, Y., et al. (1999). "Requirement of PEST domain tyrosine phosphatase PEP in B cell antigen receptor-induced growth arrest and apoptosis." Eur J Immunol 29(3): 887-96.

Hazeki, K., Nigorikawa, K. y Hazeki, O. (2007). "Role of phosphoinositide 3-kinase in innate immunity." Biol Pharm Bull 30(9): 1617-23.

Hill, R. J.Zozulya, S.Lu, Y. L.Ward, K.Gishizky, M., et al. (2002). "The lymphoid protein tyrosine phosphatase Lyp interacts with the adaptor molecule Grb2 and functions as a negative regulator of T-cell activation." Exp Hematol 30(3): 237-44.

Hinks, A.Barton, A.John, S.Bruce, I.Hawkins, C., et al. (2005). "Association between the PTPN22 gene and rheumatoid arthritis and juvenile idiopathic arthritis in a UK population: further support that PTPN22 is an autoimmunity gene." Arthritis Rheum 52(6): 1694-9.

Huang, K., Sommers, C. L., Grinberg, A., Kozak, C. A. y Love, P. E. (1996). "Cloning and characterization of PTP-K1, a novel nonreceptor protein tyrosine phosphatase highly expressed in bone marrow." Oncogene 13(7): 1567-73.

Imamoto, A. y Soriano, P. (1993). "Disruption of the csk gene, encoding a negative regulator of Src family tyrosine kinases, leads to neural tube defects and embryonic lethality in mice." Cell 73(6): 1117-24.

Jagiello, P.Aries, P.Arning, L.Wagenleiter, S. E.Csernok, E., et al. (2005). "The PTPN22 620W allele is a risk factor for Wegener's granulomatosis." Arthritis Rheum 52(12): 4039-43.

Jamieson, J. S.Tumbarello, D. A.Halle, M.Brown, M. C.Tremblay, M. L., et al. (2005). "Paxillin is essential for PTP-PEST-dependent regulation of cell spreading and motility: a role for paxillin kinase linker." J Cell Sci 118(Pt 24): 5835-47.

Jia, Z., Barford, D., Flint, A. J. y Tonks, N. K. (1995). "Structural basis for phosphotyrosine peptide recognition by protein tyrosine phosphatase 1B." Science 268(5218): 1754-8.

Joukov, V.Vihinen, M.Vainikka, S.Sowadski, J. M.Alitalo, K., et al. (1997). "Identification of csk tyrosine phosphorylation sites and a tyrosine residue important for kinase domain structure." Biochem J 322 ( Pt 3): 927-35.

Kay, L. E. (1998). "Protein dynamics from NMR." Nat Struct Biol 5 Suppl: 513-7.

Kim, Y. W.Wang, H.Sures, I.Lammers, R.Martell, K. J., et al. (1996). "Characterization of the PEST family protein tyrosine phosphatase BDP1." Oncogene 13(10): 2275-9.

Koyasu, S. (2003). "The role of PI3K in immune cells." Nat Immunol 4(4): 313-9.

Kyogoku, C.Langefeld, C. D.Ortmann, W. A.Lee, A.Selby, S., et al. (2004). "Genetic association of the R620W polymorphism of protein tyrosine phosphatase PTPN22 with human SLE." Am J Hum Genet 75(3): 504-7.

Laminet, A. A., Apell, G., Conroy, L. y Kavanaugh, W. M. (1996). "Affinity, specificity, and kinetics of the interaction of the SHC phosphotyrosine binding domain with asparagine-X-X-phosphotyrosine motifs of growth factor receptors." J Biol Chem 271(1): 264-9.

Lee, A. T.Li, W.Liew, A.Bombardier, C.Weisman, M., et al. (2005). "The PTPN22 R620W polymorphism associates with RF positive rheumatoid arthritis in a dose-dependent manner but not with HLA-SE status." Genes Immun 6(2): 129-33. 
Lefvert, A. K.Zhao, Y.Ramanujam, R.Yu, S.Pirskanen, R., et al. (2008). "PTPN22 R620W promotes production of anti-AChR autoantibodies and IL-2 in myasthenia gravis." J Neuroimmunol 197(2): 110-3.

Li, Q. J.Chau, J.Ebert, P. J.Sylvester, G.Min, H., et al. (2007). "miR-181a is an intrinsic modulator of T cell sensitivity and selection." Cell 129(1): 147-61.

Li, X.Oghi, K. A.Zhang, J.Krones, A.Bush, K. T., et al. (2003). "Eya protein phosphatase activity regulates Six1-Dach-Eya transcriptional effects in mammalian organogenesis." Nature 426(6964): 247-54.

Liu, X.Brodeur, S. R.Gish, G.Songyang, Z.Cantley, L. C., et al. (1993). "Regulation of c-Src tyrosine kinase activity by the Src SH2 domain." Oncogene 8(5): 1119-26.

Liu, Y.Stanford, S. M.Jog, S. P.Fiorillo, E.Orru, V., et al. (2009). "Regulation of lymphoid tyrosine phosphatase activity: inhibition of the catalytic domain by the proximal interdomain." Biochemistry 48(31): 7525-32.

Lowry, W. E.Huang, J.Ma, Y. C.Ali, S.Wang, D., et al. (2002). "Csk, a critical link of g protein signals to actin cytoskeletal reorganization." Dev Cell 2(6): 733-44.

Manning, G., Whyte, D. B., Martinez, R., Hunter, T. y Sudarsanam, S. (2002). "The protein kinase complement of the human genome." Science 298(5600): 1912-34.

Martin, M. C.Oliver, J.Urcelay, E.Orozco, G.Gomez-Garcia, M., et al. (2005). "The functional genetic variation in the PTPN22 gene has a negligible effect on the susceptibility to develop inflammatory bowel disease." Tissue Antigens 66(4): 314-7.

Matthews, R. J., Bowne, D. B., Flores, E. y Thomas, M. L. (1992). "Characterization of hematopoietic intracellular protein tyrosine phosphatases: description of a phosphatase containing an $\mathrm{SH} 2$ domain and another enriched in proline-, glutamic acid-, serine-, and threonine-rich sequences." Mol Cell Biol 12(5): 2396-405.

Milkiewicz, P.Pache, I.Buwaneswaran, H.Liu, X.Coltescu, C., et al. (2006). "The PTPN22 $1858 \mathrm{~T}$ variant is not associated with primary biliary cirrhosis." Tissue Antigens 67(5): 434-7.

Mustelin, T., Coggeshall, K. M. y Altman, A. (1989). "Rapid activation of the T-cell tyrosine protein kinase pp56lck by the CD45 phosphotyrosine phosphatase." Proc Natl Acad Sci U S A 86(16): 6302-6.

Mustelin, T. y Tasken, K. (2003). "Positive and negative regulation of T-cell activation through kinases and phosphatases." Biochem J 371(Pt 1): 15-27.

Nada, S., Okada, M., MacAuley, A., Cooper, J. A. y Nakagawa, H. (1991). "Cloning of a complementary DNA for a protein-tyrosine kinase that specifically phosphorylates a negative regulatory site of p60c-src." Nature 351(6321): 69-72.

Nada, S.Yagi, T.Takeda, H.Tokunaga, T.Nakagawa, H., et al. (1993). "Constitutive activation of Src family kinases in mouse embryos that lack Csk." Cell 73(6): 1125-35.

Orozco, G.Eerligh, P.Sanchez, E.Zhernakova, S.Roep, B. O., et al. (2005). "Analysis of a functional BTNL2 polymorphism in type 1 diabetes, rheumatoid arthritis, and systemic lupus erythematosus." Hum Immunol 66(12): 1235-41.

Orru, V.Tsai, S. J.Rueda, B.Fiorillo, E.Stanford, S. M., et al. (2009). "A loss-of-function variant of PTPN22 is associated with reduced risk of systemic lupus erythematosus." Hum Mol Genet 18(3): 569-79.

Palacios, E. H. y Weiss, A. (2004). "Function of the Src-family kinases, Lck and Fyn, in T-cell development and activation." Oncogene 23(48): 7990-8000.

Pearson, R. B. y Kemp, B. E. (1991). "Protein kinase phosphorylation site sequences and consensus specificity motifs: tabulations." Methods Enzymol 200: 62-81.

Prescott, N. J.Fisher, S. A.Onnie, C.Pattni, R.Steer, S., et al. (2005). "A general autoimmunity gene (PTPN22) is not associated with inflammatory bowel disease in a British population." Tissue Antigens 66(4): 318-20.

Rayapureddi, J. P., Kattamuri, C., Chan, F. H. y Hegde, R. S. (2005). "Characterization of a plant, tyrosinespecific phosphatase of the aspartyl class." Biochemistry 44(2): 751-8.

Rayapureddi, J. P.Kattamuri, C.Steinmetz, B. D.Frankfort, B. J.Ostrin, E. J., et al. (2003). "Eyes absent represents a class of protein tyrosine phosphatases." Nature 426(6964): 295-8.

Rieck, M.Arechiga, A.Onengut-Gumuscu, S.Greenbaum, C.Concannon, P., et al. (2007). "Genetic variation in PTPN22 corresponds to altered function of T and B lymphocytes." J Immunol 179(7): 4704-10. 
Rogers, S., Wells, R. y Rechsteiner, M. (1986). "Amino acid sequences common to rapidly degraded proteins: the PEST hypothesis." Science 234(4774): 364-8.

Rueda, B.Nunez, C.Orozco, G.Lopez-Nevot, M. A.de la Concha, E. G., et al. (2005). "C1858T functional variant of PTPN22 gene is not associated with celiac disease genetic predisposition." Hum Immunol 66(7): 848-52.

Salmeen, A., Andersen, J. N., Myers, M. P., Tonks, N. K. y Barford, D. (2000). "Molecular basis for the dephosphorylation of the activation segment of the insulin receptor by protein tyrosine phosphatase 1B." Mol Cell 6(6): 1401-12.

Samelson, L. E. (2002). "Signal transduction mediated by the T cell antigen receptor: the role of adapter proteins." Annu Rev Immunol 20: 371-94.

Sarmiento, M.Puius, Y. A.Vetter, S. W.Keng, Y. F.Wu, L., et al. (2000). "Structural basis of plasticity in protein tyrosine phosphatase 1B substrate recognition." Biochemistry 39(28): 8171-9.

Sastry, S. K., Lyons, P. D., Schaller, M. D. y Burridge, K. (2002). "PTP-PEST controls motility through regulation of Rac1." J Cell Sci 115(Pt 22): 4305-16.

Sastry, S. K.Rajfur, Z.Liu, B. P.Cote, J. F.Tremblay, M. L., et al. (2006). "PTP-PEST couples membrane protrusion and tail retraction via VAV2 and p190RhoGAP." J Biol Chem 281(17): 11627-36.

Seidel, R., Love, J., Piserchio, A., Cowburn, D. (2007). Lyp/PTPN22 Phosphatase Domain: Substrate Recognition and Specificity for Src family kinases (PDB 3BRH).

Shiota, M.Tanihiro, T.Nakagawa, Y.Aoki, N.Ishida, N., et al. (2003). "Protein tyrosine phosphatase PTP20 induces actin cytoskeleton reorganization by dephosphorylating p190 RhoGAP in rat ovarian granulosa cells stimulated with follicle-stimulating hormone." Mol Endocrinol 17(4): 534-49.

Sirois, J.Cote, J. F.Charest, A.Uetani, N.Bourdeau, A., et al. (2006). "Essential function of PTP-PEST during mouse embryonic vascularization, mesenchyme formation, neurogenesis and early liver development." Mech Dev 123(12): 869-80.

Smith, P. K.Krohn, R. I.Hermanson, G. T.Mallia, A. K.Gartner, F. H., et al. (1985). "Measurement of protein using bicinchoninic acid." Anal Biochem 150(1): 76-85.

Smyth, D.Cooper, J. D.Collins, J. E.Heward, J. M.Franklyn, J. A., et al. (2004). "Replication of an association between the lymphoid tyrosine phosphatase locus (Lyp/PTPN22) with type 1 diabetes, and evidence for its role as a general autoimmunity locus." Diabetes 53(11): 3020-3.

Sondhi, D. y Cole, P. A. (1999). "Domain interactions in protein tyrosine kinase Csk." Biochemistry 38(34): 11147-55.

Spencer, S.Dowbenko, D.Cheng, J.Li, W.Brush, J., et al. (1997). "PSTPIP: a tyrosine phosphorylated cleavage furrow-associated protein that is a substrate for a PEST tyrosine phosphatase." J Cell Biol 138(4): 845-60.

Tautz, L., Pellecchia, M. y Mustelin, T. (2006). "Targeting the PTPome in human disease." Expert Opin Ther Targets 10(1): 157-77.

Thomas, S. M. y Brugge, J. S. (1997). "Cellular functions regulated by Src family kinases." Annu Rev Cell Dev Biol 13: 513-609.

Thomas, S. M., Soriano, P. y Imamoto, A. (1995). "Specific and redundant roles of Src and Fyn in organizing the cytoskeleton." Nature 376(6537): 267-71.

Tootle, T. L.Silver, S. J.Davies, E. L.Newman, V.Latek, R. R., et al. (2003). "The transcription factor Eyes absent is a protein tyrosine phosphatase." Nature 426(6964): 299-302.

Tsai, S. J.Sen, U.Zhao, L.Greenleaf, W. B.Dasgupta, J., et al. (2009). "Crystal structure of the human lymphoid tyrosine phosphatase catalytic domain: insights into redox regulation." Biochemistry 48(22): 4838-45.

van Oene, M.Wintle, R. F.Liu, X.Yazdanpanah, M.Gu, X., et al. (2005). "Association of the lymphoid tyrosine phosphatase R620W variant with rheumatoid arthritis, but not Crohn's disease, in Canadian populations." Arthritis Rheum 52(7): 1993-8.

Vandiedonck, C.Capdevielle, C.Giraud, M.Krumeich, S.Jais, J. P., et al. (2006). "Association of the PTPN22*R620W polymorphism with autoimmune myasthenia gravis." Ann Neurol 59(2): 404-7.

Vang, T.Congia, M.Macis, M. D.Musumeci, L.Orru, V., et al. (2005). "Autoimmune-associated lymphoid tyrosine phosphatase is a gain-of-function variant." Nat Genet 37(12): 1317-9. 
Vang, T.Miletic, A. V.Arimura, Y.Tautz, L.Rickert, R. C., et al. (2008). "Protein tyrosine phosphatases in autoimmunity." Annu Rev Immunol 26: 29-55.

Vang, T.Torgersen, K. M.Sundvold, V.Saxena, M.Levy, F. O., et al. (2001). "Activation of the COOHterminal Src kinase (Csk) by cAMP-dependent protein kinase inhibits signaling through the T cell receptor." J Exp Med 193(4): 497-507.

Veillette, A., Latour, S. y Davidson, D. (2002). "Negative regulation of immunoreceptor signaling." Annu Rev Immunol 20: 669-707.

Veillette, A., Rhee, I., Souza, C. M. y Davidson, D. (2009). "PEST family phosphatases in immunity, autoimmunity, and autoinflammatory disorders." Immunol Rev 228(1): 312-24.

Velaga, M. R.Wilson, V.Jennings, C. E.Owen, C. J.Herington, S., et al. (2004). "The codon 620 tryptophan allele of the lymphoid tyrosine phosphatase (LYP) gene is a major determinant of Graves' disease." J Clin Endocrinol Metab 89(11): 5862-5.

Viken, M. K.Amundsen, S. S.Kvien, T. K.Boberg, K. M.Gilboe, I. M., et al. (2005). "Association analysis of the $1858 \mathrm{C}>\mathrm{T}$ polymorphism in the PTPN22 gene in juvenile idiopathic arthritis and other autoimmune diseases." Genes Immun 6(3): 271-3.

Walton, K. M. y Dixon, J. E. (1993). "Protein tyrosine phosphatases." Annu Rev Biochem 62: 101-20.

Wang, B., Lemay, S., Tsai, S. y Veillette, A. (2001). "SH2 domain-mediated interaction of inhibitory protein tyrosine kinase Csk with protein tyrosine phosphatase-HSCF." Mol Cell Biol 21(4): 1077-88.

Wu, C.Ma, M. H.Brown, K. R.Geisler, M.Li, L., et al. (2007). "Systematic identification of SH3 domainmediated human protein-protein interactions by peptide array target screening." Proteomics 7(11): 1775-85.

Wu, J.Katrekar, A.Honigberg, L. A.Smith, A. M.Conn, M. T., et al. (2006). "Identification of substrates of human protein-tyrosine phosphatase PTPN22." J Biol Chem 281(16): 11002-10.

Xu, W., Harrison, S. C. y Eck, M. J. (1997). "Three-dimensional structure of the tyrosine kinase c-Src." Nature 385(6617): 595-602.

Yaffe, M. B. (2002). "Phosphotyrosine-binding domains in signal transduction." Nat Rev Mol Cell Biol 3(3): 177-86.

Yaffe, M. B. y Elia, A. E. (2001). "Phosphoserine/threonine-binding domains." Curr Opin Cell Biol 13(2): 131-8.

Yamaguchi, H. y Hendrickson, W. A. (1996). "Structural basis for activation of human lymphocyte kinase Lck upon tyrosine phosphorylation." Nature 384(6608): 484-9.

Yang, J.Cheng, Z.Niu, T.Liang, X.Zhao, Z. J., et al. (2000). "Structural basis for substrate specificity of protein-tyrosine phosphatase SHP-1." J Biol Chem 275(6): 4066-71.

Yang, Q., Co, D., Sommercorn, J. y Tonks, N. K. (1993). "Cloning and expression of PTP-PEST. A novel, human, nontransmembrane protein tyrosine phosphatase." J Biol Chem 268(23): 17650.

Yu, X.Sun, J. P.He, Y.Guo, X.Liu, S., et al. (2007). "Structure, inhibitor, and regulatory mechanism of Lyp, a lymphoid-specific tyrosine phosphatase implicated in autoimmune diseases." Proc Natl Acad Sci U S A 104(50): 19767-72.

Zhang, W., Sloan-Lancaster, J., Kitchen, J., Trible, R. P. y Samelson, L. E. (1998). "LAT: the ZAP-70 tyrosine kinase substrate that links T cell receptor to cellular activation." Cell 92(1): 83-92.

Zhang, Z. Y. (2002). "Protein tyrosine phosphatases: structure and function, substrate specificity, and inhibitor development." Annu Rev Pharmacol Toxicol 42: 209-34.

Zhang, Z. Y., Wang, Y. y Dixon, J. E. (1994). "Dissecting the catalytic mechanism of protein-tyrosine phosphatases." Proc Natl Acad Sci U S A 91(5): 1624-7.

Zikherman, J.Hermiston, M.Steiner, D.Hasegawa, K.Chan, A., et al. (2009). "PTPN22 deficiency cooperates with the CD45 E613R allele to break tolerance on a non-autoimmune background." J Immunol 182(7): 4093-106.

Zoledziewska, M.Perra, C.Orru, V.Moi, L.Frongia, P., et al. (2008). "Further evidence of a primary, causal association of the PTPN22 620W variant with type 1 diabetes." Diabetes 57(1): 229-34. 


\section{Publicaciones}





\section{Publicaciones}

$\rightarrow$ de la Puerta ML, Trinidad AG, del Carmen Rodríguez M, Bogetz J, Sánchez Crespo M, Mustelin T, Alonso A, Bayón Y. Characterization of new substrates targeted by Yersinia tyrosine phosphatase YopH. PLoS One. 2009;4(2):e4431. Epub 2009 Feb 16.

$\rightarrow$ Bayón Y, Trinidad AG, de la Puerta ML, Del Carmen Rodríguez M, Bogetz J, Rojas A, De Pereda JM, Rahmouni S, Williams S, Matsuzawa S, Reed JC, Crespo MS, Mustelin T, Alonso A. KCTD5, a putative substrate adaptor for cullin3 ubiquitin ligases. FEBS J. 2008 Aug;275(15):3900-10. Epub 2008 Jun 28.

$\rightarrow$ Trinidad AG, de la Puerta ML, Fernández N, Bayón Y, Crespo MS, Alonso A. Coupling of $\mathrm{C} 3 \mathrm{bi}$ to $\lg \mathrm{G}$ inhibits the tyrosine phosphorylation signaling cascade downstream Syk and reduces cytokine induction in monocytes. J Leukoc Biol. 2006 May;79(5):1073-82. Epub 2006 Feb 24.

$\rightarrow$ L Jimenez, M Fernandez, de la Puerta, M a Luisa, S González-Mancebo, A Martin (2006) Estudio del efecto producido por 4-Nitrosofenol sobre la proliferación de células epiteliales renales de rata (NRK-52) y sobre la expresión de las moléculas de adhesión $C x-43, C x-32$ y CD44. Análisis del papel beneficioso de la vitamina C Oppidum 2: 337362

\section{Proyectos realizados}

$\rightarrow 15$ Julio/16 Octubre 2008 Centre for Cardiovascular Sciences Institute of Biomedical Research School of Clinical and Experimental Medicine College of Medical and Dental Sciences University of Birmingham Edgbaston, Birmingham UNITED KINGDOM. Dr Yotis Senis. EMBO (European Molecular Biology Organization) Short-term fellowship. "Regulation of GPVI signalling in platelets by the structurally distinct nontransmembrane tyrosine phosphatases Lyp and Shp1".

$\rightarrow$ Octubre 2006/Octubre 2009 Instituto de Biología y Genética Molecular (IBGM) Valladolid. Dra. Yolanda Bayón Prieto. Fundación Mutua Madrileña: “Lyp, una fosfatasa de tirosina implicada en enfermedades autoinmunes. Estudio de su mecanismo de acción molecular". 
$\rightarrow$ 2005/2007 Instituto de Biología y Genética Molecular (IBGM) Valladolid. Dra. Yolanda Bayón Prieto. Junta de Castilla y Leon. "Mecanismos moleculares por los que Yersinia pestis evade el sistema inmune adaptativo utilizando YopH".

$\rightarrow$ 2004/2007 Instituto de Biología y Genética Molecular (IBGM) Valladolid. Dr. Andrés Alonso García. Beca de la Fundación Ramón Areces con cargo al proyecto: "Identificación de proteínas fosforiladas en tirosinas y estimuladas a través de los receptores FcgR y de integrinas. Potenciales dianas farmacológicas de la inflamación".

$\rightarrow$ 2003/2004 Universidad SEK de Segovia. Facultad de Ciencias Biológicas. Dr. Samuel González Mancebo. "Estudio in vitro del efecto tóxico del N-Nitrosofenol sobre células epiteliales renales de rata y búsqueda de posibles inhibidores 0 bloqueantes". 
